Prepared in cooperation with the U.S. Army Corps of Engineers

\title{
An Evaluation of Fish Behavior Upstream of the Water Temperature Control Tower at Cougar Dam, Oregon, Using Acoustic Cameras, 2013
}

Open-File Report 2015-1124 



\section{An Evaluation of Fish Behavior Upstream of the Water Temperature Control Tower at Cougar Dam, Oregon, Using Acoustic Cameras, 2013}

By Noah S. Adams, Collin D. Smith, John M. Plumb, Gabriel S. Hansen, and John W. Beeman

Prepared in cooperation with the U.S. Army Corps of Engineers

Open-File Report 2015-1124

U.S. Department of the Interior

U.S. Geological Survey 


\section{U.S. Department of the Interior \\ SALLY JEWELL, Secretary}

\section{U.S. Geological Survey \\ Suzette M. Kimball, Acting Director}

U.S. Geological Survey, Reston, Virginia: 2015

For more information on the USGS-the Federal source for science about the Earth, its natural and living resources, natural hazards, and the environment-visit http://www.usgs.gov/ or call 1-888-ASK-USGS (1-888-275-8747).

For an overview of USGS information products, including maps, imagery, and publications, visit http://www.usgs.gov/pubprod/.

Any use of trade, firm, or product names is for descriptive purposes only and does not imply endorsement by the U.S. Government.

Although this information product, for the most part, is in the public domain, it also may contain copyrighted materials as noted in the text. Permission to reproduce copyrighted items must be secured from the copyright owner.

Suggested citation:

Adams, N.S., Smith, C.D., Plumb, J.M., Hansen, G.S., and Beeman, J.W., 2015, An evaluation of fish behavior upstream of the water temperature control tower at Cougar Dam, Oregon, using acoustic cameras, 2013: U.S. Geological Survey Open-File Report 2015-1124, 62 p., http://dx.doi.org/10.3133/ofr20151124.

ISSN 2331-1258 (online) 


\section{Acknowledgments}

This study was completed with assistance from many people and organizations. U.S Army Corps of Engineers and Reservoir Control staff at Cougar Dam were instrumental in coordinating our activities to install equipment at the dams, as were David Griffith and Fenton Khan at the Portland District office. Our administrative and science colleagues at the Columbia River Research Laboratory, particularly Scott Brewer, Theresa Liedtke, Gary Rutz, Matt Sholtis, Tyson Hatton, Amy Hansen, and Nick Swyers contributed greatly to this study. The report was improved with review comments from Michael Horn and Lisa Gee. This study was funded by the U.S. Army Corps of Engineers under contract W66QKZ30864777. 
This page left intentionally blank 


\section{Contents}

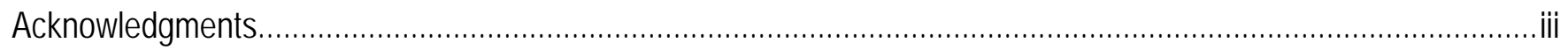

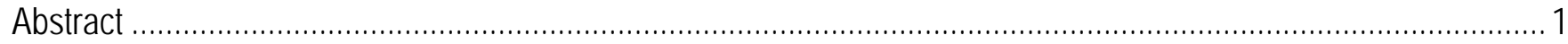

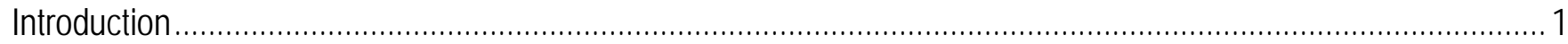

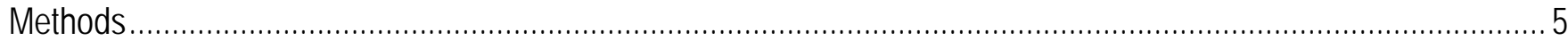

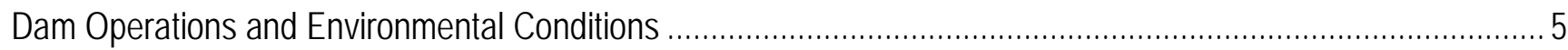

Acoustic Camera Surveillance Systems..............................................................................................

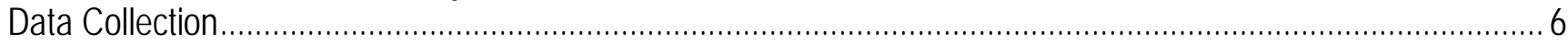

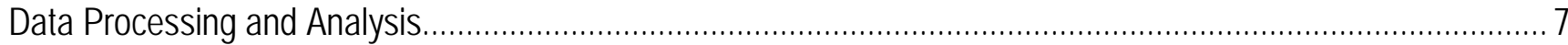

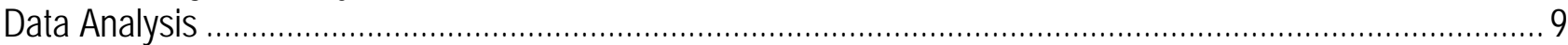

Evaluating Direction and Travel Speed of Fish Toward Water Temperature Control Tower............................. 9

Evaluating Numerical Response of Fish Movement Toward Water Temperature Control Tower ........................11

Evaluating Fish Track Density Upstream of Water Temperature Control Tower ............................................ 11

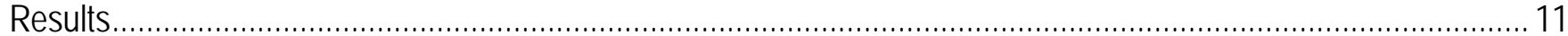

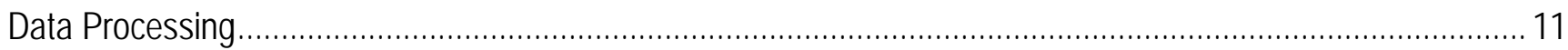

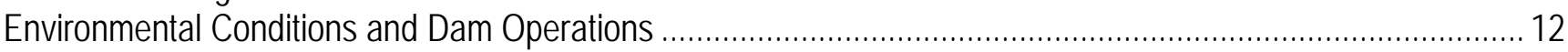

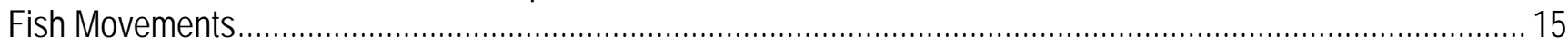

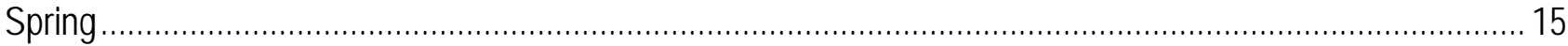

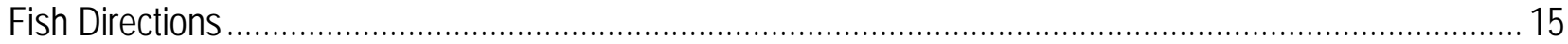

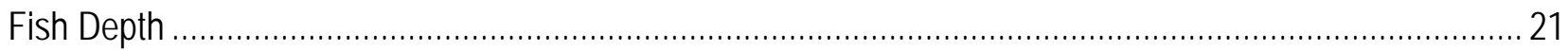

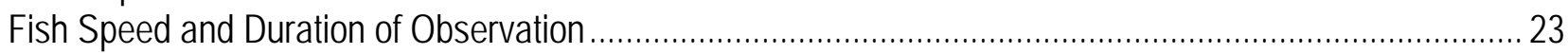

Quantifying Movement Toward the Water Temperature Control Tower...................................................... 26

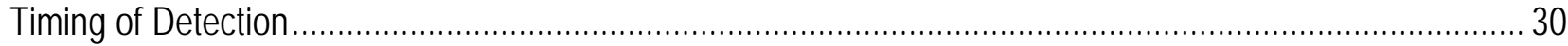

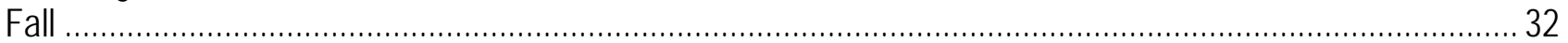

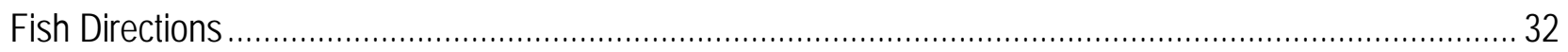

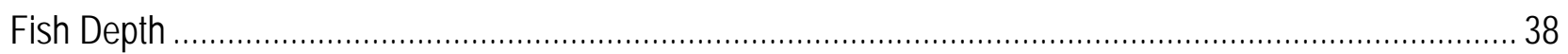

Fish Speed and Duration of Observation .......................................................................................... 40

Quantifying Movement Toward Water Temperature Control Tower...................................................... 44

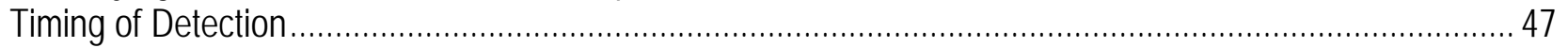

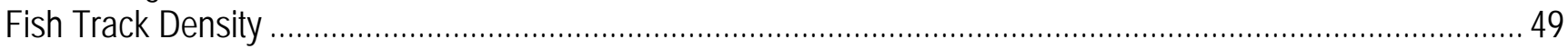

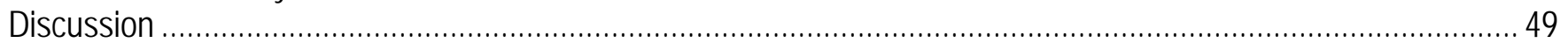

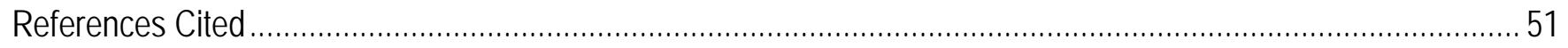

Appendix A. Sample Dates Selected for Analysis of DIDSON and ARIS Acoustic Camera Data Collected at the Cougar Reservoir Water Temperature Control (WTC) Tower, Oregon, 2013 ............................................5 53

Appendix B. Rose Plots and Circular Histograms of Mean Travel Directions of Fish Collected by Acoustic Cameras by Depth and Photoperiod at Cougar Reservoir and Dam, Oregon ...................................................... 55

Appendix C. Density Plots of Fish Target Locations from DIDSON and ARIS Acoustic Camera Data Collected during the Fish Behavior Evaluations at Cougar Reservoir and Dam, Oregon, 2013 


\section{Figures}

Figure 1. Photograph showing water temperature control (WTC) tower in the forebay of Cougar Reservoir, Oregon.

Figure 2. Cross section of water temperature control (WTC) tower showing water elevation at full conservation and minimum flood control pool and intake elevations of the regulating outlet (RO) and powerhouse penstock, Cougar Reservoir, Oregon...

Figure 3. Orthoimage showing water temperature control (WTC) tower, and the floating acoustic camera platforms at Cougar Dam, Oregon.

Figure 4. Schematic showing spring and fall coverage areas of the DIDSON ${ }^{\circledR}$, ARIS $^{\circledR}$, and BlueView ${ }^{\circledR}$ acoustic cameras near the water temperature control (WTC) tower at Cougar Reservoir, Oregon, 2013

Figure 5. Data flow of semiautomated Echoview ${ }^{\circledR}$ processing structure used to process acoustic camera targets at the water temperature control (WTC) tower at Cougar Reservoir, Oregon, 2013

Figure 6. Plots showing mean daily project discharge and head over the weir gates (top) and forebay elevation and temperature (bottom) at Cougar Reservoir. Oregon, May 1-November 14, 2013. 12

Figure 7. Plot showing daily dam operating conditions for discharge through the regulating outlet and turbines at Cougar Reservoir and Dam, Oregon, May 1-November 14, 2013.

Figure 8. Rose plots and circular histograms of mean directions (degrees) of 30-60 and 60-90 millimeter $(\mathrm{mm})$ fish-size categories by acoustic-camera type (DIDSON ${ }^{\circledR}$ or ARIS ${ }^{\circledR}$ ) and photoperiod (day, night, or combined) at Cougar Reservoir and Dam, Oregon, spring 2013

Figure 9. Rose plots and circular histograms of mean directions (degrees) of 90-250 and >300 millimeter $(\mathrm{mm})$ fish-size categories by acoustic-camera type (DIDSON ${ }^{\circledR}$ or ARIS ${ }^{\circledR}$ ) and photoperiod (day, night, or combined) at Cougar Reservoir and Dam, Oregon, spring 2013

Figure 10. Effects plots for the full circular-linear model of mean directions of fish (in degrees) within the beam of the DIDSON ${ }^{\circledR}$ acoustic camera upstream of the water temperature control (WTC) tower at Cougar Reservoir and Dam, Oregon, spring 2013

Figure 11. Effects plots for the full circular-linear model of mean directions of fish (in degrees) within the beam of the ARIS ${ }^{\circledR}$ acoustic camera upstream of the water temperature control (WTC) tower at Cougar Reservoir and Dam, Oregon, spring 2013

Figure 12. Graph showing hourly mean depth of fish (in meters [m]), by size category (in millimeters [mm]), in the area covered by DIDSON ${ }^{\circledR}$ and ARIS $^{\circledR}$ acoustic cameras, which were upstream of the water temperature control (WTC) tower at Cougar Reservoir and Dam, Oregon, spring 2013.

Figure 13. Box and whisker plots of the depth of fish (in meters [m]) observed under different camera angles using DIDSON ${ }^{\circledR}$ and ARIS ${ }^{\circledR}$ acoustic cameras at Cougar Reservoir and Dam, Oregon, spring 2013

Figure 14. Graphs showing distributions of fish travel speeds (in meters per second [m/s]) and the amount of time fish spent within the acoustic beams (in seconds [s]) of the DIDSON ${ }^{\circledR}$ and ARIS ${ }^{\circledR}$ acoustic cameras at Cougar Reservoir and Dam, Oregon, spring 2013.

Figure 15. Plots for multiple regression model estimates of mean travel speed of fish (in meters per second $[\mathrm{m} / \mathrm{s}]$ ), by size category (in millimeters [mm]), within the beams of the DIDSON ${ }^{\circledR}$ and ARIS $^{\circledR}$ acoustic cameras upstream of the water temperature control (WTC) tower at Cougar Reservoir and Dam, Oregon, spring 2013

Figure 16. Scatter plots showing number (n) of fish moving toward the water temperature control (WTC) tower (per 3-second interval) and total number of fish observed in the acoustic beam (per 3-second interval) of the DIDSON ${ }^{\circledR}$ and ARIS ${ }^{\circledR}$ acoustic cameras at Cougar Reservoir and Dam, Oregon, spring 2013 ...

Figure 17. Effects plots for the reduced Poisson rate regression modeling the numbers of fish traveling toward the water temperature control (WTC) tower while in the beam of the DIDSON${ }^{\circledR}$ acoustic camera at Cougar Reservoir and Dam, Oregon, spring 2013. 
Figure 18. Effects plots for the reduced Poisson rate regression model of numbers of fish traveling toward the water temperature control (WTC) tower while in the beam of the ARIS ${ }^{\circledR}$ acoustic camera at Cougar Reservoir and Dam, Oregon, spring 2013.

Figure 19. Graph showing hour of detection of fish, by size category (in millimeters [mm]), using the DIDSON $^{\circledR}$ and ARIS ${ }^{\circledR}$ acoustic cameras upstream of the water temperature control (WTC) tower at Cougar Reservoir and Dam, Oregon, spring 2013.

Figure 20. Graph showing hour of detection of fish, by size category (in millimeters [mm]), that were observed traveling toward the water temperature control (WTC) tower using the DIDSON ${ }^{\circledR}$ and ARIS ${ }^{\circledR}$ acoustic cameras at Cougar Reservoir and Dam, Oregon, spring 2013

Figure 21. Rose plots and circular histograms of mean directions (degrees) of 30-60 and 60-90 millimeter $(\mathrm{mm})$ fish-size categories by acoustic-camera type (DIDSON ${ }^{\circledR}$ or ARIS ${ }^{\circledR}$ ) and photoperiod (day, night, or combined) upstream of the water temperature control (WTC) tower at Cougar Dam, Oregon, fall 2013

Figure 22. Rose plots and circular histograms of mean directions (degrees) of 90-250 and $>300$ millimeter $(\mathrm{mm})$ fish-size categories by acoustic-camera type (DIDSON ${ }^{\circledR}$ or ARIS ${ }^{\circledR}$ ) and photoperiod (day, night, or combined) upstream of the water temperature control (WTC) tower at Cougar Dam, Oregon, fall 2013

Figure 23. Effects plots for the full circular-linear model of mean directions of fish (in degrees) within the beam of the DIDSON ${ }^{\circledR}$ acoustic camera upstream of the water temperature control (WTC) tower at Cougar Reservoir and Dam, Oregon, fall 2013 36

Figure 24. Effects plots for the full circular-linear model of mean directions fish (in degrees) within the beam of the ARIS ${ }^{\circledR}$ acoustic camera upstream of the water temperature control (WTC) tower at Cougar Reservoir and Dam, Oregon, fall 2013

Figure 25. Graph showing hourly mean depth of fish (in meters [m]), by size category (in millimeters [mm]), in the area covered by DIDSON ${ }^{\circledR}$ and ARIS $^{\circledR}$ acoustic cameras, which were upstream of the water temperature control (WTC) tower at Cougar Reservoir and Dam, Oregon, fall 2013

Figure 26. Box and whisker plots of the depth of fish (in meters [m]) observed under different camera angles using DIDSON ${ }^{\circledR}$ and ARIS ${ }^{\circledR}$ acoustic cameras at Cougar Reservoir and Dam, Oregon, fall 2013.

Figure 27. Graphs showing distributions of fish travel speeds (in meters per second [m/s]) and the amount of time fish spent within the acoustic beams of the DIDSON ${ }^{\circledR}$ and ARIS $^{\circledR}$ acoustic cameras at Cougar Reservoir and Dam, fall 2013

Figure 28. Plots for the multiple regression model estimates of mean travel speed of fish (in meters per second $[\mathrm{m} / \mathrm{s}]$ ), by size category (in millimeters [mm]), within the beams of the DIDSON ${ }^{\circledR}$ and ARIS $^{\circledR}$ acoustic cameras upstream of the water temperature control (WTC) tower at Cougar Reservoir and Dam, Oregon, fall 2013.

Figure 29. Scatter plots showing number ( $n$ ) of fish moving toward the water temperature control (WTC) tower (per 3-second interval) and total number of fish observed in the acoustic beam (per 3-second interval) of the DIDSON ${ }^{\circledR}$ and ARIS $^{\circledR}$ acoustic cameras at Cougar Reservoir and Dam, Oregon, fall 2013.

Figure 30. Effects plots for the reduced Poisson rate regression modeling the numbers of fish traveling toward the water temperature control (WTC) tower while in the beam of the DIDSON${ }^{\circledR}$ acoustic camera at Cougar Reservoir and Dam, Oregon, fall 2013

Figure 31. Effects plots for the reduced Poisson rate regression model of the numbers of fish traveling toward the water temperature control (WTC) tower while in the beam of the ARIS ${ }^{\circledR}$ acoustic camera at Cougar Reservoir and Dam, Oregon, fall 2013 
Figure 32. Graph showing hour of detection of fish, by size category (in millimeters [mm]), using the DIDSON $^{\circledR}$ and ARIS ${ }^{\circledR}$ acoustic cameras upstream of the water temperature control (WTC) tower at Cougar Reservoir and Dam, Oregon, fall 2013.

Figure 33. Graph showing hour of detection of fish, by size category (in millimeters [mm]), that were observed moving toward the water temperature control (WTC) tower using the DIDSON ${ }^{\circledR}$ and ARIS ${ }^{\circledR}$ acoustic cameras at Cougar Reservoir and Dam, Oregon, fall 2013.

\section{Tables}

Table 1. Mean hourly summary statistics of dam operations and environmental conditions at Cougar Reservoir and Dam, Oregon, spring 2013.

Table 2. Mean hourly summary statistics of dam operations and environmental conditions at Cougar Reservoir and Dam, Oregon, fall 2013.

Table 3. Mean directions (radians) and concentration parameters by fish-size category and acoustic-camera type (DIDSON ${ }^{\circledR}$ or ARIS $^{\circledR}$ ) at Cougar Reservoir and Dam, Oregon, spring 2013.

Table 4. Results for circular-linear models of mean directions (radians) of fish in the acoustic beams of the DIDSON $^{\circledR}$ and ARIS ${ }^{\circledR}$ acoustic cameras upstream of the water temperature control (WTC) tower at Cougar Reservoir and Dam, Oregon, spring 2013.

Table 5. Sample size, and mean, standard deviation, minimum, and maximum depths of each fish-size category observed with the DIDSON ${ }^{\circledR}$ and ARIS $^{\circledR}$ acoustic cameras upstream of the water temperature control (WTC) tower at Cougar Reservoir and Dam, spring 2013.

Table 6. Summary statistics for the travel speeds and duration of fish observed with the DIDSON ${ }^{\circledR}$ and ARIS $^{\circledR}$ acoustic cameras at the water temperature control (WTC) tower at Cougar Reservoir and Dam, Oregon, spring 2013

Table 7. Results for multiple regression models of mean travel speeds $(\sqrt{\mathrm{m} / \mathrm{s}})$ of fish while in the acoustic beams of the DIDSON ${ }^{\circledR}$ and ARIS ${ }^{\circledR}$ acoustic cameras upstream of the water temperature control (WTC) tower at Cougar Reservoir and Dam, Oregon, spring 2013

Table 8. Results for Poisson rate regression models of fish moving toward the water temperature control (WTC) tower while in the acoustic beams of the DIDSON ${ }^{\circledR}$ and ARIS ${ }^{\circledR}$ acoustic cameras at Cougar Reservoir and Dam, Oregon, spring 2013

Table 9. Results for reduced Poisson rate regression models of fish moving toward the water temperature control (WTC) tower while in the acoustic beam of the DIDSON ${ }^{\circledR}$ and ARIS ${ }^{\circledR}$ cameras at Cougar Reservoir and Dam, Oregon, spring 2013

Table 10. Mean directions (radians) and concentration parameters by fish-size category and acoustic-camera type (DIDSON ${ }^{\circledR}$ or ARIS $^{\circledR}$ ) at Cougar Reservoir and Dam, Oregon, fall 2013

Table 11. Results for circular-linear models of mean directions (radians) of fish in the acoustic beams of the DIDSON ${ }^{\circledR}$ and ARIS $^{\circledR}$ acoustic cameras upstream of the water temperature control (WTC) tower at Cougar Reservoir and Dam, Oregon, fall 2013

Table 12. Sample size, and mean, standard deviation, minimum, and maximum depths of each fish-size category observed with the DIDSON ${ }^{\circledR}$ and ARIS $^{\circledR}$ acoustic cameras upstream of the water temperature control (WTC) tower at Cougar Reservoir, Oregon, fall 2013.

Table 13. Summary statistics for the travel speeds and duration that fish were observed by the DIDSON and ARIS acoustic cameras at the water temperature control (WTC) tower at Cougar Reservoir and Dam, Oregon, fall 2013 
Table 14. Results for multiple regression models of mean travel speeds (square root of meter per second $[\sqrt{\mathrm{m} / \mathrm{s}}]$ ) of fish while in the acoustic beams of the DIDSON ${ }^{\circledR}$ and ARIS $^{\circledR}$ acoustic cameras upstream of the water temperature control (WTC) tower at Cougar Reservoir and Dam, Oregon, fall 2013

Table 15. Results for reduced Poisson rate regression models of fish traveling toward the water temperature control (WTC) tower while in the acoustic beams of the DIDSON ${ }^{\circledR}$ and ARIS ${ }^{\circledR}$ acoustic cameras at Cougar Reservoir and Dam, Oregon, fall 2013

Table 16. Results for reduced Poisson rate regression models with removal of nonsignificant predictors of fish traveling toward the water temperature control (WTC) tower while in the acoustic beams of the DIDSON ${ }^{\circledR}$ and ARIS acoustic cameras at Cougar Reservoir and Dam, Oregon, fall 2013.

\section{Conversion Factors}

Inch/Pound to International System of Units

\begin{tabular}{lll}
\multicolumn{1}{c}{ Multiply } & \multicolumn{1}{c}{ By } & \multicolumn{1}{c}{ To obtain } \\
\hline foot $(\mathrm{ft})$ & 0.3048 & meter $(\mathrm{m})$ \\
cubic foot per second $\left(\mathrm{ft}^{3} / \mathrm{s}\right)$ & 0.02832 & cubic meter per second $\left(\mathrm{m}^{3} / \mathrm{s}\right)$ \\
\hline
\end{tabular}

International System of Units to Inch/Pound

\begin{tabular}{lll}
\hline \multicolumn{1}{c}{ Multiply } & \multicolumn{1}{c}{ By } & \multicolumn{1}{c}{ To obtain } \\
\hline millimeter $(\mathrm{mm})$ & 0.03937 & inch (in.) \\
centimeter $(\mathrm{cm})$ & 0.3937 & inch (in.) \\
meter $(\mathrm{m})$ & 3.281 & foot (ft) \\
kilometer $(\mathrm{km})$ & 0.6214 & mile (mi) \\
meter per second $(\mathrm{m} / \mathrm{s})$ & 3.281 & foot per second $(\mathrm{ft} / \mathrm{s})$ \\
\hline
\end{tabular}

Temperature in degrees Celsius $\left({ }^{\circ} \mathrm{C}\right)$ may be converted to degrees Fahrenheit $\left({ }^{\circ} \mathrm{F}\right)$ as ${ }^{\circ} \mathrm{F}=\left(1.8 \times{ }^{\circ} \mathrm{C}\right)+32$.

\section{Datums}

Vertical coordinate information is referenced to the National Geodetic Vertical Datum of 1929 (NGVD 29).

Horizontal coordinate information is referenced to the World Geodetic System of 1984 (WGS 84).

Elevation, as used in this report, refers to distance above the vertical datum.

\section{Abbreviations}

$\begin{array}{ll}\text { AIC } & \text { Akaike Information Criterion } \\ \text { CSV } & \text { comma-separated value } \\ \text { GLMS } & \text { Generalized Linear Models } \\ \text { PFFC } & \text { Portable Floating Fish Collector } \\ \text { RO } & \text { regulating outlet } \\ R^{2} & \text { coefficient of determination } \\ \text { USACE } & \text { U.S. Army Corps of Engineers } \\ \text { UWR } & \text { Upper Willamette River } \\ \text { WTC } & \text { Water Temperature Control Tower }\end{array}$


This page left intentionally blank 


\title{
An Evaluation of Fish Behavior Upstream of the Water Temperature Control Tower at Cougar Dam, Oregon, Using Acoustic Cameras, 2013
}

By Noah S. Adams, Collin D. Smith, John M. Plumb, Gabriel S. Hansen, and John W. Beeman

\begin{abstract}
This report describes the initial year of a 2-year study to determine the feasibility of using acoustic cameras to monitor fish movements to help inform decisions about fish passage at Cougar Dam near Springfield, Oregon. Specifically, we used acoustic cameras to measure fish presence, travel speed, and direction adjacent to the water temperature control tower in the forebay of Cougar Dam during the spring (May, June, and July) and fall (September, October, and November) of 2013. Cougar Dam is a high-head flood-control dam, and the water temperature control tower enables depth-specific water withdrawals to facilitate adjustment of water temperatures released downstream of the dam. The acoustic cameras were positioned at the upstream entrance of the tower to monitor free-ranging subyearling and yearling-size juvenile Chinook salmon (Oncorhynchus tshawytscha). Because of the large size discrepancy, we could distinguish juvenile Chinook salmon from their predators, which enabled us to measure predators and prey in areas adjacent to the entrance of the tower. We used linear models to quantify and assess operational and environmental factors - such as time of day, discharge, and water temperature - that may influence juvenile Chinook salmon movements within the beam of the acoustic cameras. Although extensive milling behavior of fish near the structure may have masked directed movement of fish and added unpredictability to fish movement models, the acoustic-camera technology enabled us to ascertain the general behavior of discrete size classes of fish. Fish travel speed, direction of travel, and counts of fish moving toward the water temperature control tower primarily were influenced by the amount of water being discharged through the dam.
\end{abstract}

\section{Introduction}

The U.S. Army Corps of Engineers (USACE) operates the Willamette Project (Project) in western Oregon, including 13 dams, about $68 \mathrm{~km}$ of revetments, and several fish hatcheries. The primary purpose of the Project is flood control, but it also is operated to provide hydroelectricity, irrigation water, navigation, instream flows for wildlife, and recreation. The dams, including Cougar Dam, are all on tributaries of the Willamette River. The National Oceanic and Atmospheric Administration determined in a recent Biological Opinion that the Project jeopardizes the sustainability of anadromous fish stocks in the Willamette River Basin (National Oceanic and Atmospheric Administration, 2008). 
Cougar Dam is a 158 m-high rock-fill dam on the South Fork of the McKenzie River, about 63 km east of Springfield, Oregon. The dam, completed in 1964, is owned and operated by the USACE, Portland District. The powerhouse has a hydraulic capacity of 1,050 $\mathrm{ft}^{3} / \mathrm{s}$ and uses two Francis turbine units capable of generating a total of 25 megawatts. The dam also has a spillway with two Tainter gates, and a water temperature control (WTC) tower that was installed in 2005 (fig. 1). Water passes the dam through the WTC tower either into a flow regulating outlet (RO) or through the powerhouse penstock, both of which are supplied through a common wet well. The reservoir is used primarily for flood control, power generation, and irrigation. The forebay elevation normally is maintained at high levels during summer months and low levels during winter months. The maximum conservation-pool elevation of 1,690 ft typically is reached in May, and the minimum flood-control pool elevation of 1,532 $\mathrm{ft}$ usually is reached in December.

Juvenile salmon that migrate downstream are required to pass through the WTC tower. Prior to installation of the WTC tower, water passing through the dam was drawn from deep within the reservoir and often was too cold for attraction and spawning of salmon downstream. The WTC tower allows the use of water from various depths in the forebay to provide water temperatures suitable for salmon. All water passing through the dam enters the WTC tower and passes to the tailrace either through the RO at a centerline elevation of $1,485.0 \mathrm{ft}$, or through the powerhouse penstock intake at a centerline elevation of $1,424.8 \mathrm{ft}$. At water elevations of $1,571.0 \mathrm{ft}$ or greater, water passes over or between weir gates into the wet well of the temperature control tower and then through the RO or the penstock (fig. 2). At elevations lower than $1,571.0 \mathrm{ft}$, water can pass into the wet well through either the RO bypass gate (centerline elevation 1,488.5 ft) or the penstock bypass gate (centerline elevation 1,429.0 ft). A fish ladder and trapping facility are used to collect adult salmon in the tailrace for transportation upstream and provide a means of upstream passage for adult salmon. There currently is no passage route designed for downstream passage of juvenile salmon.

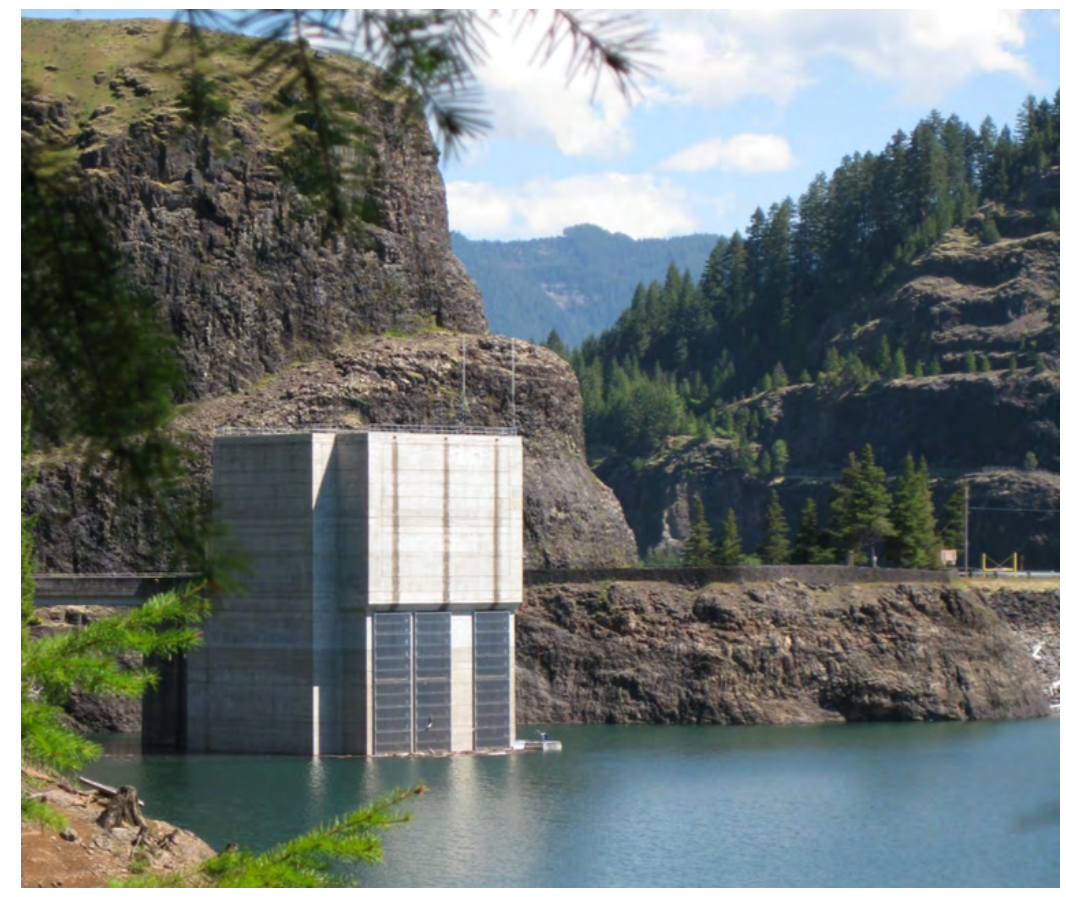

Figure 1. Photograph showing water temperature control (WTC) tower in the forebay of Cougar Reservoir, Oregon. Photograph by John Beeman, U.S. Geological Survey, 2010. 


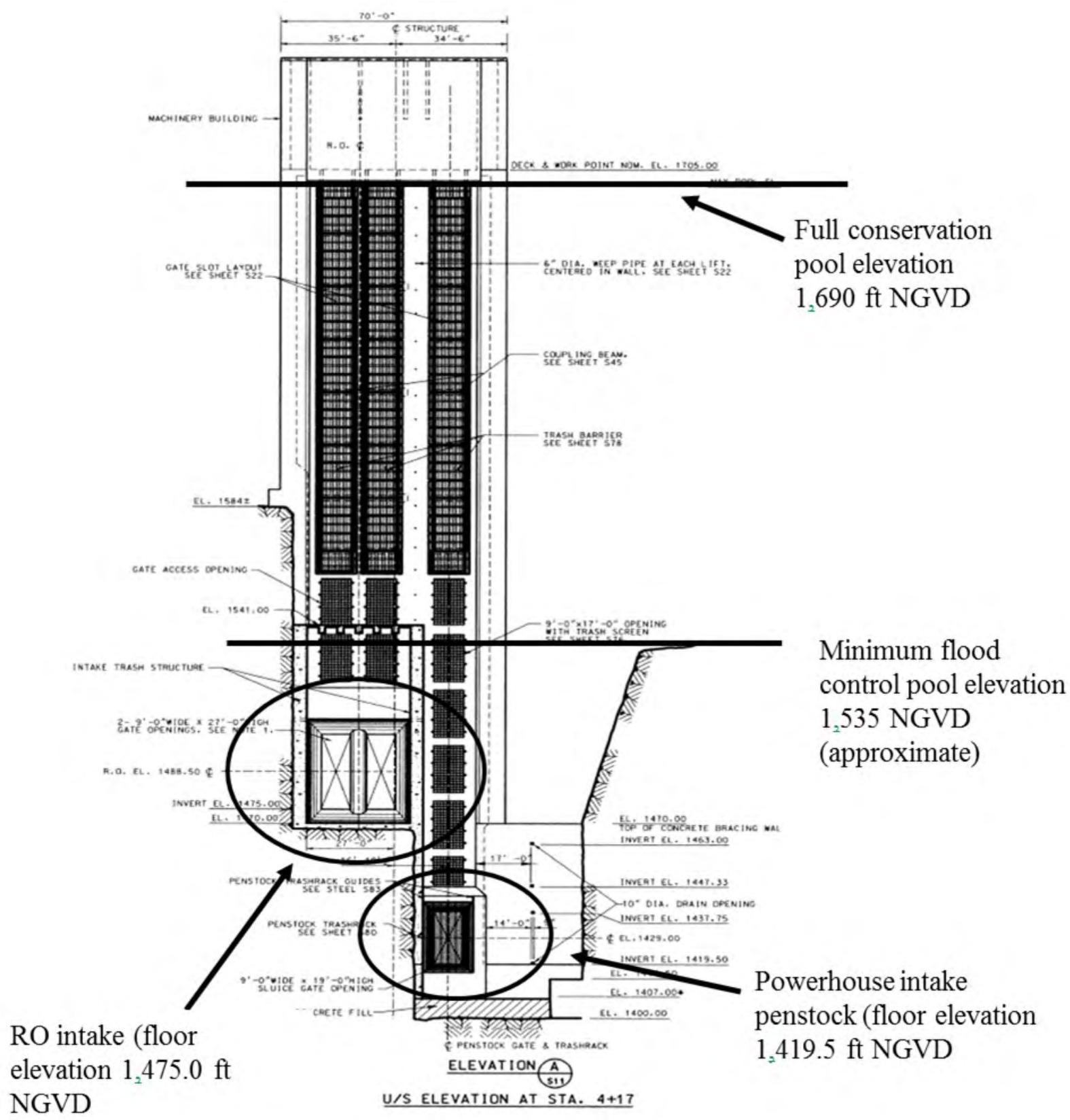

Figure 2. Cross section of water temperature control (WTC) tower showing water elevation at full conservation and minimum flood control pool and intake elevations of the regulating outlet (RO) and powerhouse penstock, Cougar Reservoir, Oregon. Schematic from U.S. Army Corps of Engineers.

The 2008 Willamette Biological Opinion requires improvements to operations or structures to reduce impacts on Upper Willamette River (UWR) Chinook salmon (Oncorhynchus tshawytscha) and UWR steelhead (Oncorhynchus mykiss) (National Oceanic and Atmospheric Administration, 2008). The Opinion includes a requirement to install fish passage facilities to provide safe downstream passage for juvenile salmonids at Cougar Dam by 2014, a goal that has yet to be reached but may be achieved 
through operational or structural alternatives. Information about the presence and behavior of juvenile salmonids and predator activity near the upstream face of the WTC tower during various dam operating conditions can be used to inform decisions about downstream passage alternatives.

Several important factors affecting dam passage rates at Cougar Dam have been identified. A study of juvenile Chinook salmon implanted with acoustic transmitters and released near the head of the reservoir showed that dam passage was positively related to the night diel period and increased dam discharge and negatively related to high reservoir elevation (Beeman and others, 2013). Volitional dam passage rates at night were about 9 times greater than during the day. As such, the greatest dam passage rates occurred at night during high discharge and low pool elevation. Data from radio-tagged fish released near the water surface at the WTC tower and from volitionally migrating fish released in the reservoir corroborate the preponderance of passage through the WTC tower at night (Beeman and others, 2012, 2014).

To meet the requirement of the Biological Opinion, the USACE installed a Portable Floating Fish Collector (PFFC) near the WTC tower in early 2014 to test surface-passage technology as a means to collect juvenile salmonids at Cougar Dam. The objective of this study was to use acoustic cameras to summarize the presence and behavior of untagged fish at Cougar Reservoir and Dam to inform decisions about the arrival timing, movements, and predator activity near the upstream face of the WTC tower, prior to the operation of the PFFC. A similar evaluation of fish movements upstream of the WTC tower was done in 2010 (Khan and others, 2012), but just one low-resolution acoustic camera was used, and a small fraction of the data collected was analyzed to quantify fish behavior just upstream of the WTC tower. Therefore, our study attempts to overcome these shortcomings by using multiple highresolution acoustic cameras and an automated proofing process that will allow for the inclusion of more data in the analysis. These improvements should enable a better characterization of the response of juvenile salmon in relation to biological and environmental factors such as day and night, fish size, water temperature, river flow, and the presence of other predatory fish, such as Bull Trout (Salvelinus confluentus).

This study used acoustic cameras to collect behavioral data on juvenile salmonids and their predators at the Cougar Reservoir and Dam WTC tower during spring through fall of 2013. Acoustic cameras are capable of recording near-video quality sonar images in a wide variety of habitats and environmental conditions (Tiffan and others, 2005; Doehring and others, 2011; Able and others, 2014 ). An advantage of using acoustic cameras for behavioral observations of aquatic species is that the images are constructed from data collected from target ensonification, and not from methods requiring visual observation. Therefore, data collection can occur in turbid conditions (Liedtke and others, 2013) without altering fish behavior, or can be used at night to investigate diurnal effects, which are an important behavioral factor for migrating salmonids (Dunbar, 2008; Pavlov and others, 2009). Data collected with the acoustic camera provides information on fish size (target strength), entrance depth, movement direction, and fish travel speed. The date, time, water temperature, and river flow also were recorded concurrently with the acoustic camera to enable us to assess the response of fish to environmental conditions upstream of the WTC tower. A Generalized Linear Models (GLMs) framework was then used to assess the response of fish to biological and environmental covariates. Using GLMs for the different responses (for example, directions or counts) allowed different error structures of the data to be accounted for while enabling the assessment of multiple effects on the different responses by fish upstream of the tower. 


\section{Methods}

\section{Dam Operations and Environmental Conditions}

Powerhouse discharge, discharge through the regulating outlet (RO), forebay elevation, head over the temperature control tower weir gates, and water temperature data were summarized to document the environmental conditions of juvenile Chinook salmon during the 2013 study periods. Hourly powerhouse discharge, RO discharge, and forebay elevation data were obtained from the USACE Web site http://www.nwd-wc.usace.army.mil/perl/dataquery.pl?k=id:CGR. Weir elevation and RO gate opening data were provided by the USACE. Hourly temperature data were obtained from the USACE Web site http://www.nwd-wc.usace.army.mil/ftppub/water_quality/tempstrings/. Diel periods were assigned using U.S. Naval civil twilight data for Springfield, Oregon, which was obtained at http://www.usno.navy.mil/USNO/astronomical-applications. Data were summarized using hourly observations, but mean daily values were plotted to increase clarity in the plots. Water-elevation data and fish depths are presented in feet and discharge is presented as cubic feet per second because this is the preferred local convention. Head differential was calculated by subtracting the water-surface elevation inside the tower from the water-surface elevation outside the tower. Water-elevation data were provided by the USACE.

\section{Acoustic Camera Surveillance Systems}

In this study, we used three acoustic cameras with different resolution and field-of-view capabilities to collect data on fish movements. A BlueView ${ }^{\circledR}$ P900 $\left(0.9 \mathrm{MHz}, 130^{\circ}\right.$ beam and $100-\mathrm{m}$ range) was used to monitor fish behavior upstream of the WTC tower. The higher resolution DIDSON ${ }^{\circledR}$ 300 (1.8 MHz, 29 beam, 15-m range) and ARIS ${ }^{\circledR} 3000$ (3.0 MHz, 30 ${ }^{\circ}$ beam, 5-m range) acoustic cameras were mounted on the sides of the WTC tower to monitor fish behavior at the entrance of the structure. We selected these different acoustic-camera technologies to balance the likelihood of observing the greatest number of fish targets, while still capturing sufficient behavioral data from small fish targets. The minimum size of fish targets that generally can be observed varies by camera type, with the ARIS and DIDSON acoustic cameras capable of detecting fish targets greater than 30 and $40 \mathrm{~mm}$, respectively, whereas the BlueView acoustic camera was limited to detecting targets larger than about $250 \mathrm{~mm}$. Positively determining the species of each individual target, especially with small fish, is not possible with acoustic camera technology.

The acoustic cameras were deployed from two 14-ft floating platforms positioned on the southeastern and southwestern corners of the WTC tower (fig. 3). The platforms were guided by stainless steel cables that were vertically tensioned on the exterior of the parapet walls, which allowed the vertical movement of the platforms with fluctuations in pool elevation, but restricted lateral movement. Spring-tensioned spoolers were installed on each platform to provide automatic tensioning of lines for the guidance and support of data and electrical cables from the top of the WTC tower to the deck of each platform. 


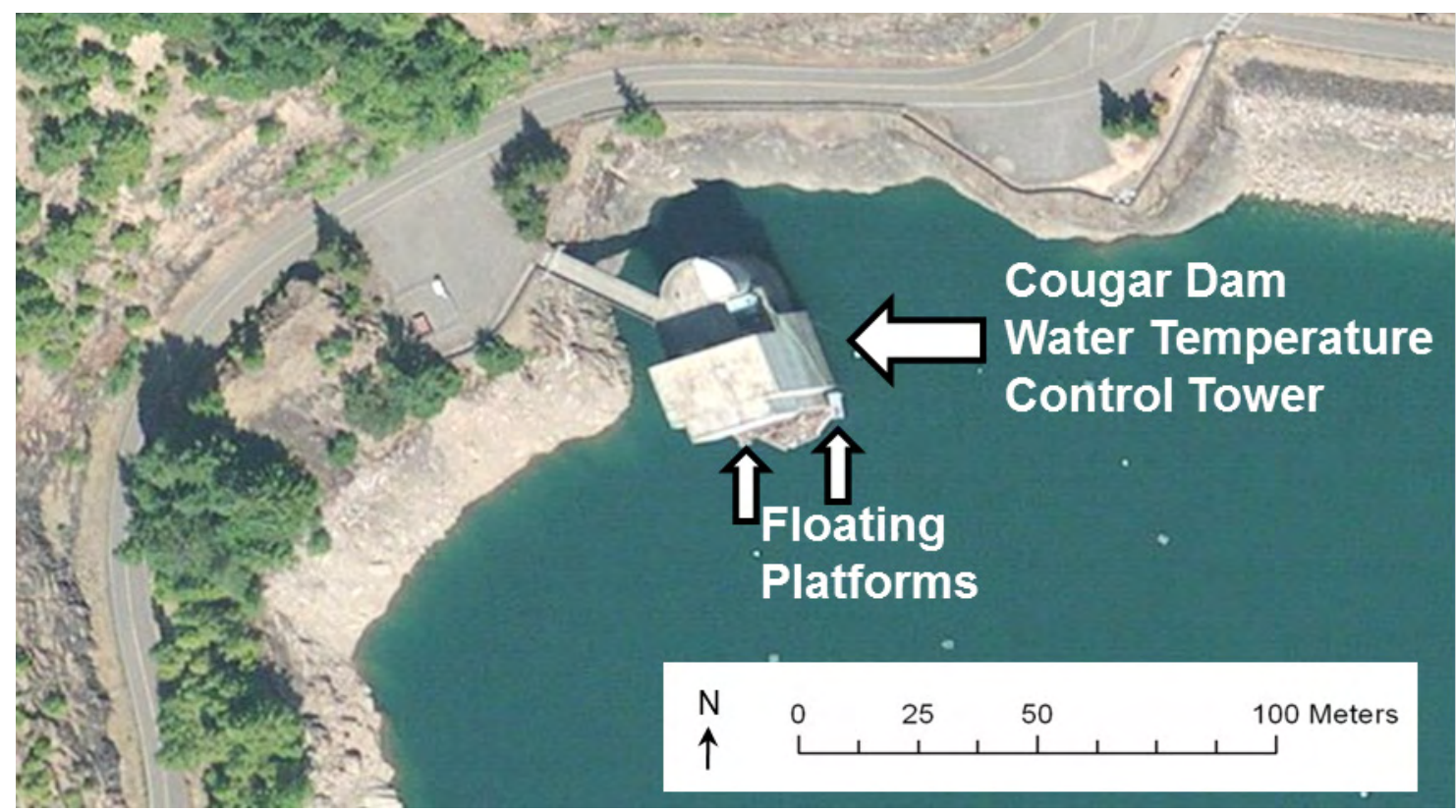

Figure 3. Orthoimage showing water temperature control (WTC) tower, and the floating acoustic camera platforms at Cougar Dam, Oregon. Photograph by U.S. Geological Survey, High Resolution State Orthoimagery for Oregon, 2013, 0.5-meter resolution.

All acoustic cameras were attached to poles mounted on each platform, and lowered to a depth of $2 \mathrm{~m}$ below the surface of the water. The BlueView was mounted on the east platform, and was pointed directly away from the tower (fig. 4). During the spring season, the DIDSON was mounted on the west platform, and aimed horizontally (west to east) across the west and center WTC tower intakes. Because of anticipated underwater obstructions that would be present when the elevation of the pool was low, the DIDSON was moved prior to the fall season to the east platform and positioned horizontally (east to west) across the east and center WTC tower intakes. The ARIS was deployed from the east platform and aimed (east to west) across the east WTC tower intake for both the spring and fall seasons. All three acoustic cameras were deployed on rotators to provide precise aiming of the cameras. To capture vertical distribution data near the upstream face of the WTC tower, the rotators were automated to randomly tilt the DIDSON and ARIS acoustic cameras every $36 \mathrm{~min}$, at three angles through the water column $\left(0^{\circ}, 25^{\circ}\right.$, and $50^{\circ}$ from horizontal angle).

\section{Data Collection}

Data were collected continuously at the WTC tower starting on May 1 and ending on July 11, 2013, for the spring season, and again between September 26 and November 14, 2013, for the fall season. We collected about $6,300 \mathrm{~h}$ of data over the $120 \mathrm{~d}$ that the acoustic cameras were recording. Data collection was interrupted only when equipment malfunctioned or when the cameras were removed for servicing and calibration between the spring and fall seasons. All data collected were stored to hard drives for archival and subsequent processing. 


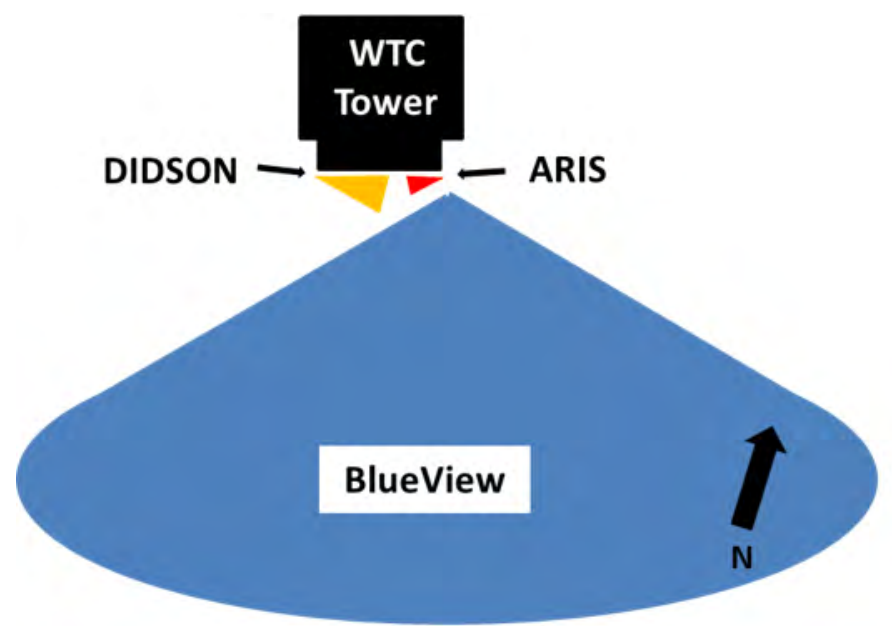

Spring Deployment

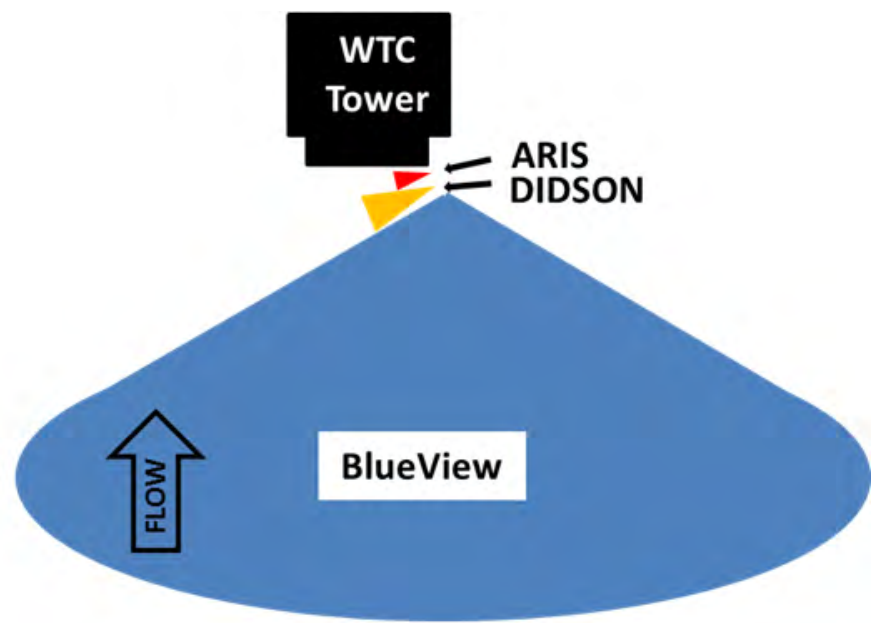

Fall Deployment

Figure 4. Schematic showing spring and fall coverage areas of the DIDSON $^{\circledR}, \mathrm{ARIS}^{\circledR}$, and BlueView ${ }^{\circledR}$ acoustic cameras near the water temperature control (WTC) tower at Cougar Reservoir, Oregon, 2013.

\section{Data Processing and Analysis}

Traditionally, acoustic camera data are processed by having a person review each file in real time, record the number of fish, and, if desired, characterize swimming behavior. This is very time consuming and often limits the amount of data that can be included in the analysis. Alternatively, signal processing software can be used to automate data processing, thereby allowing a greater proportion of data to be processed. Other researches have used this method when the fish of interest are relatively large (that is, greater than $300 \mathrm{~mm}$ fork length), but few have successfully implemented it when fish are smaller than $150 \mathrm{~mm}$ fork length. A main objective for the 2013 evaluation was to develop automated data processing procedures that would allow more of the information collected on small fish to be included in the analysis. To do this, we used Echoview ${ }^{\circledR}$ software (version 5.4, Myriax Pty. Ltd., Hobart, Tasmania, Australia) to process the data. The Echoview platform allows the operator to use successive filters to manipulate data in order to enhance the acoustic signal and remove static objects and noise from acoustic returns (Kang, 2011). Non-stationary acoustic returns are then identified as targets within individual camera frames and converted to two-dimensional position and time data, which can then be applied to target tracking. The conceptual layout of the virtual variable interface for the processing of acoustic camera data is shown in figure 5. Each object in the layout represents operational steps applied to the original data, which allows each individual step to be optimized to maximize efficiency and improve consistency (Boswell and others, 2008).

Initially, geospatial and positional data for each acoustic camera were associated with the geographic location of the platform to enable each target to be geospatially referenced (fig. 5, step 1). Next, acoustic camera data files were loaded into Echoview and converted to volume back-scattering strength (Sv) from raw signal magnitudes (fig. 5, step 2). To remove stationary objects (WTC tower) from the data, targets were deemed immobile by calculating the mean results of the four previous pings, which also had targets that did not move. These targets were then removed from the dataset (fig. 5 step 3). Next, static noise was removed by implementing a sample statistic subtract operator (fig. 5 step 4). 
This process implements a synthetic ping into the background signal, then subsequently subtracts the synthetic ping from each actual ping. This process leads to an increase in the signal-to-noise ratio by the removal of pings returned from inanimate objects and background noise. Following subtraction of background noise, the image was enhanced by applying a convolution ( $3 \times 3$ median) algorithm filter (fig. 5, step 5). This filter used the median value of a data point and the eight direct neighboring cells to remove interference and smooth the image without significantly affecting the shape of the target.

The next step was to use the multibeam target detection operator to generate multibeam targets from the multibeam data (fig. 5, step 6). These three-dimensional targets were created from groups of adjoining data points (clusters), which were then reduced to point data that include the geometric values of each fish target. The target conversion process was used next (fig. 5, step 7) to transform multibeam targets into single-point targets. Because of the multiple acoustic cameras operating near each other, much crosstalk noise in the form of vertical banding was not removed from the data by the filters in Echoview. To further reduce the volume of these non-fish targets in the data files, the filtered data were imported into SAS (version 9.3 of the SAS System for Windows, Copyright ${ }^{\odot}$ 2002-2010, SAS Institute Inc., Cary, North Carolina), and vertical banding was removed by comparing consecutive pings at a given range and eliminating the stationary noise (fig. 5, step 8).

Following the operational steps of filtering noise and smoothing the data, all single targets with all associated target properties were exported as comma-separated values (CSVs; fig. 5, step 9). These CSV files were then reimported into Echoview for further tracking and analysis (fig. 5, step 10). The purpose of fish tracking is to obtain counts and movements of individual fish, along with their associated behavioral and morphometric data (Simmonds and MacLennan, 2005).

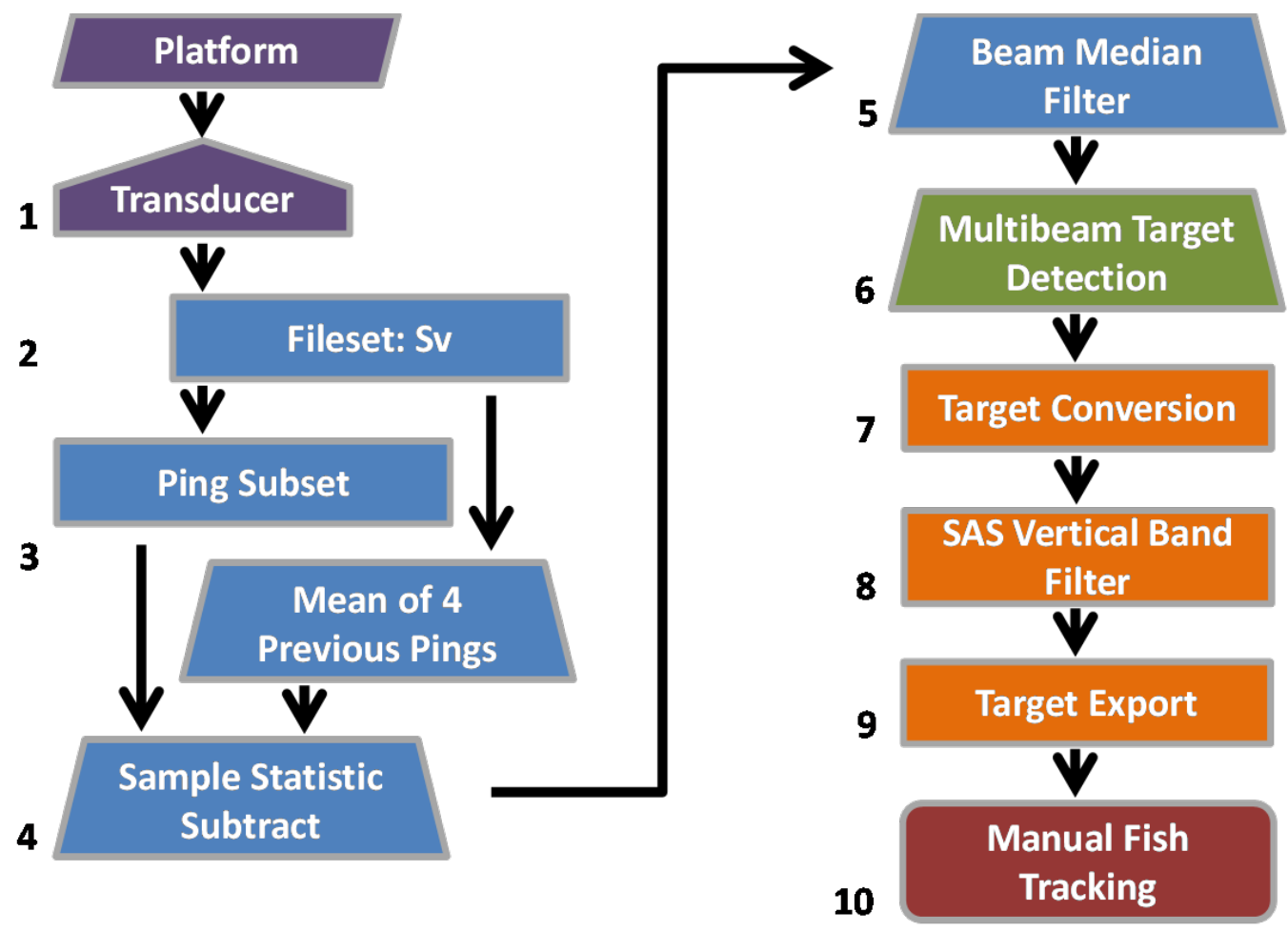

Figure 5. Data flow of semiautomated Echoview ${ }^{\circledR}$ processing structure used to process acoustic camera targets at the water temperature control (WTC) tower at Cougar Reservoir, Oregon, 2013. 


\section{Data Analysis}

Summary statistics of fish targets derived from Echoview (for example, mean length, direction, speed, angle, and orientation) were imported into SAS for subsequent proofing and to combine datasets with dam operations and environmental conditions. Data were proofed to eliminate non-valid records or records that did not provide measurable morphometric or behavioral data. To consider a fish track as valid, we required that each fish track consisted of at least five pings and had a minimum duration of detection of $1 \mathrm{~s}$. The acoustic-camera technology cannot distinguish fish that have entered and exited the field of view multiple times; therefore, the detection duration for each individual fish track within a camera beam was determined by the time a fish was first detected by the camera, to the time that the fish exited the camera view. Datasets for each acoustic-camera type and spring and fall seasons were then exported as CSV files for statistical modeling.

\section{Evaluating Direction and Travel Speed of Fish Toward Water Temperature Control Tower}

The direction of a given fish $j, d_{j}$, within the acoustic beam may be assumed to follow a von Mises distribution with a mean direction $\mu$ and concentration parameter $\kappa$. To summarize these data, we use circular statistics to calculate means and measures of variability (Mardia and Jupp, 2000) and use a circular-linear model as described by Pewsey and others (2013), which was implemented in R software (R Core Team, 2014). By proposing a set of candidate model subsets from a global model, we assess how combinations of covariates affect fish direction just upstream of the WTC tower. For example, the mean direction of the fish, $\mu$, in the acoustic beam (in radians) for the $d_{j}$ may be expressed as

$$
d_{j}=\mu+g\left(\gamma_{1} \cdot F_{\text {size }}+\gamma_{2} \cdot P_{\text {diel }}+\gamma_{3} \cdot Q+\gamma_{4} \cdot T\right)+\varepsilon_{d_{j}}
$$

where $\mu, \kappa$, and the $\gamma$ coefficients for each predictor will be estimated using maximum likelihood. The variable $F_{\text {size }}$ is the maximum target strength of the fish in the array providing a rough measure of fish size, $P_{\text {diel }}$ is a two-level class factor that resolves to 1 if the fish entered the acoustic beam during night or 0 if during the day. Water flow $(Q)$ and water temperature $(T)$ are factors that may affect fish passage and behavior upstream of dams, so we included total discharge and the water temperature during the hour the fish enter the acoustic beam as continuous covariates in the model. These predictors and their coefficients are linked to the response using the following link function as $g(u)=2 \tan ^{-1}(u)$, where $\tan ^{-}$ ${ }^{1}$ is also known as the arc tangent.

Using a similar set of predictors, we also model factors affecting the mean travel speed of fish, $v_{j}$, toward the WTC tower as

$$
\sqrt{v_{j}}=\beta_{0}+\beta_{1} \cdot F_{\text {size }}+\beta_{2} \cdot P_{\text {diel }}+\beta_{3} \cdot Q+\beta_{4} \cdot T+\beta_{5} \cdot D D+\varepsilon_{v_{j}}
$$

where the $\beta$ s are coefficients to be estimated. We assume the errors, ${ }^{\varepsilon_{v_{j}}}$, are normally distributed about the model for the $\sqrt{v_{j}}$. We square-root transformed the response to fulfill the assumption of normally distributed errors. Preliminary attempts to account for different error distributions using link functions were relatively unsuccessful compared to the more simple square-root transformation. We used standard diagnostics for linear models to assess goodness of fit. For example, we calculated variance inflation factors to assess collinearity among the predictors, as well as use diagnostic plots to determine outliers and assess homogeneity among the residuals. 


\section{Evaluating Numerical Response of Fish Movement Toward Water Temperature Control Tower}

Another approach to modeling fish responses in the acoustic beam is to model the number of fish that exit the area ensonified by the acoustic beam toward the WTC tower given the total number of fish in the acoustic beam. When compiling these counts on a per unit of time basis, we can evaluate how factors might influence the number of fish moving toward the tower by using a Poisson rate regression (Faraway, 2006) to test hypotheses about the numerical response of fish to environmental covariates. On preliminary inspection of the data, the median observation time for a fish in the acoustic camera was about $3 \mathrm{~s}$, which influenced the application of the Poisson rate regression to the counts of fish per unit time within the acoustic beams. First, to minimize the counting of a single fish as a multiple within a single observation in the analysis, we defined the time interval as $3 \mathrm{~s}$, which roughly equaled the median residence time of fish in the beam (see section, "Results"). A consequence of using such a short time interval was a preponderance of zeros in the dataset. When using the DIDSON acoustic camera, 96 percent $(234,902$ of 244,800$)$ of all 3-s observations were zeros in the spring, and 94 percent $(67,332$ of 72,000 ) of all 3-s observations were zeros in the fall. Therefore, we conditioned all the following Poisson rate regressions on there being at least one fish present in the acoustic beam.

The Poisson rate regressions, constructed from the logarithm of the number of fish that exit the acoustic beam toward the WTC tower (per unit time $t$ ) given the total number of fish that entered the acoustic beam, can be modeled as a function of covariates:

$$
\log _{e}\left(\frac{N_{\mathrm{WTC}, t}}{N_{\text {beam }, t}}\right)=\delta_{0}+\delta_{1} x_{1, t}+, \ldots,+\delta_{n} x_{n, t}
$$

where $\mathrm{t}$ is the given time period (most likely in minutes), $x_{1, t}, \ldots, x_{n, t}$ are the values of $\mathrm{n}$ covariates for time period $t, \delta_{1}, \ldots, \delta_{n}$ are the corresponding slope coefficients, and $\delta_{0}$ is the intercept. To fit this model to the data, we can express this equation as

$$
\log _{e}\left(N_{\mathrm{WTC}, t}\right)=\log _{e}\left(N_{\text {beam }, t}\right)+\delta_{0}+\delta_{1} x_{1, t}+, \ldots,+\delta_{n} x_{n, t}
$$

and then use a generalized linear model with a Poisson family, a log link function, and an offset for $\log _{e}\left(N_{\text {beam, }, t}\right)$ (that is, slope coefficient fixed to 1$)$. This formulation assumes that the count of fish exiting toward the WTC tower $\left(N_{\mathrm{WTC}, t}\right)$ is Poisson distributed. This assumption can be verified by estimating a dispersion parameter $\varphi$, (that is, $\left(X^{2} / \mathrm{df}\right)^{0.5}$; Agresti, 1996), which if greater than 1 , may be used to adjust model selection statistics and standard errors of the coefficients. We also can test model fit by conducting a bootstrapped goodness-of-fit test (Efron and Tibshirani, 1993; Faraway, 2006). By including the numbers of predators in the acoustic beam as a covariate to the model, we should be able to assess how numbers of predators upstream of the WTC tower may affect the numbers of fish exiting the acoustic beam toward the WTC tower.

We used Akaike Information Criterion (AIC) to help determine the relative importance and strength of a given response (Burnham and Anderson, 2002). We compared relative differences in AIC values amongst the set of single-predictor models that are subsets of their respective full models (equations 1 and 2). For model selection, however, we took a more cursory and simple approach by simply deleting the non-significant predictors from the full models. 


\section{Evaluating Fish Track Density Upstream of Water Temperature Control Tower}

The collected point samples for each individual fish track were used to create three-dimensional density plots of unique fish track locations for the volume sampled (Tecplot $360^{\mathrm{TM}}$, Bellevue, Washington). The spatial resolution within the view of each acoustic camera was about $1 \mathrm{~cm}$, and no interpolation of point data was performed. The magnitude of the point count is defined as the count of unique observations of each individual fish location within each cell. Datasets for each camera type and both spring and fall seasons were used for plotting location data for each size category of fish by diel period.

\section{Results}

\section{Data Processing}

We divided the acoustic camera operation and data collection into spring and fall study periods. The spring study period was from May 1 to July 11, 2013, and the fall study period was from September 26 to November 14, 2013. The cameras were removed for servicing and calibration between the spring and fall seasons, a time when smolt abundance at the WTC tower has been low (Khan and others, 2012). All acoustic cameras were removed on November 15, 2013, when the forebay elevation became insufficient for data collection in front of the WTC tower intakes.

We were successful in using the Echoview software platform to automate the processing of the data collected with the acoustic cameras. These methods allow substantially more of the data to be processed in a relatively short time than has previously been possible using standard manual methods. However, the nature of the data collected in 2013 prevented us from realizing the maximum benefit of the automated process. First, there was a large amount of debris in the water immediately upstream of the WTC tower, which made it difficult to identify fish as they swam among the debris field. Second, wind and wave action caused the platforms that the cameras were mounted on to move. This gave the appearance that otherwise stationary objects were moving, which further complicated identifying fish targets in the beam. The level of debris in the water, combined with the moving platforms, made it difficult to fully implement the automated data processing methods we developed. As a result, it was not feasible to process all data, so we subsampled dates throughout the study period (appendix A). The duration of each subsampled date was from midnight to midnight. On each date, we randomly subsampled 15-min blocks of every hour for each 24-h period. For the DIDSON data, we subsampled and processed 34 days of the data collected in the spring and 10 days in the fall. For the ARIS data, we subsampled and processed 30 days during the spring and 20 days during the fall.

The high volume of debris and the moving platforms not only affected our ability to process the data, but it also hindered our ability to take full advantage of the automated tracking feature in the Echoview software. Once again, in future studies this feature would be implemented to increase the volume of data that could be used in the analysis. However, this was not the case in 2013, so instead we manually tracked all data (fig. 5 step 10) to ensure that fish targets were accurately determined and that targets from woody debris and noise were excluded from analysis.

Finally, initial subsampling and inspection of the images collected with the BlueView acoustic camera revealed that the $0.9 \mathrm{mHz}$ camera was not capable of detecting either individual smolt-sized fish or schooling fish in this size range of interest. The limitation of this technology did not allow us to address the proposed research questions for this study, so no further processing or analysis was performed on the data collected with the BlueView acoustic camera. 


\section{Environmental Conditions and Dam Operations}

Dam operations and environmental conditions varied during the spring (fig. 6). The hourly total project discharge (mean $707.6 \mathrm{ft}^{3} / \mathrm{s}$, range 400.0-1,220.0 $\mathrm{ft}^{3} / \mathrm{s}$ ) through the dam primarily was through the turbines and not the regulating outlet (fig. 7). Mean hourly discharge was $63.4 \mathrm{ft}^{3} / \mathrm{s}$ (range $0.0-$ $1,050.0 \mathrm{ft}^{3} / \mathrm{s}$ ) through the regulating outlet, and $644.2 \mathrm{ft}^{3} / \mathrm{s}$ (range $60.0-1,000.0 \mathrm{ft}^{3} / \mathrm{s}$ ) through the powerhouse (table 1). The seasonal change in forebay elevation (mean 1,661.4 ft NGVD 29, range 1,652.1-1,670.0 ft NGVD 29) and head elevation over the upper weir gates (mean $4.4 \mathrm{ft}$, range 1.1-10.2 $\mathrm{ft}$ ) also varied throughout the season (table 1), but this change was related to total discharge, which was positively related to the amount of head ( $r=0.73, p<0.0001$, Pearson's) such that when the total discharge was high, so was the head. The temperature of the top 13-19 ft of the reservoir increased through the spring season, with the mean hourly temperature of $13.0^{\circ} \mathrm{C}$ (range $8.2-18.1^{\circ} \mathrm{C}$ ) (table 1 ). We did not find any marked differences in dam operations or water temperatures between day and night operations, although discharge through the regulating outlet was slightly higher at night, and turbine discharge was slightly higher during the day.
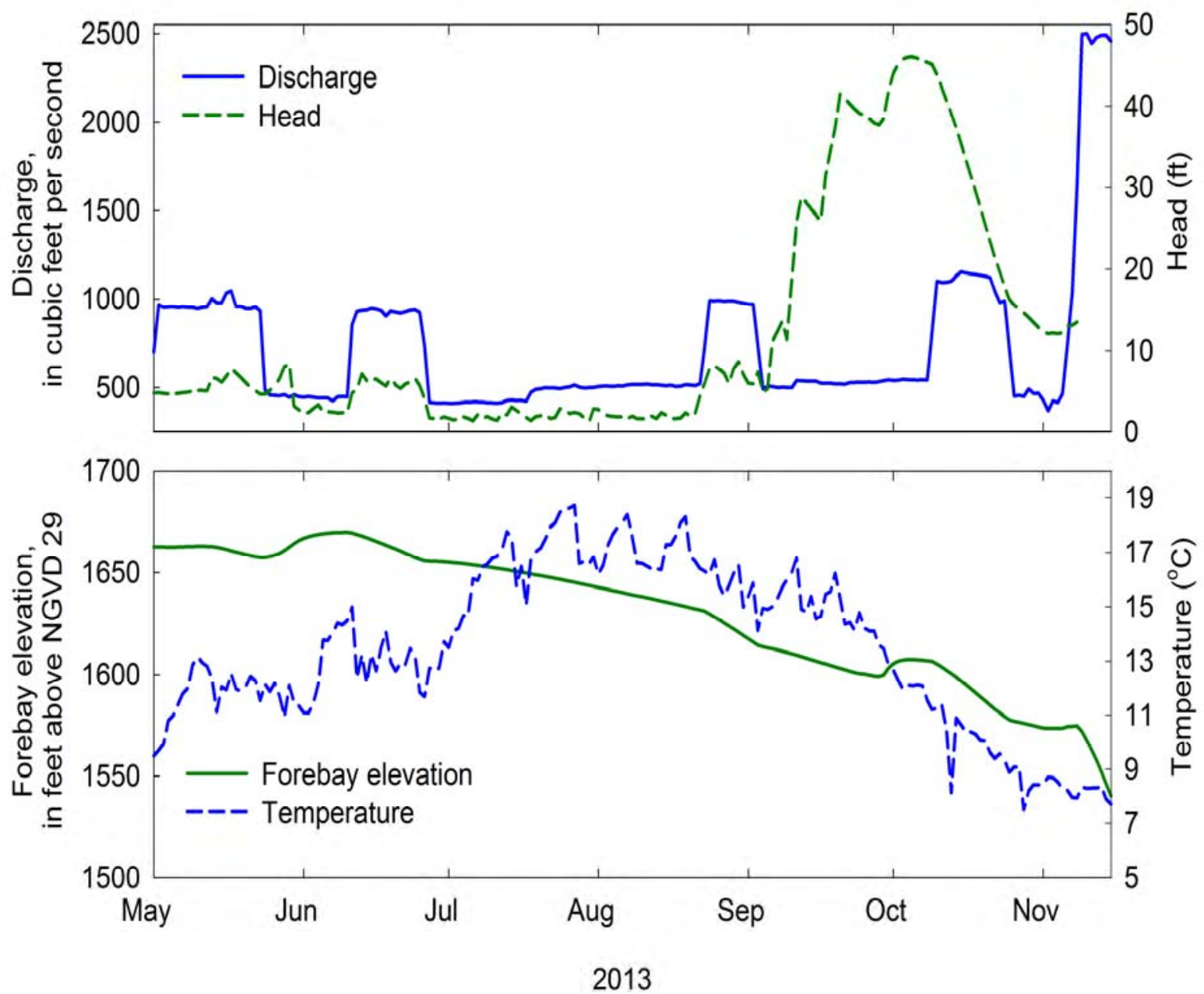

Figure 6. Plots showing mean daily project discharge and head over the weir gates (top) and forebay elevation and temperature (bottom) at Cougar Reservoir. Oregon, May 1-November 14, 2013. Water temperature is the average of the upper 13-19 feet of the water column near the water temperature control (WTC) tower. 


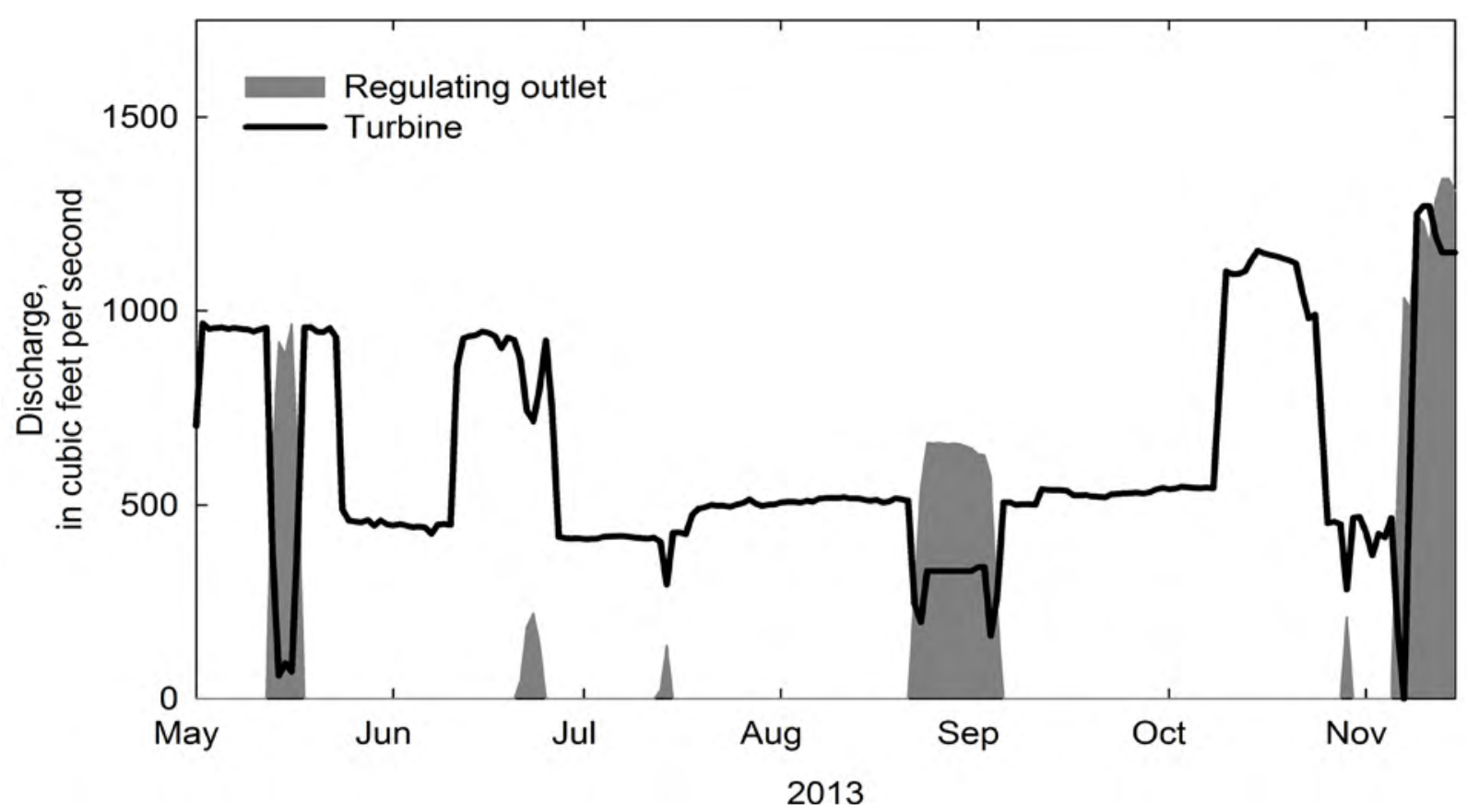

Figure 7. Plot showing daily dam operating conditions for discharge through the regulating outlet and turbines at Cougar Reservoir and Dam, Oregon, May 1-November 14, 2013.

Table 1. Mean hourly summary statistics of dam operations and environmental conditions at Cougar Reservoir and Dam, Oregon, spring 2013.

[SD, standard deviation; $\mathrm{ft}^{3}$ /s, cubic foot per second; NGVD 29, National Geodetic Vertical Datum of 1929]

\begin{tabular}{llrrrr}
\hline \multicolumn{1}{c}{ Dam operation } & Period & Mean & Median & \multicolumn{1}{c}{ Range } & SD \\
\hline Total proiect discharge $\left(\mathrm{ft}^{3} / \mathrm{s}\right)$ & Overall & 707.6 & 910.0 & $400.0-1,220.0$ & 258.6 \\
& Day & 711.2 & 910.0 & $400.0-1,220.0$ & 258.4 \\
& Night & 701.5 & 910.0 & $400.0-1,120.0$ & 258.9 \\
Powerhouse $\left(\mathrm{ft}^{3} / \mathrm{s}\right)$ & Overall & 644.2 & 460.0 & $60.0-1,000.0$ & 283.8 \\
& Day & 652.0 & 460.0 & $60.0-1,000.0$ & 285.9 \\
& Night & 631.1 & 460.0 & $60.0-1,000.0$ & 280.1 \\
Regulating outlet $\left(\mathrm{ft}^{3} / \mathrm{s}\right)$ & Overall & 63.4 & 0.0 & $0.0-1,050.0$ & 228.5 \\
& Day & 59.3 & 0.0 & $0.0-1,050.0$ & 226.7 \\
& Night & 70.4 & 0.0 & $0.0-1,050.0$ & 231.6 \\
Forebay elevation (feet, NGVD 29) & Overall & $1,661.4$ & $1,662.4$ & $1,652.1-1,670.0$ & 5.1 \\
& Day & $1,661.4$ & $1,662.4$ & $1,652.1-1,670.1$ & 5.1 \\
& Night & $1,661.4$ & $1,662.3$ & $1,652.1-1,670.0$ & 5.1 \\
Head over the weir gates (feet) & Overall & 4.4 & 4.9 & $1.1-10.2$ & 2.0 \\
& Day & 4.4 & 4.9 & $1.1-10.2$ & 2.1 \\
& Night & 4.4 & 4.9 & $1.1-9.2$ & 2.0 \\
Water temperature (degrees Celsius) & Overall & 13.0 & 12.8 & $8.2-18.1$ & 1.8 \\
& Day & 12.7 & 12.5 & $8.2-18.0$ & 1.7 \\
& Night & 13.4 & 13.3 & $8.2-18.1$ & 1.9 \\
\hline
\end{tabular}


During the fall, dam discharge generally was greater than during the spring, and reservoir elevation and water temperature decreased throughout most of the period. Total project discharge peaked in November $\left(2,590.0 \mathrm{ft}^{3} / \mathrm{s}\right)$ and remained greater than $2,400 \mathrm{ft}^{3} / \mathrm{s}$ until the end of the study period (fig. 6, table 2). The turbine(s) operated throughout the fall, except for $28 \mathrm{~h}$ during November 68, 2013 (fig. 7). Mean hourly turbine discharge was $750.7 \mathrm{ft}^{3} / \mathrm{s}$ (range $0.0-1,345.0 \mathrm{ft}^{3} / \mathrm{s}$ ), and mean hourly regulating outlet discharge was $204.7 \mathrm{ft}^{3} / \mathrm{s}$ (range $0.0-1,570.0 \mathrm{ft}^{3} / \mathrm{s}$ ) (table 2). Forebay elevation decreased from 1,607.5 to a low of 1,543.5 ft NGVD 29 in mid-November (table 2). The weir gates in the temperature control tower were out of the water after November 18, 2013, at 11:00 a.m. Water temperature in the top 13-19 ft of the water column near the WTC tower decreased from 14.6 to $6.9{ }^{\circ} \mathrm{C}$ (table 2). Dam operations during day and night periods generally were similar.

Table 2. Mean hourly summary statistics of dam operations and environmental conditions at Cougar Reservoir and Dam, Oregon, fall 2013.

[SD, standard deviation; $\mathrm{ft}^{3} / \mathrm{s}$ is cubic foot per second; NGVD 29, National Geodetic Vertical Datum of 1929]

\begin{tabular}{llrrrr}
\hline \multicolumn{1}{c}{ Dam operation } & Period & \multicolumn{1}{c}{ Mean } & \multicolumn{1}{c}{ Median } & \multicolumn{1}{c}{ Range } & SD \\
\hline Total project discharge $\left(\mathrm{ft}^{3} \mathrm{~s} /\right.$ ) & Overall & 955.4 & 550.0 & $350.0-2,590.0$ & 642.5 \\
& Day & 912.7 & 550.0 & $360.0-2,530.0$ & 607.8 \\
& Night & 989.5 & 560.0 & $350.0-2,590.0$ & 667.4 \\
Powerhouse (ft $\left.{ }^{3} / \mathrm{s}\right)$ & Overall & 750.7 & 550.0 & $0.0-1,345.0$ & 360.4 \\
& Day & 738.6 & 550.0 & $0.0-1,345.0$ & 364.5 \\
& Night & 760.4 & 550.0 & $0.0-1,270.0$ & 357.2 \\
Regulating outlet (ft $\left.{ }^{3} / \mathrm{s}\right)$ & Overall & 204.7 & 0.0 & $0.0-1,570.0$ & 458.0 \\
& Day & 174.2 & 0.0 & $0.0-1,380.0$ & 410.1 \\
Forebay elevation (feet, NGVD 29) & Night & 229.1 & 0.0 & $0.0-1,570.0$ & 491.9 \\
& Overall & $1,586.5$ & $1,585.1$ & $1,543.5-1,607.5$ & 16.2 \\
& Day & $1,587.3$ & $1,586.8$ & $1,545.2-1,607.5$ & 15.8 \\
Head over the weir arrays (feet) & Night & $1,586.0$ & $1,583.7$ & $1,543.5-1,607.5$ & 16.4 \\
& Overall & 28.8 & 30.2 & $12.0-46.0$ & 13.3 \\
& Day & 29.0 & 31.2 & $12.0-46.0$ & 13.2 \\
Water temperature (degrees Celsius) & Night & 28.6 & 30.0 & $12.0-46.0$ & 13.3 \\
& Overall & 10.1 & 9.8 & $6.9-14.6$ & 1.9 \\
& Day & 10.2 & 9.9 & $6.9-14.6$ & 1.9 \\
& Night & 10.0 & 9.4 & $7.0-14.5$ & 1.9 \\
\hline
\end{tabular}




\section{Fish Movements}

Spring

\section{Fish Directions}

Mean directions within each of the four fish-size categories indicated size-specific differences in fish directions near the WTC tower at Cougar Dam. In particular, the small fish (30-60 mm) had a mean direction that was opposite the direction of the larger fish (60-90 and 90-250 mm), and predators (>300 $\mathrm{mm}$; table 3). Rose plots and circular histograms of the mean directions support this conclusion (figs. 8 and 9).

The directions of fish in the acoustic beams also were dependent on photoperiod and the location of the camera just upstream of the WTC tower (figs. 8 and 9). The mean direction of small fish (30-60 $\mathrm{mm}$ ) observed by the DIDSON acoustic camera was toward the east of the WTC tower (during day and night), but these fish moved toward the WTC tower when in the area covered by the ARIS acoustic camera during the day, and toward the northeast during the night. Movements of medium fish (60-90 $\mathrm{mm}$ ) near the DIDSON acoustic camera were to the west of the WTC tower during the day, and toward the WTC tower during the night. Medium fish also were moving toward the WTC tower near the ARIS acoustic camera regardless of photoperiod. The large fish $(90-250 \mathrm{~mm})$ were highly variable in their movements with mean direction of fish toward the west side of the WTC tower during the day (regardless of the acoustic camera location), whereas at night, fish observed by both acoustic cameras moved away from the WTC tower. Predator-sized fish $(>300 \mathrm{~mm})$ were most consistent in their movement directions with the mean direction of movement toward the west side of the WTC tower when in the area covered by the DIDSON acoustic camera, and toward the northwest when observed with the ARIS acoustic camera. Additional rose plots and circular histograms of fish travel directions by depth and photoperiod are shown in appendix B.

Table 3. Mean directions (radians) and concentration parameters by fish-size category and acoustic-camera type (DIDSON ${ }^{\circledR}$ or ARIS $^{\circledR}$ ) at Cougar Reservoir and Dam, Oregon, spring 2013.

[ $n$, sample size; $\mu$, mean direction of the fish, $\kappa$, concentration parameter; SE, standard error; mm, millimeter; >, greater than]

\begin{tabular}{|c|c|c|c|}
\hline Fish-size category (type) & $n$ & $\mu$ (SE) & $\kappa(\mathrm{SE})$ \\
\hline \multicolumn{4}{|c|}{ DIDSON } \\
\hline 30-60 mm (small fish) & 336 & $0.641(0.161)$ & $0.486(0.081)$ \\
\hline 60-90 mm (medium fish) & 712 & $-2.490(0.161)$ & $0.331(0.054)$ \\
\hline 90-250 mm (large fish) & 3,464 & $-2.390(0.069)$ & $0.351(0.025)$ \\
\hline >300 mm (predators) & 1,095 & $-2.390(0.067)$ & $0.649(0.046)$ \\
\hline \multicolumn{4}{|c|}{ ARIS } \\
\hline 30-60 mm (small fish) & 507 & $-0.145(0.157)$ & $0.405(0.065)$ \\
\hline 60-90 mm (medium fish) & 570 & $-0.320(0.136)$ & $0.443(0.061)$ \\
\hline 90-250 mm (large fish) & 1,008 & $-2.183(0.729)$ & $0.061(0.045)$ \\
\hline >300 mm (predators) & 50 & $-1.007(0.469)$ & $0.436(0.207)$ \\
\hline
\end{tabular}


Fish Size $30-60 \mathrm{~mm}$ DIDSON

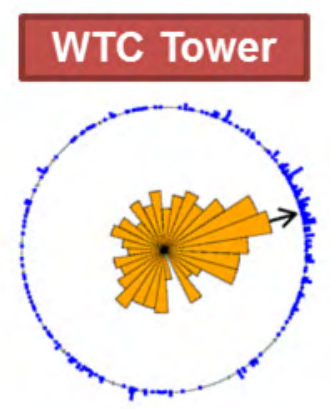

\section{WTC Tower}

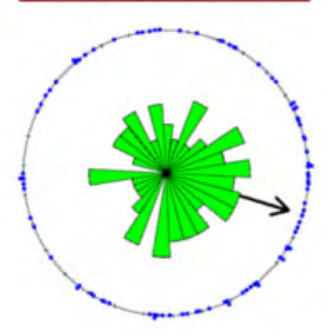

\section{WTC Tower}

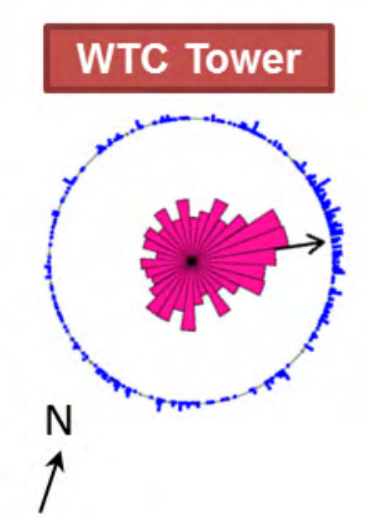

ARIS

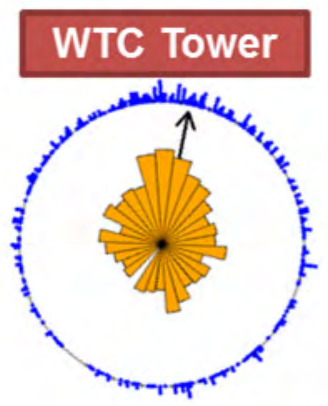

Fish Size $60-90 \mathrm{~mm}$ DIDSON
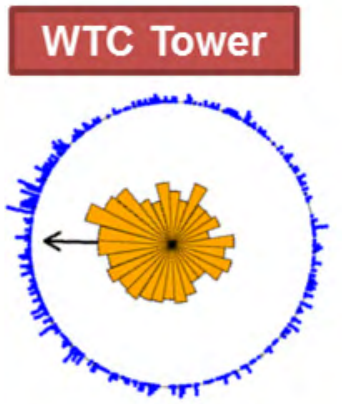

Day
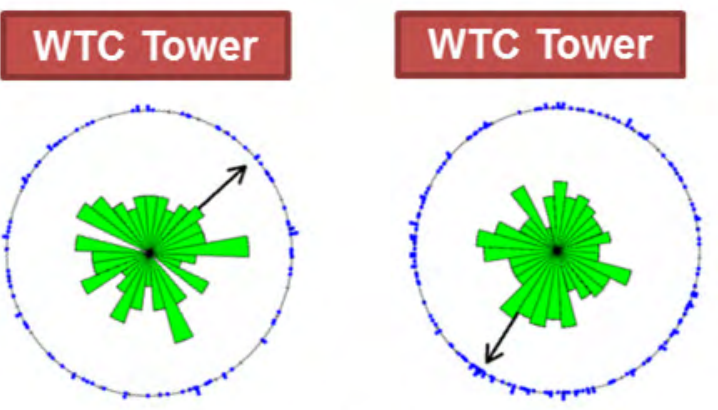

\section{WTC Tower}

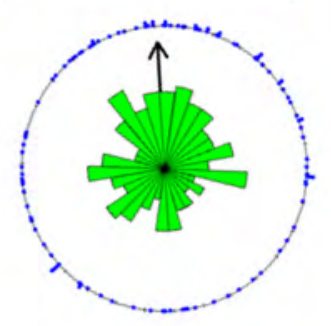

\section{Night}
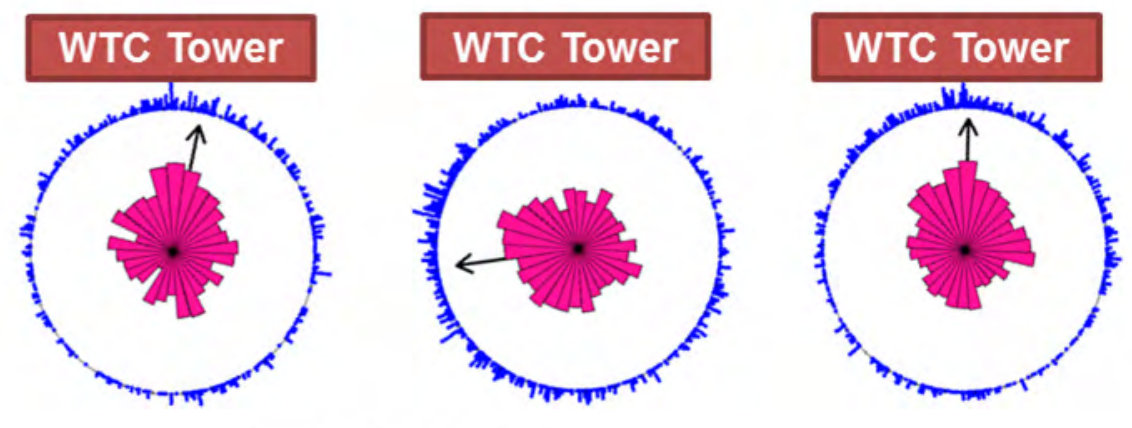

Figure 8. Rose plots and circular histograms of mean directions (degrees) of 30-60 and 60-90 millimeter ( $\mathrm{mm}$ ) fish-size categories by acoustic-camera type (DIDSON ${ }^{\circledR}$ or ARIS ${ }^{\circledR}$ ) and photoperiod (day, night, or combined) at Cougar Reservoir and Dam, Oregon, spring 2013. 
Fish Size $90-250 \mathrm{~mm}$ DIDSON

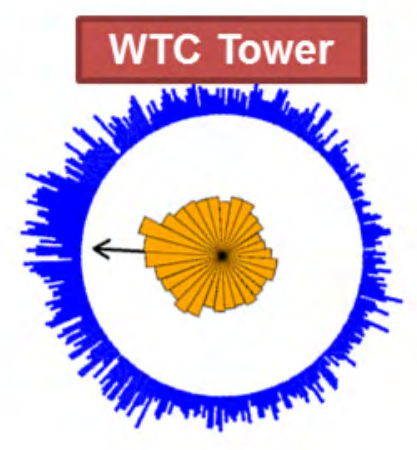

\section{WTC Tower}
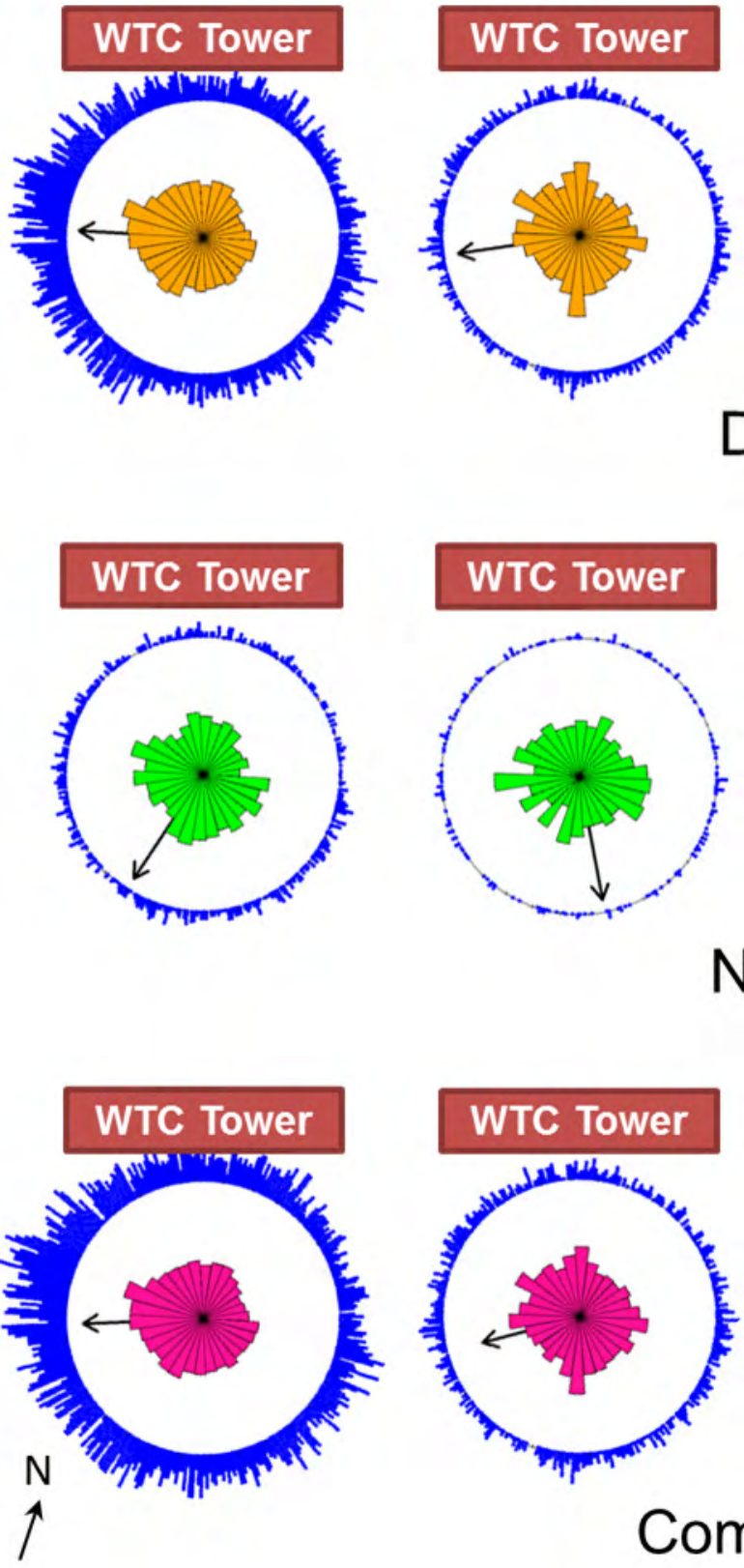

Fish Size $>300 \mathrm{~mm}$

DIDSON
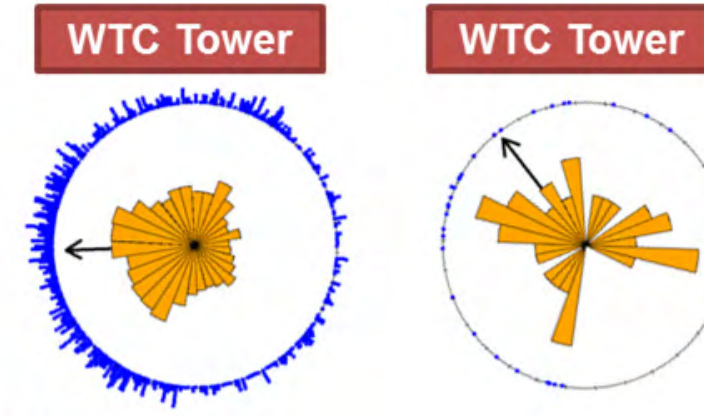

Day

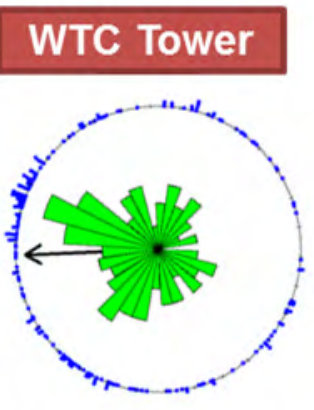

\section{WTC Tower}

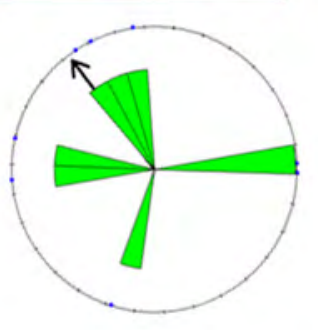

Night
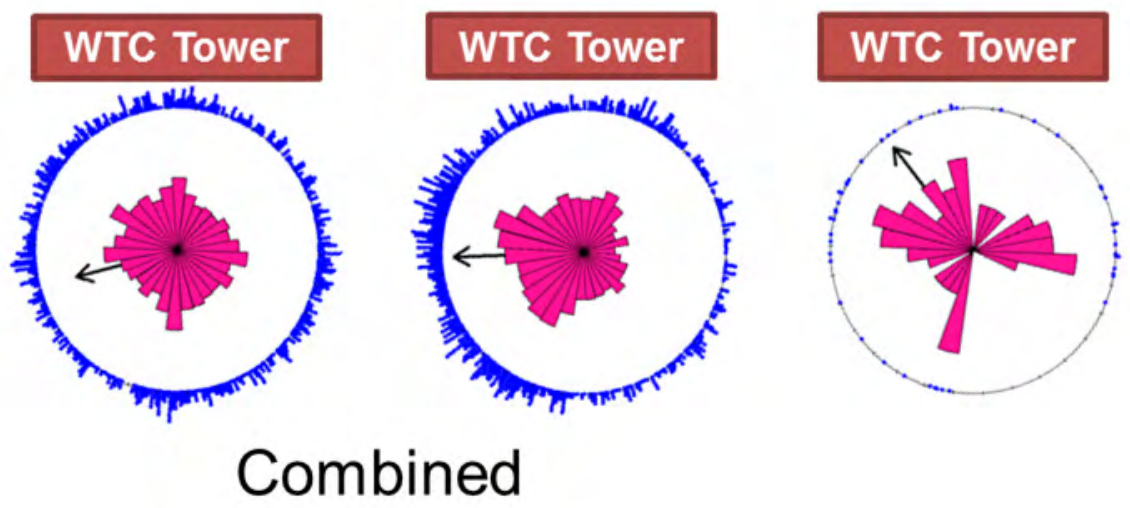

Figure 9. Rose plots and circular histograms of mean directions (degrees) of 90-250 and $>300$ millimeter ( $\mathrm{mm}$ ) fish-size categories by acoustic-camera type (DIDSON ${ }^{\circledR}$ or ARIS ${ }^{\circledR}$ ) and photoperiod (day, night, or combined) at Cougar Reservoir and Dam, Oregon, spring 2013. 
Overall, our full model of the fish directions within the DIDSON acoustic beam provided little ability to predict fish directions near the WTC tower. As a consequence of having 4,512 observations, statistical (although not necessarily biological) significance was virtually ensured for all factors included in the full model (table 4, fig. 10). Based on the differences in AIC values for single-predictor candidate model subsets, diel period had the most influence (AIC=-211.83) on fish directions, followed by fish size (AIC=-198.39), and then discharge (AIC=-195.99) and temperature (AIC=-189.99). Although our modeling of fish directions provided little standing for predicting fish responses near the WTC tower, our findings support the premise that diel period, fish size, and dam operations help to determine fish direction upstream of the WTC tower.

The full model of fish directions within the ARIS acoustic beam also had little predictive ability. Similar to our findings with fish directions with the DIDSON acoustic camera, we had a total of 2,085 observations, and so we were able to determine statistical significance for all modeled effects on fish directions in the area covered by the ARIS acoustic camera (table 4, fig. 11). Based on the differences in AIC values for the single-predictor models, fish size had the most influence (AIC=-49.05) on fish directions, followed by temperature (AIC=-45.50), and then discharge (AIC=-42.09) and diel period (AIC=-41.99). This again suggests that environmental conditions and dam operations have a modest influence on fish directions upstream of the WTC tower at Cougar Reservoir.

Table 4. Results for circular-linear models of mean directions (radians) of fish in the acoustic beams of the DIDSON ${ }^{\circledR}$ and ARIS $^{\circledR}$ acoustic cameras upstream of the water temperature control (WTC) tower at Cougar Reservoir and Dam, Oregon, spring 2013.

[AIC values denote estimates for each single-predictor model. The factor in brackets is factor level being measured against the reference category. SE, standard error; AIC, Akaike Information Criterion; $\mu$, mean direction of the fish; $\kappa$, concentration parameter; $n$, ]sample size; NA, not applicable

\begin{tabular}{|c|c|c|c|c|c|}
\hline Model effect & Estimate & SE & $t$-value & $p$-value & AIC \\
\hline \multicolumn{6}{|c|}{ DIDSON (log-likelihood = 145.40, $n=4,512$ ) } \\
\hline$\mu$ & 1.202 & 0.058 & NA & NA & NA \\
\hline$\kappa$ & 0.365 & 0.022 & NA & NA & NA \\
\hline Diel period[LIGHT] & 3.629 & 0.646 & 5.620 & $<0.0001$ & -211.83 \\
\hline Discharge & 3.842 & 1.135 & 3.385 & 0.0004 & -195.99 \\
\hline Temperature & 0.174 & 0.051 & 3.413 & 0.0003 & -189.99 \\
\hline Fish size & 0.263 & 0.127 & 2.069 & 0.0193 & -198.39 \\
\hline \multicolumn{6}{|c|}{ ARIS (log-likelihood $=37.02, n=2,085)$} \\
\hline$\mu$ & 3.773 & 0.116 & NA & NA & NA \\
\hline$\kappa$ & 0.269 & 0.031 & NA & NA & NA \\
\hline Diel period[LIGHT] & 2.817 & 0.596 & 4.725 & $<0.0001$ & -41.99 \\
\hline Discharge & 1.466 & 0.341 & 4.296 & $<0.0001$ & -42.09 \\
\hline Temperature & 0.168 & 0.046 & 3.624 & 0.0001 & -45.50 \\
\hline Fish size & -1.008 & 0.285 & 3.543 & 0.0002 & -49.05 \\
\hline
\end{tabular}



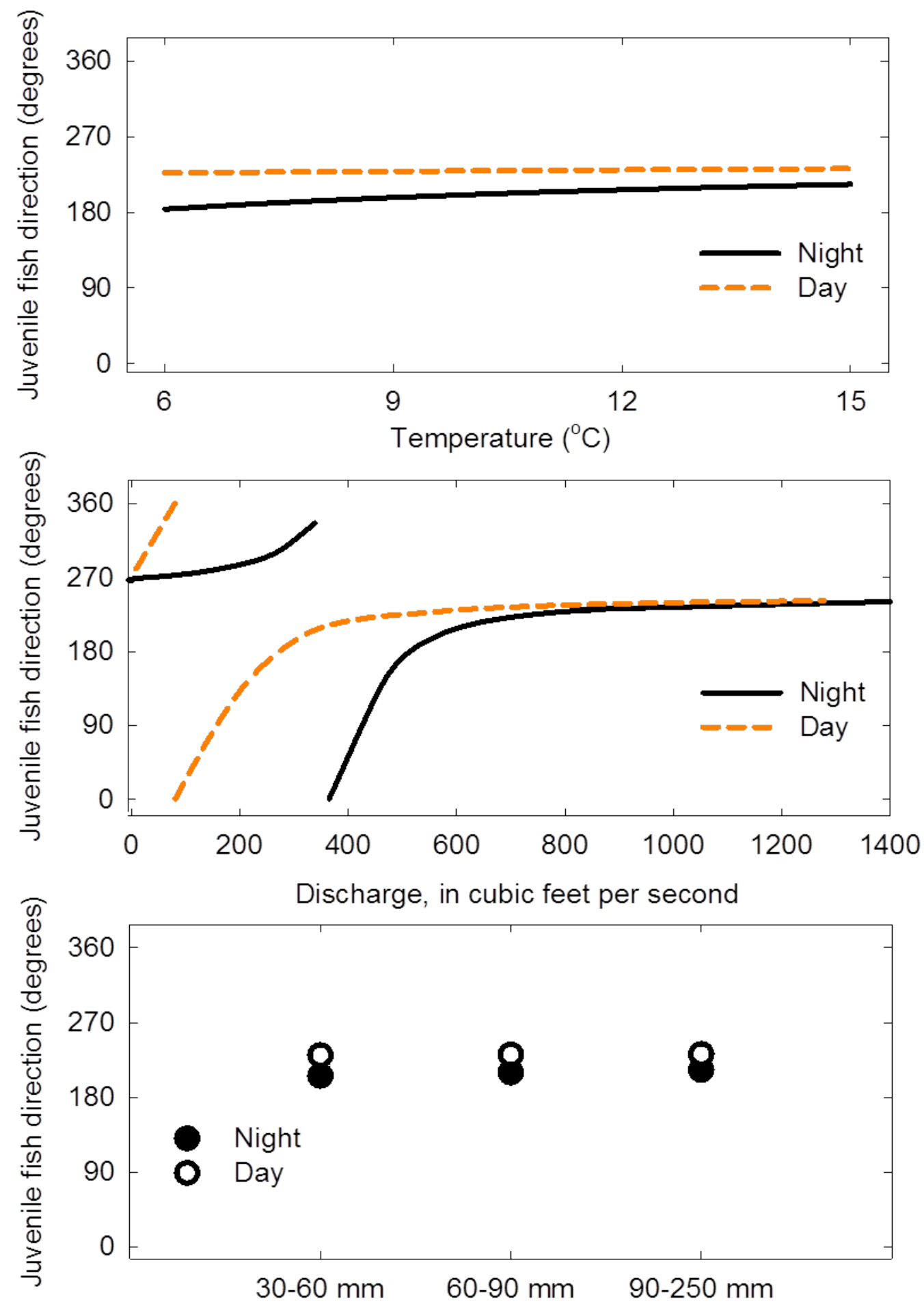

Fish size

Figure 10. Effects plots for the full circular-linear model of mean directions of fish (in degrees) within the beam of the DIDSON ${ }^{\circledR}$ acoustic camera upstream of the water temperature control (WTC) tower at Cougar Reservoir and Dam, Oregon, spring 2013. 

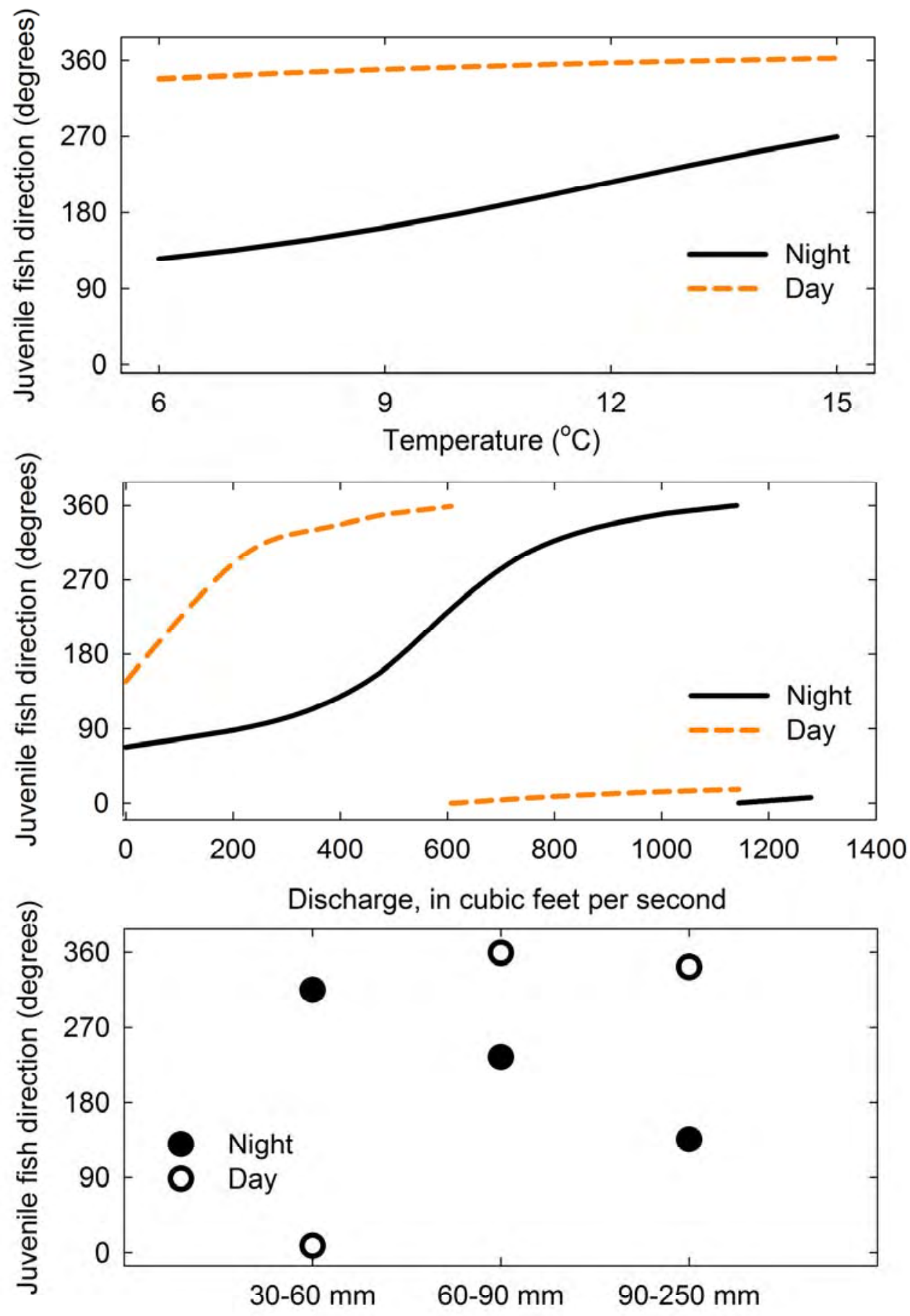

Fish size

Figure 11. Effects plots for the full circular-linear model of mean directions of fish (in degrees) within the beam of the ARIS ${ }^{\circledR}$ acoustic camera upstream of the water temperature control (WTC) tower at Cougar Reservoir and Dam, Oregon, spring 2013. 


\section{Fish Depth}

The mean hourly depth of fish during the spring differed among camera type and fish-size categories (fig. 12). In general, smaller fish targets were observed nearer to the surface than larger fish targets. As fish size increased, the hourly mean depth of the fish also increased. During daylight, fish tended to remain closer to the surface than during night. Irrespective of daytime; however, the larger predator-sized fish (>300 mm) generally were about 1-2 m deeper than the smaller sized fish.

For fish observed with the DIDSON acoustic camera, mean depth of fish increased with larger fish (table 5). An exception to this was the 90-250 mm size class, where mean depths were $8 \mathrm{~mm}$ shallower than the 60-90 mm size class, recognizing that this small difference was unlikely to be biologically significant. For fish observed with the ARIS acoustic camera, mean depth of fish increased with each successive fish-size class. Predators were at depths greater than the smaller fish, irrespective of the different acoustic cameras and locations. Additionally, for fish observed with both acoustic cameras, mean depth of fish during spring (3.4 m) increased with increasing camera angle (fig. 13).

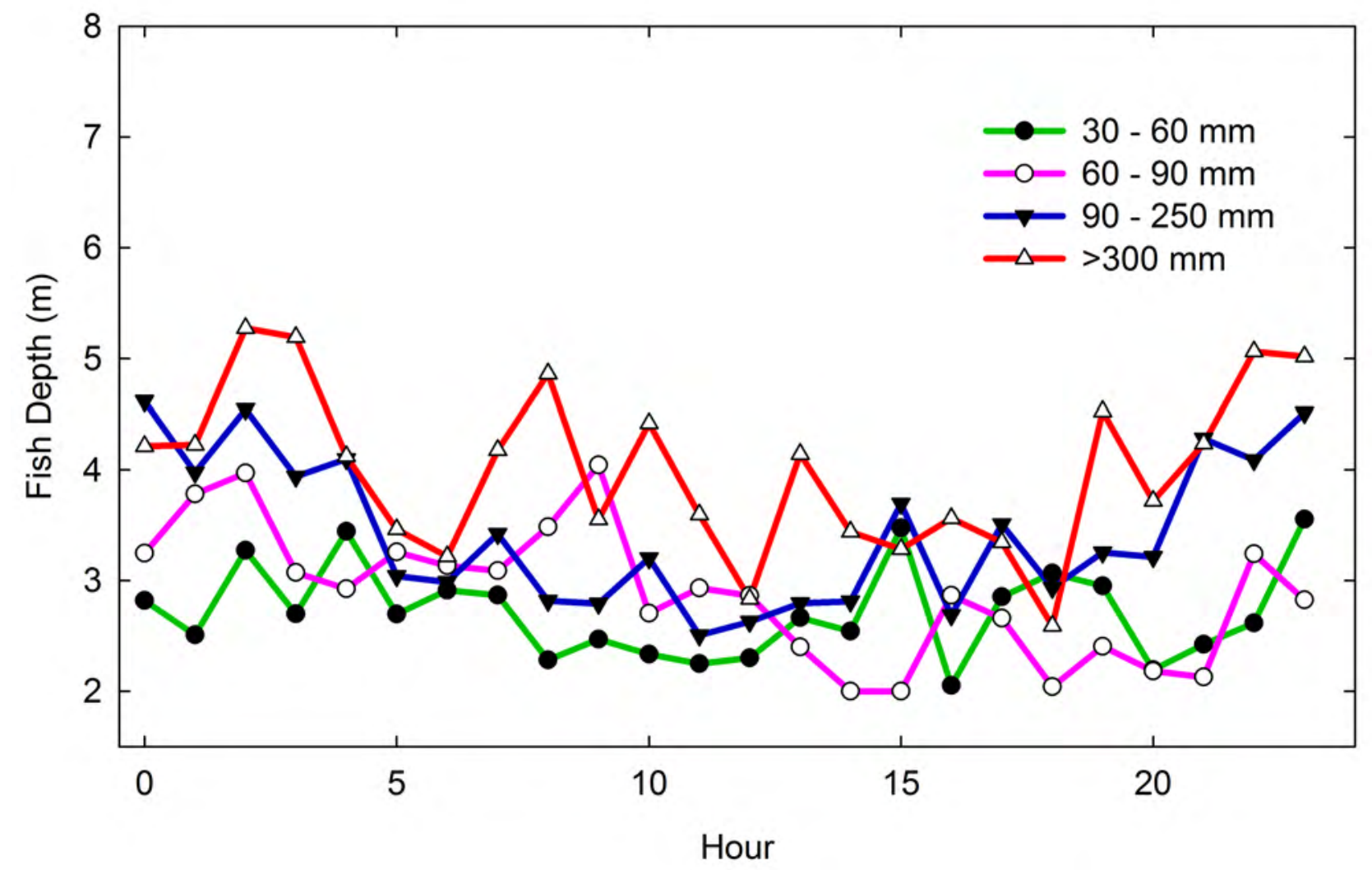

Figure 12. Graph showing hourly mean depth of fish (in meters [m]), by size category (in millimeters [mm]), in the area covered by DIDSON ${ }^{\circledR}$ and ARIS $^{\circledR}$ acoustic cameras, which were upstream of the water temperature control (WTC) tower at Cougar Reservoir and Dam, Oregon, spring 2013. 
Table 5. Sample size, and mean, standard deviation, minimum, and maximum depths of each fish-size category observed with the DIDSON ${ }^{\circledR}$ and ARIS ${ }^{\circledR}$ acoustic cameras upstream of the water temperature control (WTC) tower at Cougar Reservoir and Dam, spring 2013.

[n, sample size; SD, standard deviation; mm, millimeter; >, greater than]

\begin{tabular}{|c|c|c|c|c|c|}
\hline \multirow[b]{2}{*}{ Fish-size category (type) } & \multirow[b]{2}{*}{$n$} & \multicolumn{4}{|c|}{ Depth (meters) } \\
\hline & & Mean & SD & Minimum & Maximum \\
\hline \multicolumn{6}{|c|}{ DIDSON } \\
\hline 30-60 mm (small fish) & 408 & 3.05 & 0.96 & 2 & 6.87 \\
\hline 60-90 mm (medium fish) & 809 & 3.34 & 1.18 & 2 & 8.39 \\
\hline 90-250 mm (large fish) & 3,866 & 3.26 & 1.49 & 2 & 9.39 \\
\hline >300 mm (predators) & 1,154 & 3.88 & 1.71 & 2 & 9.41 \\
\hline \multicolumn{6}{|c|}{ ARIS } \\
\hline 30-60 mm (small fish) & 518 & 2.37 & 0.68 & 2 & 6.17 \\
\hline 60-90 mm (medium fish) & 525 & 2.65 & 0.93 & 2 & 6.76 \\
\hline 90-250 mm (large fish) & 882 & 2.83 & 0.94 & 2 & 5.95 \\
\hline >300 mm (predators) & 43 & 2.94 & 0.77 & 2 & 4.22 \\
\hline
\end{tabular}

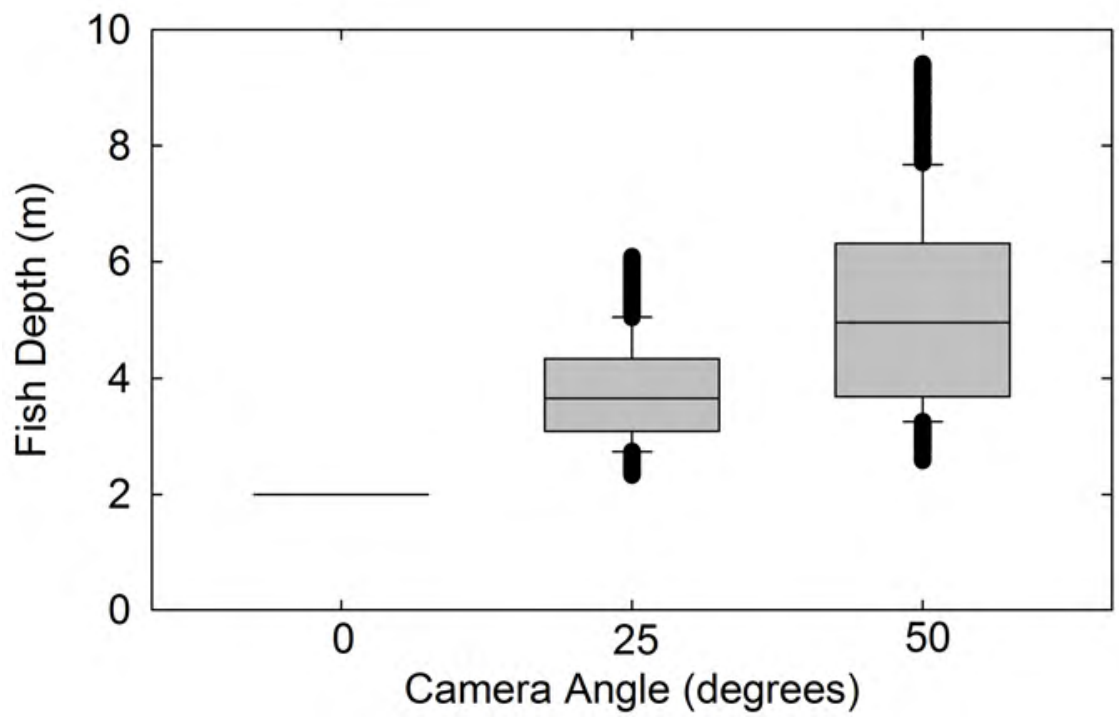

Figure 13. Box and whisker plots of the depth of fish (in meters [m]) observed under different camera angles using DIDSON ${ }^{\circledR}$ and ARIS ${ }^{\circledR}$ acoustic cameras at Cougar Reservoir and Dam, Oregon, spring 2013. The upper and lower boundaries of the box represent the 25th and 75th quartiles, the line inside the box is the mean, the whiskers represent the 5 - and 95 -percent confidence intervals, and outliers are shown by solid points. 
Fish Speed and Duration of Observation

Irrespective of fish size and the acoustic camera used to collect the data, fish traveled at similar speeds (table 6, fig. 14). For example, the mean travel speed of fish passing through the DIDSON acoustic beam was $0.101 \mathrm{~m} / \mathrm{s}$ (interquartile range $=0.080 \mathrm{~m} / \mathrm{s}$ ), and the mean travel speed of fish passing through the ARIS acoustic beam was $0.062 \mathrm{~m} / \mathrm{s}$ (interquartile range $=0.055 \mathrm{~m} / \mathrm{s}$ ). The duration of time that fish were observed in the acoustic beam also varied by camera type. Fish were observed in the DIDSON acoustic beam for a median of $2.630 \mathrm{~s}$ (mean $9.795 \mathrm{~s} ; \mathrm{IQR}=3.510 \mathrm{~s}$ ), but in the ARIS acoustic beam for a median of $3.498 \mathrm{~s}$ (mean $=17.634 \mathrm{~s}$; IQR $=6.988 \mathrm{~s}$ ). Thus, in comparison to the DIDSON acoustic camera, the distribution of travel times was more skewed toward longer travel times and slower swimming fish in the area covered by the ARIS acoustic camera.

Table 6. Summary statistics for the travel speeds and duration of fish observed with the DIDSON ${ }^{\circledR}$ and ARIS $^{\circledR}$ acoustic cameras at the water temperature control (WTC) tower at Cougar Reservoir and Dam, Oregon, spring 2013.

[n, sample size; SD, standard deviation; IQR, interquartile range]

\begin{tabular}{lccccccccc}
\hline Camera & $\boldsymbol{n}$ & Mean & SD & IQR & Minimum & $\begin{array}{c}\mathbf{2 . 5} \\
\text { percent }\end{array}$ & $\begin{array}{c}\mathbf{5 0} \\
\text { percent }\end{array}$ & $\begin{array}{c}\text { 97.5 } \\
\text { percent }\end{array}$ & Maximum \\
\hline \multicolumn{8}{c}{ Travel speed (meter per second) } \\
\hline DIDSON & 4,512 & 0.101 & 0.063 & 0.080 & 0.001 & 0.014 & 0.088 & 0.250 & 0.456 \\
ARIS & 2,085 & 0.062 & 0.053 & 0.055 & 0.001 & 0.005 & 0.048 & 0.194 & 0.500 \\
\hline \multicolumn{8}{c}{ Time in acoustic beam (second) } \\
\hline DIDSON & 4,512 & 9.795 & 49.330 & 3.510 & 0.500 & 0.660 & 2.630 & 53.340 & 900.000 \\
ARIS & 2,085 & 17.634 & 62.733 & 6.988 & 0.526 & 0.771 & 3.498 & 145.986 & 875.873 \\
\hline
\end{tabular}



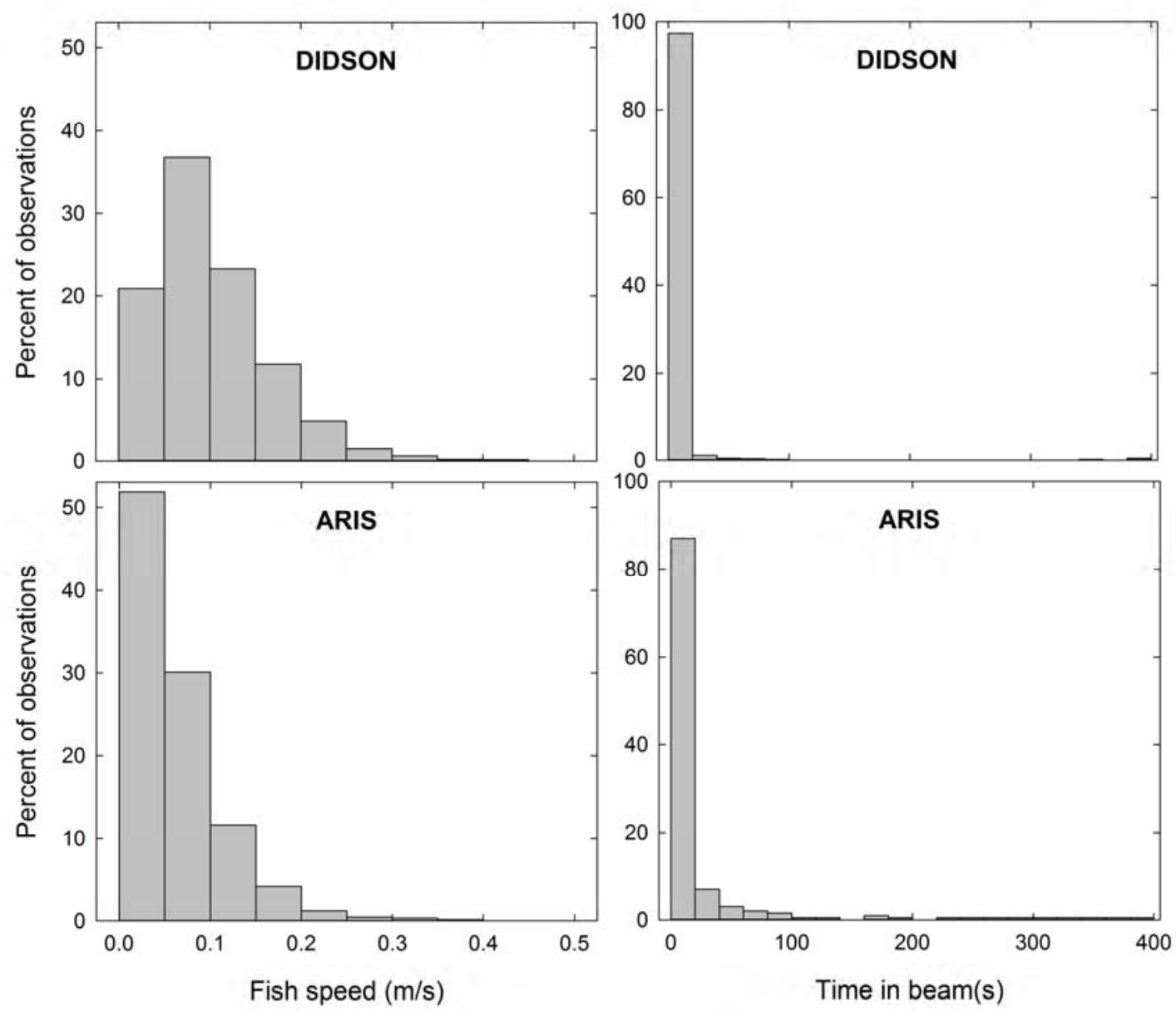

Figure 14. Graphs showing distributions of fish travel speeds (in meters per second [m/s]) and the amount of time fish spent within the acoustic beams (in seconds [s]) of the DIDSON ${ }^{\circledR}$ and ARIS ${ }^{\circledR}$ acoustic cameras at Cougar Reservoir and Dam, Oregon, spring 2013.

Application of linear models to estimate the travel speeds of fish in the acoustic beams indicated a poor ability to predict fish movements. All models had residuals that were evenly distributed over the predicted range, but they only explained less than 5 percent of the variation. Regardless of this poor model fit, however, modeling indicated camera- and location-specific differences in travel speeds near the WTC tower (table 7). In particular, modeling confirmed that travel speeds were faster in the area of the DIDSON acoustic camera, and that the response to discharge was more acute compared to travel speeds measured in the area of the ARIS acoustic camera. This finding was especially apparent for the larger fish (table 7, fig. 15). Based on the AIC values for the single-predictor models, the most important predictors of the travel speeds of fish in the area of the DIDSON acoustic camera in spring were, in descending importance, (1) fish size (AIC = -8,310, (2) discharge (AIC = -8,295, (3) diel period $(\mathrm{AIC}=-8,149)$, and $(4)$ temperature (AIC $=-8,127)$. In the area of the ARIS acoustic camera, the order of single-predictor importance to fish travel speed was ranked slightly different with (1) size (AIC = 3,921, (2) diel period (AIC = -3,892), (3) discharge (AIC = -3,868), and (4) temperature (AIC = -3,859). 
Table 7. Results for multiple regression models of mean travel speeds $(\sqrt{\mathrm{m} / \mathrm{s}})$ of fish while in the acoustic beams of the DIDSON ${ }^{\circledR}$ and ARIS ${ }^{\circledR}$ acoustic cameras upstream of the water temperature control (WTC) tower at Cougar Reservoir and Dam, Oregon, spring 2013.

[SE, standard error; AIC, Akaike Information Criterion; $R^{2}$, coefficient of determination; $n$, sample size; mm, millimeter; <, less than]

\begin{tabular}{lccccl}
\hline \multicolumn{1}{c}{ Model effect } & Estimate & SE & $t$-value & $p$-value & Single-predictor AIC \\
\hline Intercept & \multicolumn{2}{c}{ DIDSON $\left(R^{2}=0.062, n=4,512\right.$, AIC=-8362) } & \\
Diel period (day) & 0.223 & 0.016 & 13.870 & $<0.0001$ & (intercept only) $-8,149$ \\
Fish size (60-90 mm) & -0.0001 & 0.004 & -0.025 & 0.9798 & $-8,149$ \\
Fish size (90-250 mm) & 0.024 & 0.006 & 3.771 & 0.0002 & $-8,310$ \\
Discharge & 0.053 & 0.006 & 9.575 & $<0.0001$ & $-8,310$ \\
Temperature & 0.018 & 0.002 & 10.191 & $<0.0001$ & $-8,295$ \\
& 0.003 & 0.001 & 2.588 & 0.0097 & $-8,127$ \\
\hline Intercept & ARIS $\left(R^{2}=0.044, n=2,085\right.$, AlC=-3952) & \\
Diel period (day) & 0.168 & 0.028 & 6.086 & $<0.0001$ & (intercept only) $-3,870$ \\
Fish size (60-90 mm) & -0.026 & 0.005 & -4.961 & $<0.0001$ & $-3,892$ \\
Fish size (90-250 mm) & 0.011 & 0.006 & 1.836 & 0.0665 & $-3,921$ \\
Discharge & 0.044 & 0.006 & 7.786 & $<0.0001$ & $-3,921$ \\
Temperature & -0.005 & 0.002 & -2.300 & 0.0216 & $-3,868$ \\
\hline
\end{tabular}



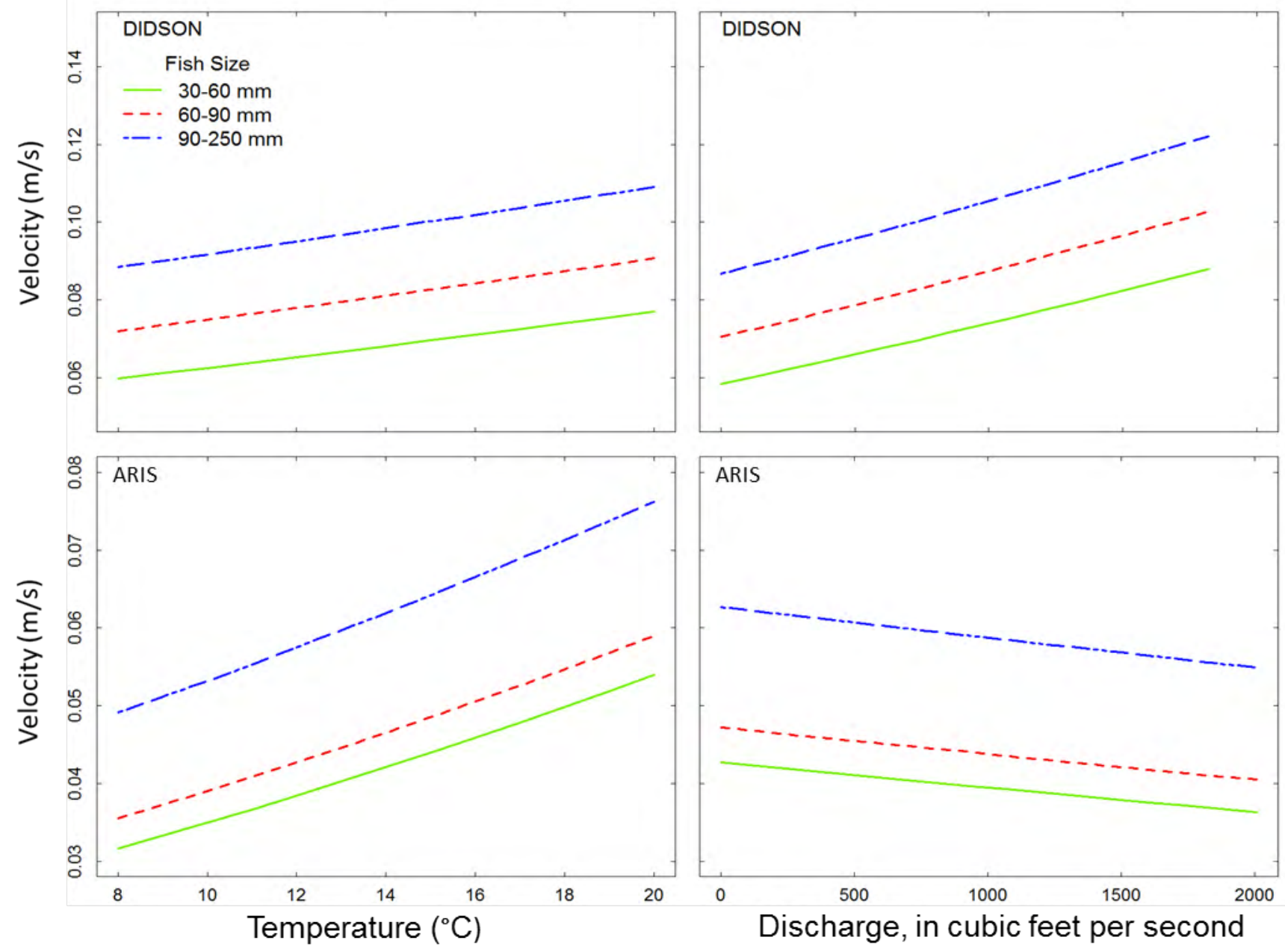

Figure 15. Plots for multiple regression model estimates of mean travel speed of fish (in meters per second $[\mathrm{m} / \mathrm{s}]$ ), by size category (in millimeters [mm]), within the beams of the DIDSON ${ }^{\circledR}$ and ARIS ${ }^{\circledR}$ acoustic cameras upstream of the water temperature control (WTC) tower at Cougar Reservoir and Dam, Oregon, spring 2013.

\section{Quantifying Movement Toward the Water Temperature Control Tower}

Use of Poisson rate regressions to quantify the numbers of fish moving toward the WTC tower given the total number of fish in the acoustic beam (per 3-s interval) provided some insight into how factors may influence fish movement toward the WTC tower. However, it should be cautioned that the global model has some structural problems. For example, the Q-Q plots were jagged and suggested departure from the theoretical quantiles at the upper tail of the distribution. Additionally, calculation of Nagelkerke's (1991) coefficient of determination $\left(R^{2}\right)$ indicated that less than 5 percent of the deviance was explained, regardless of the camera type used to collect the data, corroborating poor model predictive ability (table 8). The most important factor determining the number of fish moving toward the tower was the total number of fish in the acoustic beam per unit time $\left(N_{\text {beam }, t} ;\right.$ table 8 , fig. 16$)$. Using the $\log$ of $N_{\text {beam, },}$ as the rate variable for the number of fish moving toward the tower yielded a slope $=$ 0.9866 (SE=0.0392) for the DIDSON acoustic camera, and a slope=1.054 ( $\mathrm{SE}=0.0621$ ) for the ARIS 
acoustic camera, supporting the assumption of 1:1 relation between the total number of fish in the acoustic beam and those moving toward the WTC tower; therefore, we offset this parameter from the Poisson rate regression models (table 9).

Perhaps the most significant finding from this analysis was the effect of predators on fish moving toward the WTC tower at the different locations. For example, in the area covered by the DIDSON acoustic camera, the number of predators was important to the model, but in the area covered by the ARIS acoustic camera, the number of predators had little influence on the numbers of fish moving toward the WTC tower (table 8). In the area covered by the DIDSON acoustic camera, there also was evidence for an interaction between predators and photoperiod, and predators and discharge, supporting the conclusion that predation risk, time of day, and discharge interact to influence the number of fish moving toward the WTC tower (fig. 17); however, the importance of predators and their effect on fish movements seems to be site-specific.

Table 8. Results for Poisson rate regression models of fish moving toward the water temperature control (WTC) tower while in the acoustic beams of the DIDSON ${ }^{\circledR}$ and ARIS ${ }^{\circledR}$ acoustic cameras at Cougar Reservoir and Dam, Oregon, spring 2013.

[SE, standard error; <, less than; $R^{2}$, coefficient of determination; $n$, sample size]

\begin{tabular}{lcccc}
\hline \multicolumn{1}{c}{ Model effect } & Estimate & SE & z-value & $p$-value \\
\hline DIDSON (Nagelkerke's $\left.R^{2}=0.011, n=9,371\right)$ & & \\
\hline Intercept & -2.0021 & 0.2547 & -7.859 & 0.000 \\
$\log \left(N_{\text {beam } t}\right)$ & 0.9866 & 0.0392 & 25.160 & $<0.00001$ \\
Predators & -0.2952 & 0.1572 & -1.878 & 0.060 \\
Discharge & -0.0002 & 0.0001 & -2.025 & 0.043 \\
Temperature & 0.0100 & 0.0154 & 0.652 & 0.514 \\
Photoperiod[LIGHT] & -0.1267 & 0.0471 & -2.689 & 0.007 \\
Photoperiod[LIGHT]*Predators & 0.3362 & 0.1416 & 2.375 & 0.018 \\
Discharge*Predators & 0.0002 & 0.0001 & 1.929 & 0.054 \\
\hline & ARIS (Nagelkerke's $\left.R^{2}=0.050, n=8,140\right)$ & & \\
\hline Intercept & -3.232 & 0.3270 & -9.883 & $<0.00001$ \\
log( $N_{\text {beam } t}$ ) & 1.054 & 0.0621 & 16.967 & $<0.00001$ \\
Predators & 0.424 & 0.8916 & 0.476 & 0.634 \\
Discharge & -0.001 & 0.0001 & -7.284 & $<0.00001$ \\
Temperature & 0.092 & 0.0215 & 4.281 & $<0.00001$ \\
Photoperiod[LIGHT] & 0.611 & 0.0621 & 9.831 & $<0.00001$ \\
Photoperiod[LIGHT]*Predators & 0.435 & 0.8267 & 0.526 & 0.599 \\
Discharge*Predators & -0.001 & 0.0008 & -1.487 & 0.137 \\
\hline
\end{tabular}


Table 9. Results for reduced Poisson rate regression models of fish moving toward the water temperature control (WTC) tower while in the acoustic beam of the DIDSON ${ }^{\circledR}$ and ARIS $^{\circledR}$ cameras at Cougar Reservoir and Dam, Oregon, spring 2013.

[The model effect in brackets is the factor level being measured against the reference category. SE, standard error; $n$, sample size; <, less than]

\begin{tabular}{lcccc}
\hline \multicolumn{1}{c}{ Model effect } & Estimate & SE & z-value & $p$-value \\
\hline Intercept & \multicolumn{3}{c}{ DIDSON $(n=9,371)$} & \\
Predators & -1.8110 & 0.0589 & -30.7390 & $<0.00001$ \\
Discharge & -0.2838 & 0.1496 & -1.8980 & 0.058 \\
Photoperiod[LIGHT] & -0.0003 & 0.0001 & -3.9900 & 0.0001 \\
Photoperiod[LIGHT]*Predators & -0.1412 & 0.0452 & -3.1220 & 0.002 \\
Discharge*Predators & 0.3150 & 0.1322 & 2.3820 & 0.017 \\
& 0.0002 & 0.0001 & 2.1290 & 0.033 \\
\hline Intercept & & ARIS $(n=8,140)$ & \\
Discharge & -3.2410 & 0.3260 & -9.936 & $<0.00001$ \\
Temperature & -0.0007 & 0.0001 & -7.433 & $<0.00001$ \\
Photoperiod[LIGHT] & 0.0957 & 0.0214 & 4.482 & $<0.00001$ \\
\hline
\end{tabular}
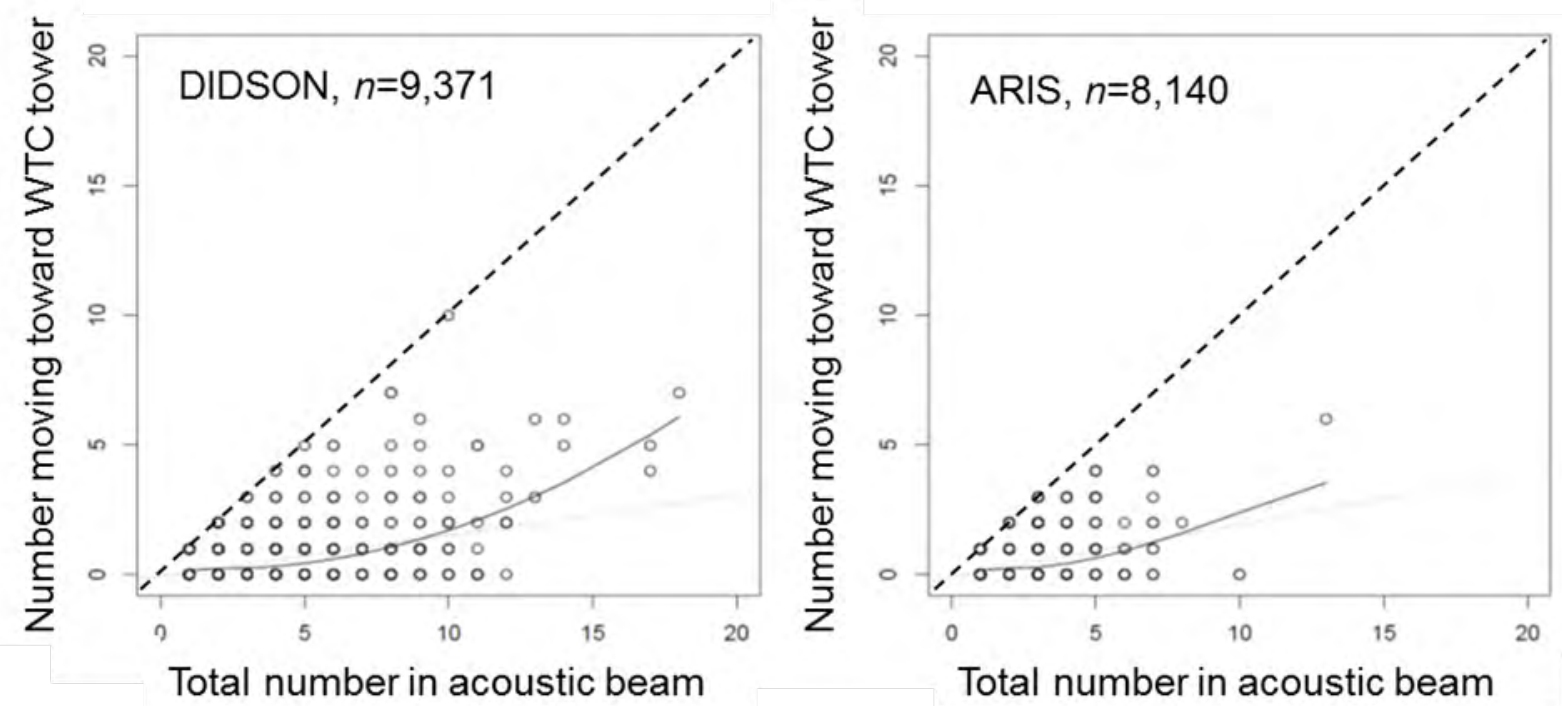

Figure 16. Scatter plots showing number $(n)$ of fish moving toward the water temperature control (WTC) tower (per 3-second interval) and total number of fish observed in the acoustic beam (per 3-second interval) of the DIDSON ${ }^{\circledR}$ and ARIS ${ }^{\circledR}$ acoustic cameras at Cougar Reservoir and Dam, Oregon, spring 2013. Solid fitted lines represent the average trend using a loess smoothing function, dotted lines represent average trend using a linear model, and the dashed lines represent 1:1 lines of equality. 


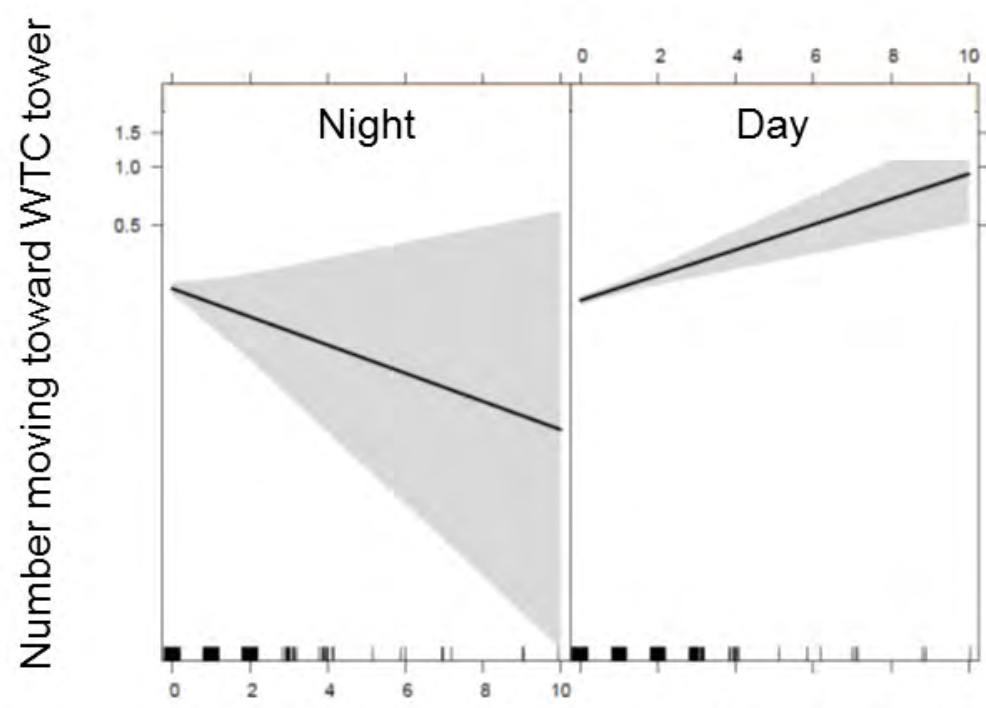

Number of predators in acoustic beam

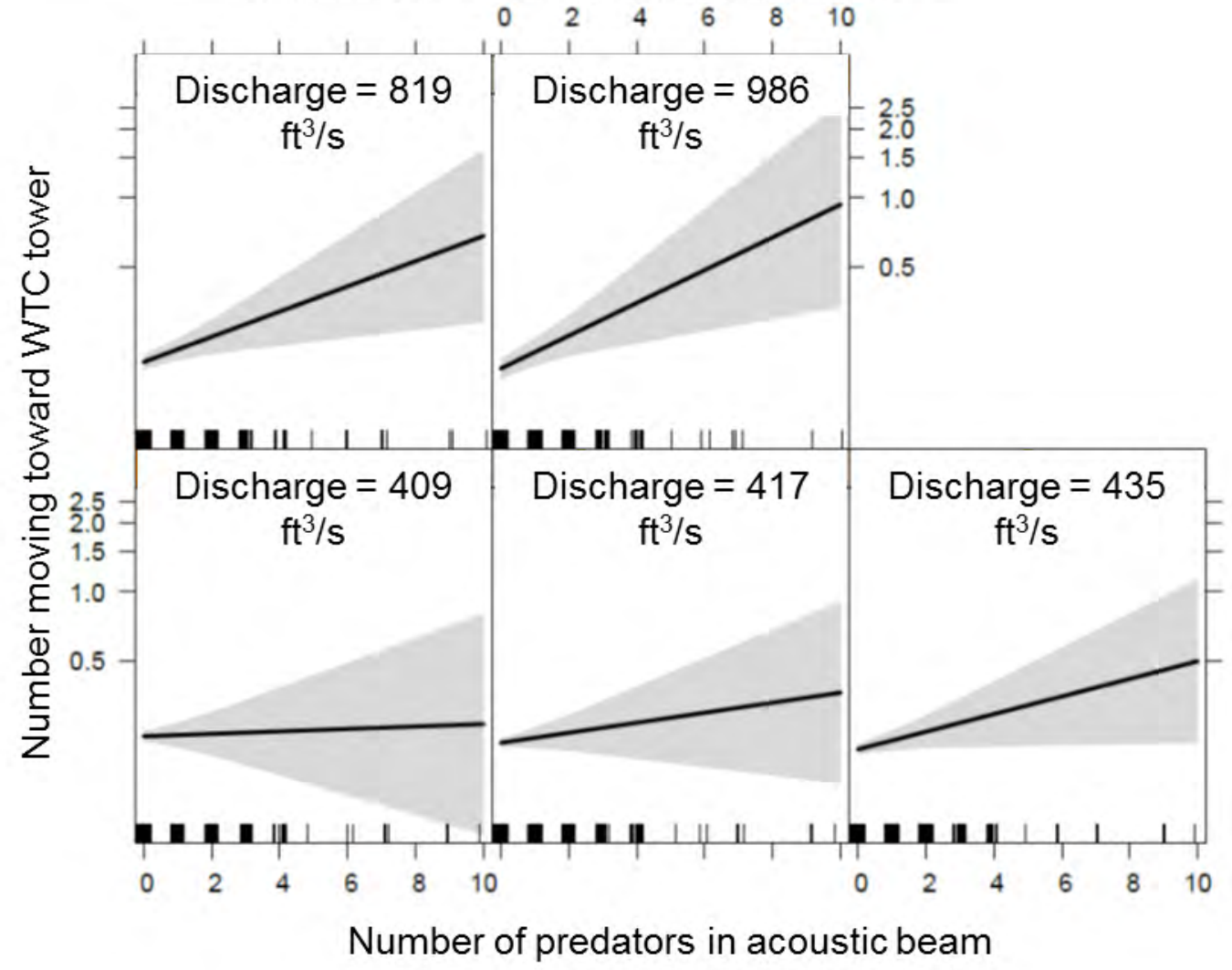

Figure 17. Effects plots for the reduced Poisson rate regression modeling the numbers of fish traveling toward the water temperature control (WTC) tower while in the beam of the DIDSON ${ }^{\circledR}$ acoustic camera at Cougar Reservoir and Dam, Oregon, spring 2013. 

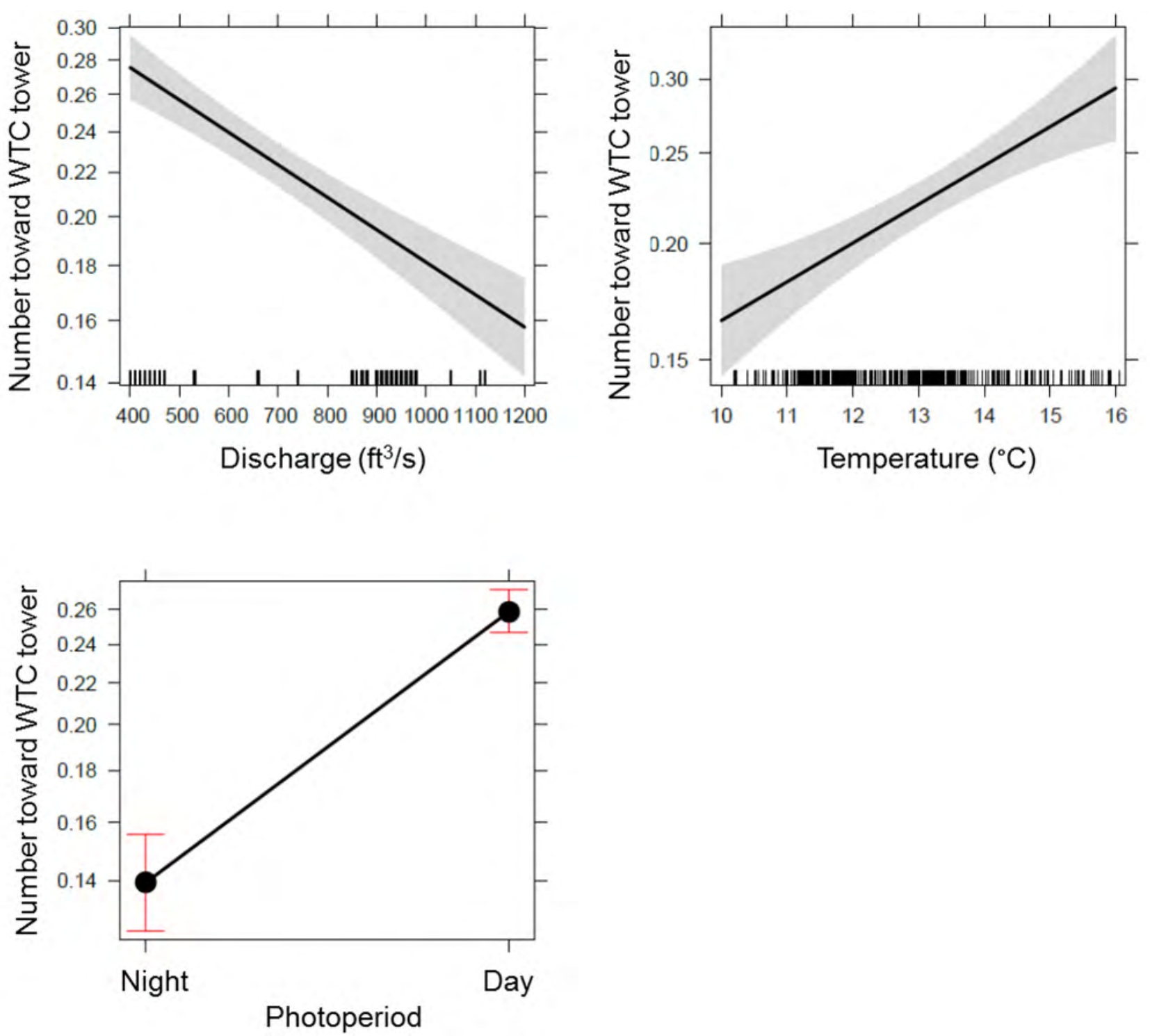

Figure 18. Effects plots for the reduced Poisson rate regression model of numbers of fish traveling toward the water temperature control (WTC) tower while in the beam of the ARIS ${ }^{\circledR}$ acoustic camera at Cougar Reservoir and Dam, Oregon, spring 2013.

\section{Timing of Detection}

The timing of fish observations over the 24-h diel cycle may be considered an indicator of animal movement. The percentage of juvenile fish detections peaked at about 6:00 a.m., and then generally declined throughout the day until about 5:00 p.m., when fish detections began to increase again (fig. 19). These two periods of greater fish detection coincided with the crepuscular period during the spring. Percentage of detections of predator size fish $(>300 \mathrm{~mm})$ was similar to percentage of detections of the smaller fish, except that the peak number of observations occurred later in the day (at about 11:00 a.m.). The timing of detection for fish that were traveling directly toward the WTC tower peaked about $1 \mathrm{~h}$ earlier (between 5:00and 10:00 a.m.; fig. 20) than detections for all fish, but trends for both groups were otherwise similar. Detections of fish of all size categories, and regardless of the direction of movement, were low during the night. 


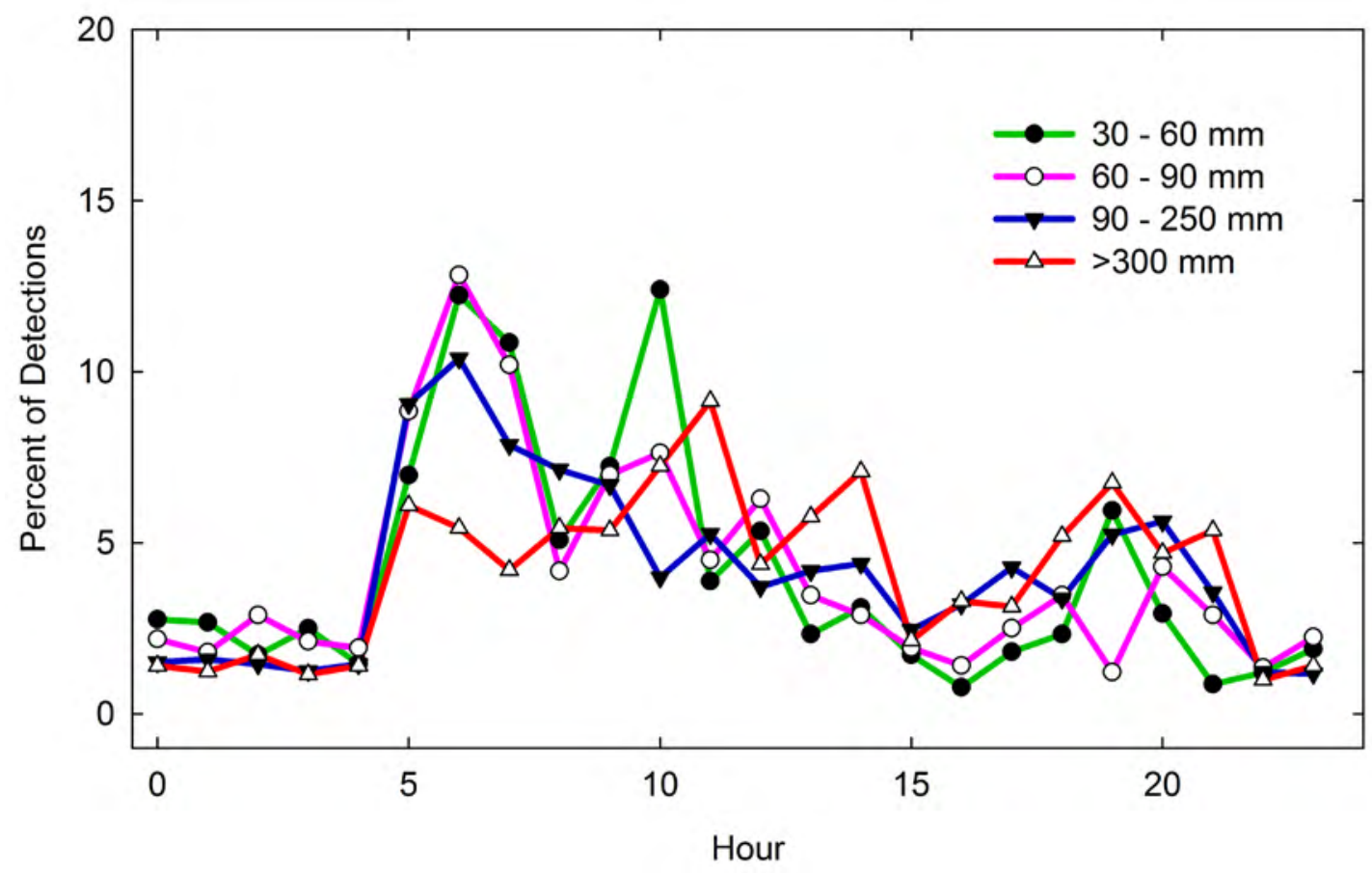

Figure 19. Graph showing hour of detection of fish, by size category (in millimeters [mm]), using the DIDSON ${ }^{\circledR}$ and ARIS $^{\circledR}$ acoustic cameras upstream of the water temperature control (WTC) tower at Cougar Reservoir and Dam, Oregon, spring 2013.

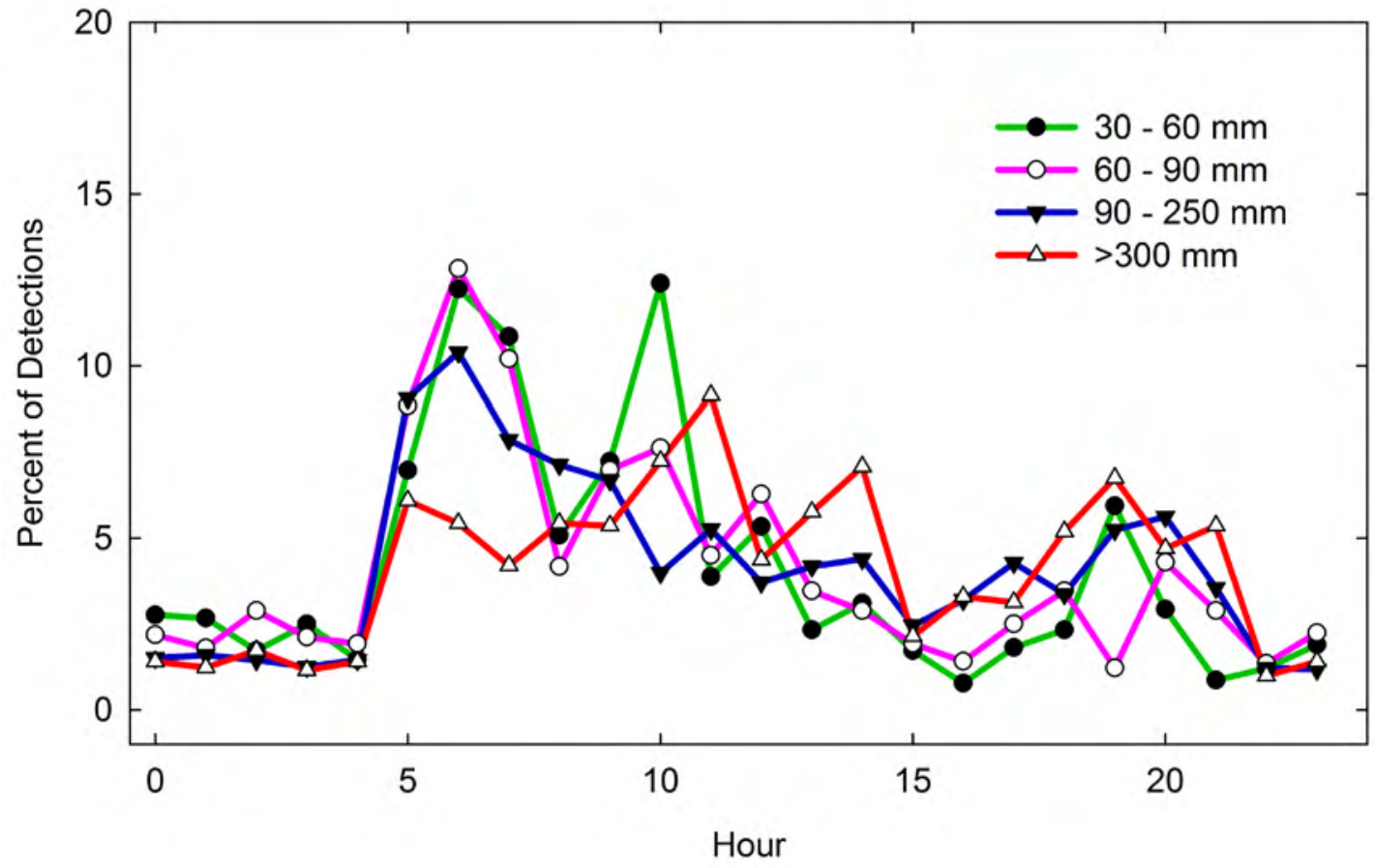

Figure 20. Graph showing hour of detection of fish, by size category (in millimeters [mm]), that were observed traveling toward the water temperature control (WTC) tower using the DIDSON ${ }^{\circledR}$ and ARIS $^{\circledR}$ acoustic cameras at Cougar Reservoir and Dam, Oregon, spring 2013. 
Fall

Fish Directions

Mean directions of fish in the acoustic beams indicated size- or species-specific differences depending on the location and the type of acoustic camera (table 10). Using the DIDSON acoustic camera, the two smallest size categories of fish (30-60 and 60-90 mm) had mean directions of movement that were opposite the mean directions of the large fish $(90-250 \mathrm{~mm})$ and predators (>300 $\mathrm{mm}$ ). Movements were similar for the 30-60 $\mathrm{mm}$ and predator categories using the ARIS acoustic camera, and were more similar for the medium and large fish (figs. 21 and 22).

The directions of fish in the acoustic beams also were dependent on photoperiod (figs. 21 and 22). The mean direction of small fish $(30-60 \mathrm{~mm})$ in the DIDSON acoustic beam was toward the WTC tower during the day, but to the northeast of the WTC tower during the night. Alternatively, in the area covered by the ARIS acoustic camera, fish tended to be directed to the east of the WTC tower during the day, but away from the WTC tower during the night. Medium fish (60-90 mm) within the DIDSON acoustic beam were directed toward the WTC tower during the day, and to the west of the tower during the night. Fish were directed to the east of the WTC tower when in the beam of the ARIS acoustic camera both day and night. The mean directions of the large fish-size category $(90-250 \mathrm{~mm})$ seemed unrelated to the photoperiod, with fish movement directed away from the WTC tower when in the DIDSON acoustic beam, and to the east of the WTC tower when in the ARIS acoustic beam. The movement of predator-sized fish ( $>300 \mathrm{~mm}$ ) was directed away from the WTC tower during day and night when within the DIDSON acoustic beam, and when in the ARIS acoustic beam, the predators moved away from the tower during the day but to the east of the tower during the night. Additional rose plots and circular histograms of fish travel directions by depth and photoperiod are shown in appendix B.

Table 10. Mean directions (radians) and concentration parameters by fish-size category and acoustic-camera type (DIDSON ${ }^{\circledR}$ or ARIS ${ }^{\circledR}$ ) at Cougar Reservoir and Dam, Oregon, fall 2013.

[ $n$, sample size; $\mu$, mean direction of the fish, $\kappa$, concentration parameter; SE, standard error; mm, millimeter; >, greater than]

\begin{tabular}{lccc}
\hline \multicolumn{1}{c}{ Fish-size category (type) } & $n$ & $\mu$ (SE) & $\kappa$ (SE) \\
\hline \multicolumn{5}{c}{ DIDSON } & & \\
\hline 30-60 mm (small fish) & 44 & $-0.294(0.794)$ & $0.273(0.216)$ \\
60-90 mm (medium fish) & 128 & $-0.350(0.710)$ & $0.177(0.126)$ \\
90-250 mm (large fish) & 1,760 & $-3.429(0.179)$ & $0.189(0.034)$ \\
$>300$ mm (predators) & 514 & $-2.891(0.216)$ & $0.290(0.063)$ \\
\hline \multicolumn{3}{c}{ ARIS } & \\
\hline 30-60 mm (small fish) & 86 & $-3.978(0.373)$ & $0.415(0.157)$ \\
60-90 mm (medium fish) & 180 & $1.483(0.199)$ & $0.541(0.111)$ \\
90-250 mm (large fish) & 582 & $0.856(0.133)$ & $0.447(0.061)$ \\
$>300$ mm (predators) & 106 & $-4.072(1.502)$ & $0.092(0.138)$ \\
\hline
\end{tabular}




\section{Fish Size $30-60 \mathrm{~mm}$ DIDSON \\ ARIS}

\section{WTC Tower}

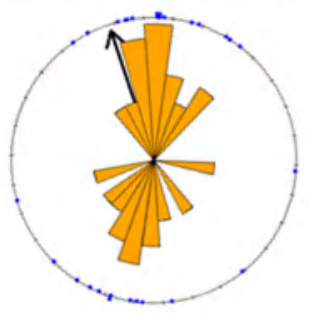

\section{WTC Tower}

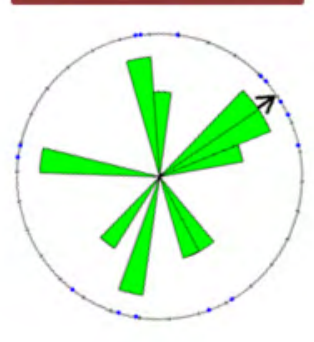

\section{WTC Tower}

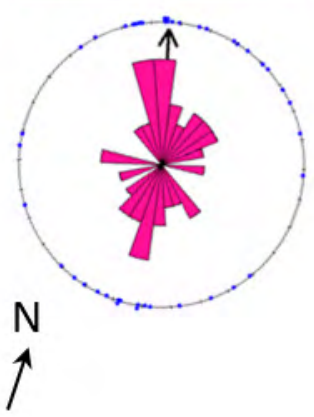

\section{WTC Tower}

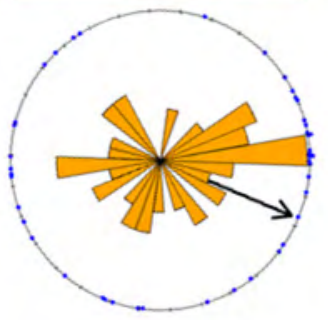

\section{Fish Size 60 - $90 \mathrm{~mm}$}

DIDSON

\section{WTC Tower \\ WTC Tower}
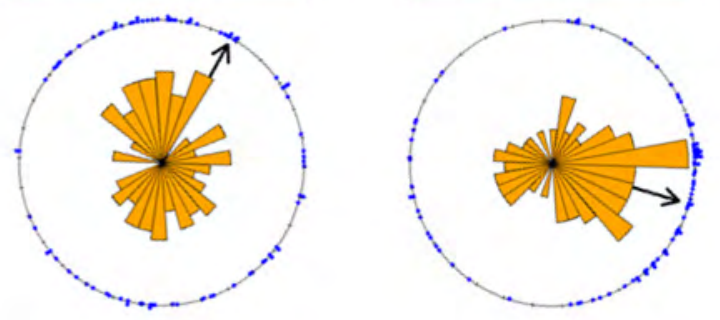

\section{Day}

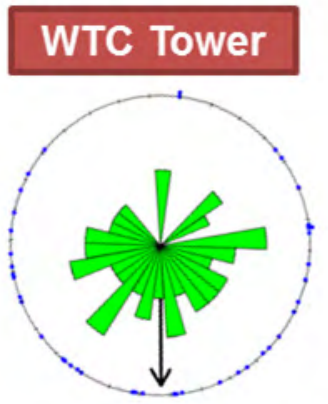

\section{WTC Tower}

\section{WTC Tower}
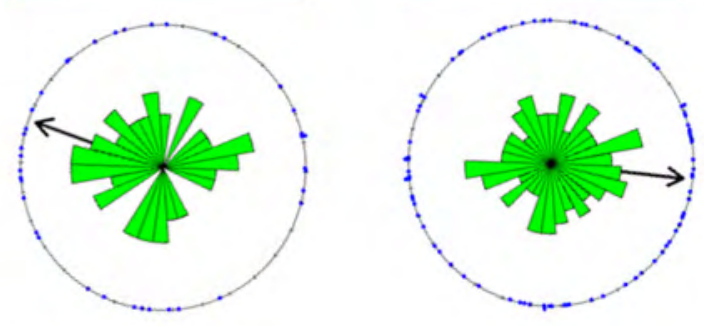

\section{Night}
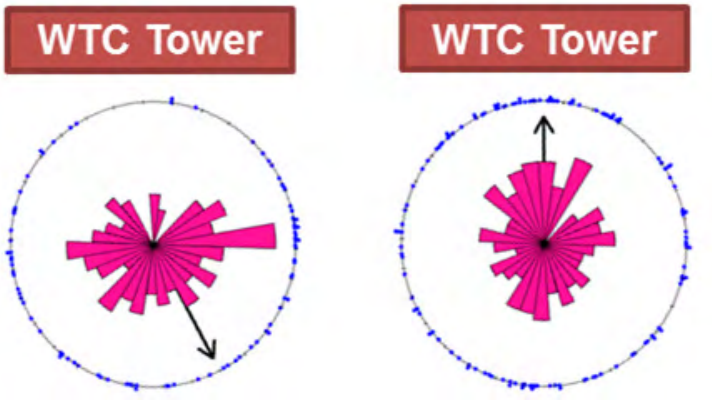

\section{WTC Tower}

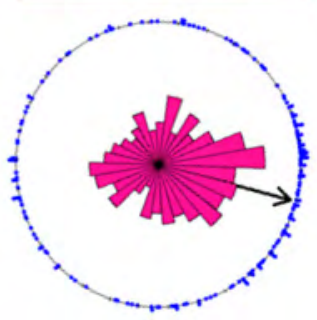

Figure 21. Rose plots and circular histograms of mean directions (degrees) of 30-60 and 60-90 millimeter (mm) fish-size categories by acoustic-camera type (DIDSON ${ }^{\circledR}$ or ARIS ${ }^{\circledR}$ ) and photoperiod (day, night, or combined) upstream of the water temperature control (WTC) tower at Cougar Dam, Oregon, fall 2013. 


\section{Fish Size 90 - $250 \mathrm{~mm}$} DIDSON
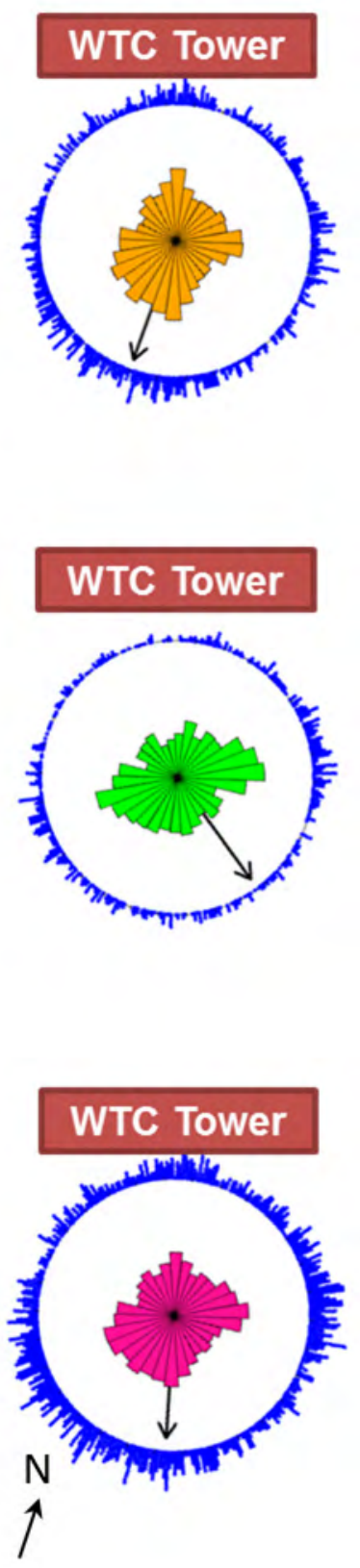

Fish Size $>300 \mathrm{~mm}$ DIDSON

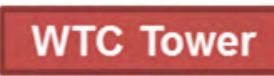

\section{WTC Tower}

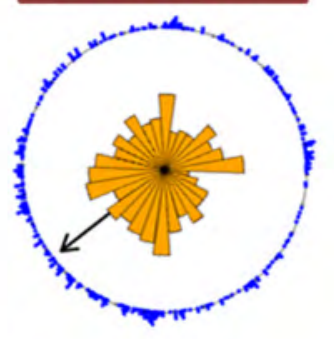

Day

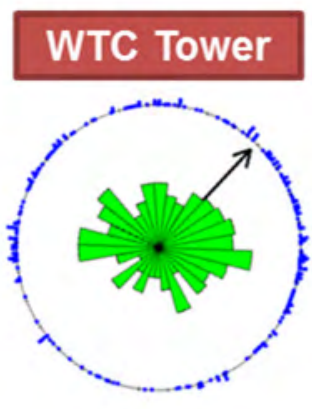

\section{WTC Tower}
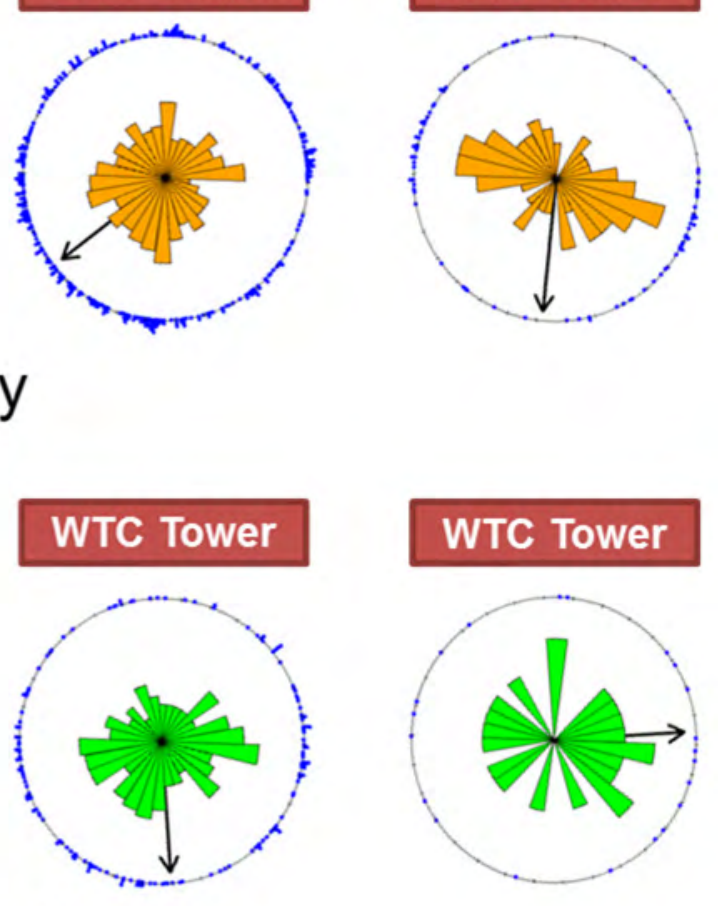

\section{Night}


Models of fish directions in the acoustic beam of the DIDSON acoustic camera had little predictive ability. However, with 1,932 observations, we were able to determine which variables provided statistical (although not biological) significance to the model (table 11, fig. 23). Based on the differences in AIC values for the single-predictor models, discharge had the most influence (AIC=45.42) on fish directions, followed by diel period (AIC=-26.04), temperature (AIC=-24.94), and fish size (AIC=-22.22). These findings support the premise that fish movement upstream of the WTC tower was influenced by the diel period and the size of the fish, and that additional variation in fish directions may arise from differences in dam operations and water temperatures.

There were 848 observations of fish direction in the area covered by the ARIS acoustic camera, so statistical significance should be easily obtained. Nevertheless, diel period was the only nonsignificant $(p=0.0604)$ contributor to the model (table 11, fig. 24). Based on the differences in AIC values for single-predictor models, fish size had the most influence (AIC $=-83.75$ ) on fish directions, but diel period (AIC=-71.54), temperature (AIC=-71.41), and discharge $(\mathrm{AIC}=-69.49)$ were equivocal.

Table 11. Results for circular-linear models of mean directions (radians) of fish in the acoustic beams of the DIDSON ${ }^{\circledR}$ and ARIS $^{\circledR}$ acoustic cameras upstream of the water temperature control (WTC) tower at Cougar Reservoir and Dam, Oregon, fall 2013.

[AIC values denote estimates for each single-predictor model. SE, standard error; AIC, Akaike Information Criterion $\mu$, mean direction of the fish, $\kappa$, concentration parameter; $n$, sample size]

\begin{tabular}{|c|c|c|c|c|c|}
\hline Model effect & Estimate & SE & $t$-value & $p$-value & AIC \\
\hline \multicolumn{6}{|c|}{ DIDSON $(n=1,932)$} \\
\hline$\mu$ & 1.474 & 0.106 & -- & -- & \\
\hline$\kappa$ & 0.307 & 0.033 & -- & -- & \\
\hline Diel period & 0.594 & 0.183 & 3.244 & 0.0006 & -26.04 \\
\hline Discharge & 0.399 & 0.121 & 3.298 & 0.0005 & -45.42 \\
\hline Temperature & -0.645 & 0.106 & 6.057 & $<0.0001$ & -24.94 \\
\hline Fish size & 2.004 & 0.315 & 6.367 & $<0.0001$ & -22.22 \\
\hline \multicolumn{6}{|c|}{ ARIS $(n=848)$} \\
\hline$\mu$ & 0.822 & 0.101 & & & \\
\hline$\kappa$ & 0.490 & 0.051 & & & \\
\hline Diel period & 0.175 & 0.113 & 1.552 & 0.0604 & -71.54 \\
\hline Discharge & 0.127 & 0.060 & 2.138 & 0.0136 & -69.49 \\
\hline Temperature & 0.126 & 0.027 & 4.679 & $<0.0001$ & -71.41 \\
\hline Fish size & -0.447 & 0.095 & 4.714 & $<0.0001$ & -83.75 \\
\hline
\end{tabular}



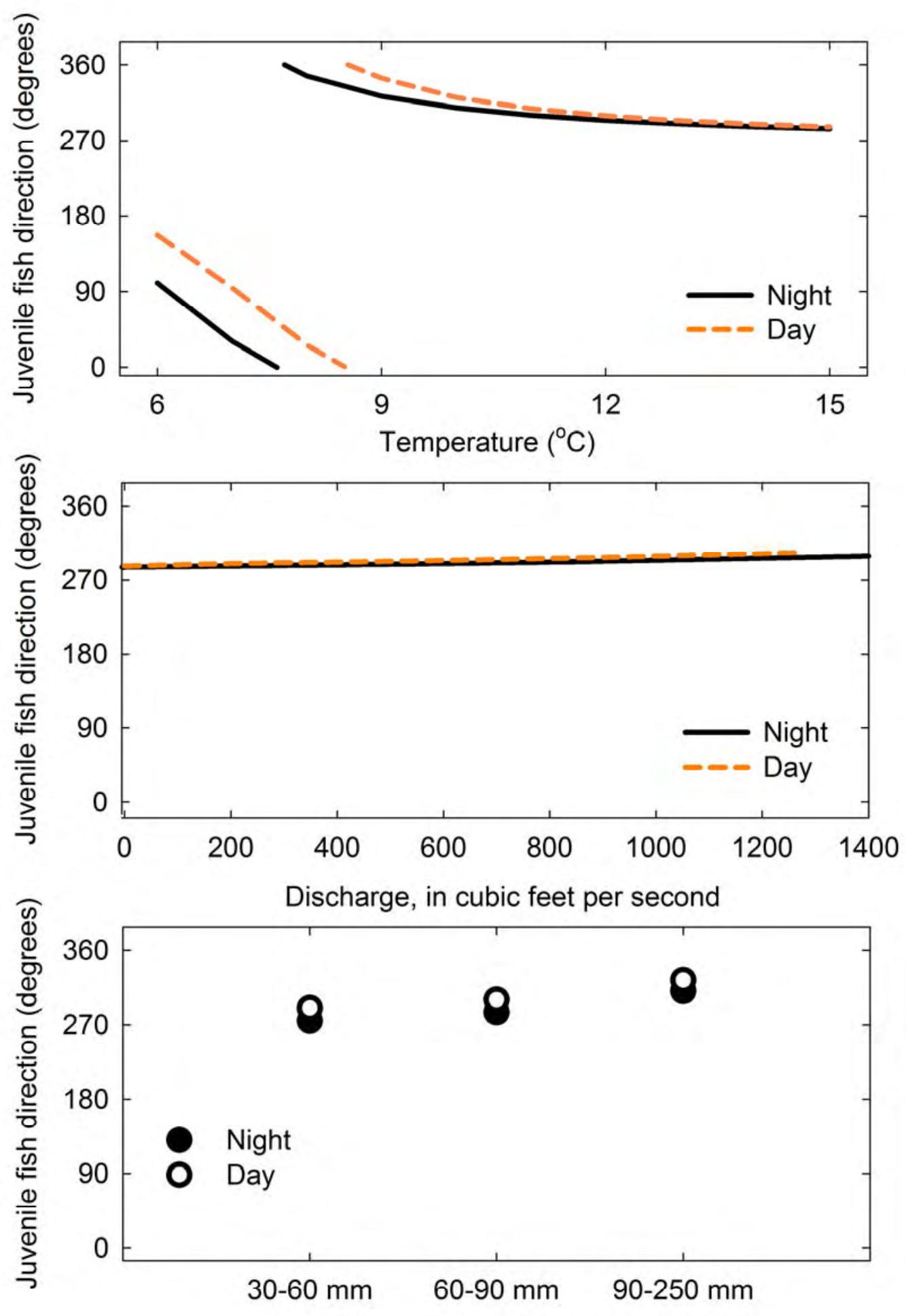

Fish size

Figure 23. Effects plots for the full circular-linear model of mean directions of fish (in degrees) within the beam of the DIDSON ${ }^{\circledR}$ acoustic camera upstream of the water temperature control (WTC) tower at Cougar Reservoir and Dam, Oregon, fall 2013 

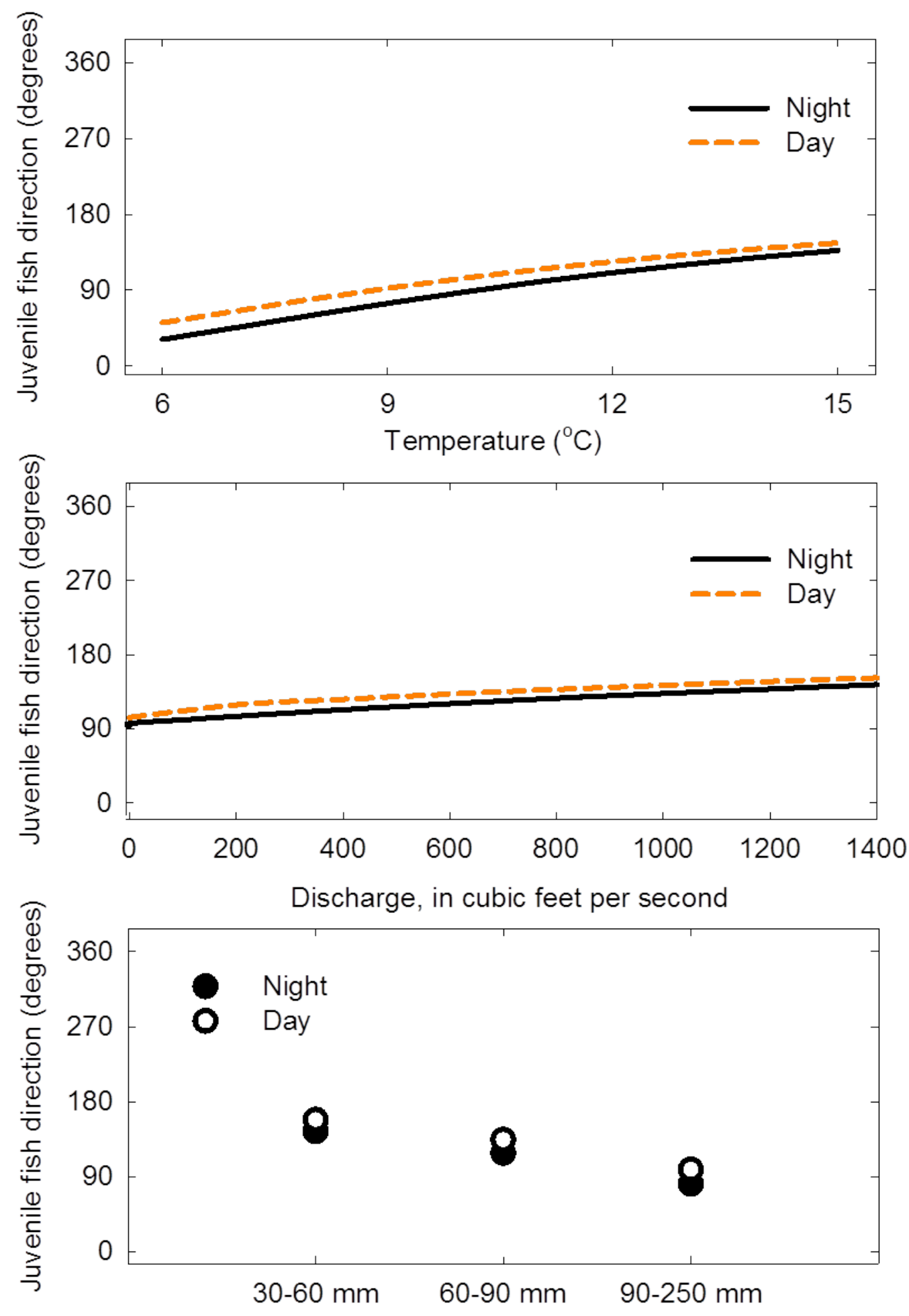

Fish size

Figure 24. Effects plots for the full circular-linear model of mean directions fish (in degrees) within the beam of the ARIS ${ }^{\circledR}$ acoustic camera upstream of the water temperature control (WTC) tower at Cougar Reservoir and Dam, Oregon, fall 2013. 


\section{Fish Depth}

The mean hourly depth of fish in the area covered by the DIDSON and ARIS acoustic cameras was more variable among the size groups during the fall (fig. 25) than during the spring (fig. 12). Small fish (30-60 mm) had the greatest amount of variability among hourly mean depths, and there was no clear response to changes in photoperiod. The 60-90 mm fish-size category generally was observed nearer to the surface during both photoperiods than the other fish-size categories. Fish in the 90-250 $\mathrm{mm}$ size category showed little change in mean depth with time of day. Fish in the predator size category (>300 mm) generally were observed at greater depths than the smaller fish throughout the day, with the greatest mean depth occurring during the night.

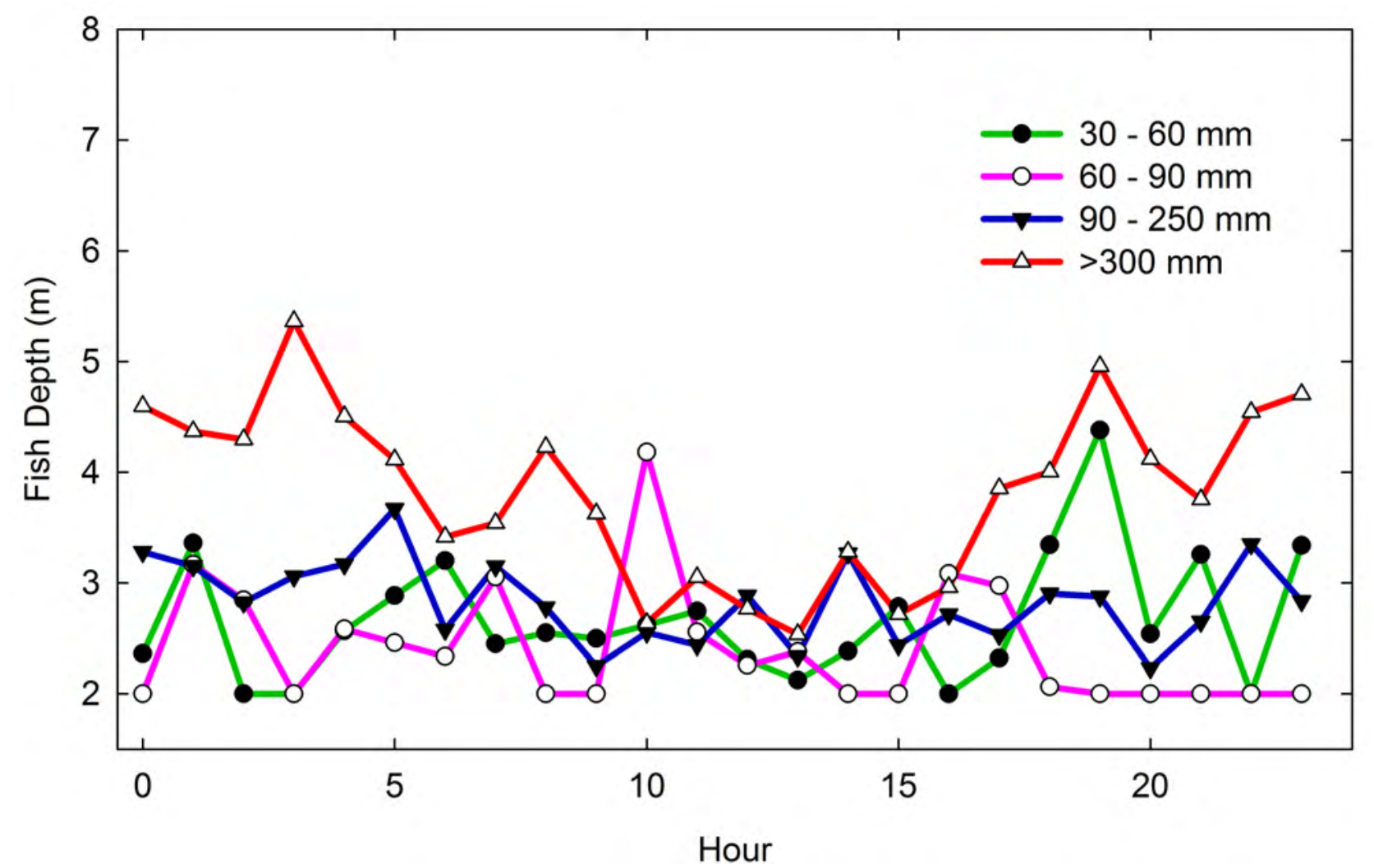

Figure 25. Graph showing hourly mean depth of fish (in meters [m]), by size category (in millimeters [mm]), in the area covered by DIDSON ${ }^{\circledR}$ and ARIS $^{\circledR}$ acoustic cameras, which were upstream of the water temperature control (WTC) tower at Cougar Reservoir and Dam, Oregon, fall 2013. 
The mean depths by fish-size category during the fall varied by location and acoustic-camera type (table 12). For the fish observed in the area covered by the DIDSON acoustic camera, the mean depths increased with the size category of the fish. The predator size fish $(>300 \mathrm{~mm})$ that were observed with the DIDSON acoustic camera were observed at mean depths of about $1 \mathrm{~m}$ deeper than the smaller size categories. Conversely, the mean depth of fish in the area covered by the ARIS acoustic camera generally decreased with increasing fish-size category. Fish were shallowest in the area covered by the ARIS acoustic camera. Differences in observations between camera types may be attributed to the location of the camera and the limited range of the ARIS acoustic camera. Predators also tended to occupy the region nearer the center of the WTC tower, thus remaining out of the range of the ARIS acoustic camera. Additionally, the mean depth of fish observed with both acoustic cameras during the fall season $(3.0 \mathrm{~m})$ increased as the camera angle increased from horizontal, but were similar between 25 and 50 degrees (fig. 26).

Table 12. Sample size, and mean, standard deviation, minimum, and maximum depths of each fish-size category observed with the DIDSON ${ }^{\circledR}$ and ARIS ${ }^{\circledR}$ acoustic cameras upstream of the water temperature control (WTC) tower at Cougar Reservoir, Oregon, fall 2013.

[n, sample size; SD, standard deviation; mm, millimeter; >, greater than]

\begin{tabular}{|c|c|c|c|c|c|}
\hline \multirow[b]{2}{*}{ Fish-size class (type) } & \multirow[b]{2}{*}{$n$} & \multicolumn{4}{|c|}{ Depth (meters) } \\
\hline & & Mean & SD & Minimum & Maximum \\
\hline \multicolumn{6}{|c|}{ DIDSON } \\
\hline 30-60 mm (small fish) & 58 & 2.56 & 1.08 & 2 & 5.92 \\
\hline 60-90 mm (medium fish) & 165 & 2.82 & 1.35 & 2 & 6.11 \\
\hline 90-250 mm (large fish) & 1,961 & 2.86 & 1.34 & 2 & 8.75 \\
\hline >300 mm (predators) & 531 & 3.73 & 1.52 & 2 & 6.39 \\
\hline \multicolumn{6}{|c|}{ ARIS } \\
\hline 30-60 mm (small fish) & 126 & 2.80 & 1.09 & 2 & 6.27 \\
\hline 60-90 mm (medium fish) & 206 & 2.85 & 1.12 & 2 & 5.97 \\
\hline 90-250 mm (large fish) & 650 & 2.53 & 0.91 & 2 & 6.26 \\
\hline >300 mm (predators) & 109 & 2.32 & 0.52 & 2 & 4.46 \\
\hline
\end{tabular}




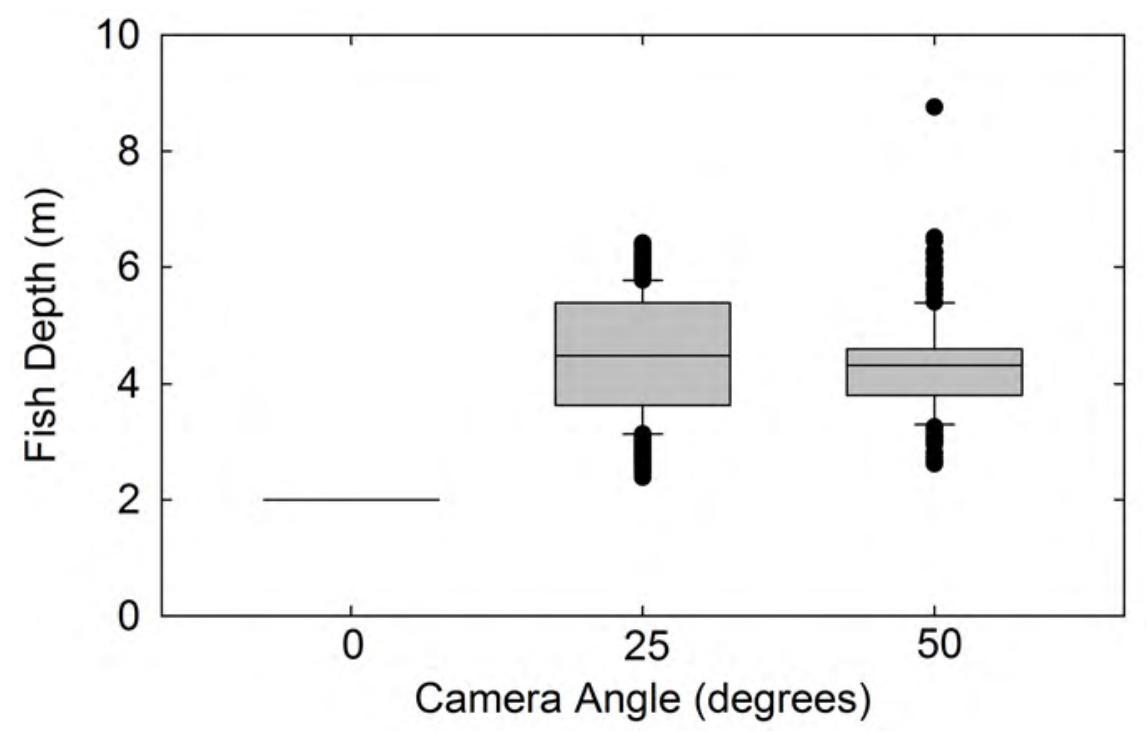

Figure 26. Box and whisker plots of the depth of fish (in meters [m]) observed under different camera angles using DIDSON ${ }^{\circledR}$ and ARIS $^{\circledR}$ acoustic cameras at Cougar Reservoir and Dam, Oregon, fall 2013. The upper and lower boundaries of the box represent the 25th and 75th quartiles, the line inside the box is the mean, the whiskers represent the 5- and 95-percent confidence intervals, and outliers are shown by solid points.

Fish Speed and Duration of Observation

Juvenile salmon-sized fish traveled at speeds that generally were less than $1 \mathrm{~m} / \mathrm{s}$ in the areas covered by both the DIDSON and ARIS acoustic cameras (table 13, fig. 27). The mean swim speed of fish in the DIDSON acoustic beam was $0.078 \mathrm{~m} / \mathrm{s}$ (interquartile range $=0.063 \mathrm{~m} / \mathrm{s}$ ), and the mean travel speed of fish in the ARIS acoustic beam was $0.098 \mathrm{~m} / \mathrm{s}$ (interquartile range $=0.082 \mathrm{~m} / \mathrm{s}$ ). The duration of time that fish were observed in the acoustic beams also was similarly short in the areas covered by the two acoustic cameras. Fish in the area covered by the DIDSON acoustic camera spent, on average, $8.783 \mathrm{~s}$ (interquartile range $=3.960 \mathrm{~s}$ ) in the acoustic beam, whereas fish in the area covered by the ARIS acoustic camera spent $7.865 \mathrm{~s}$ (interquartile range $=5.890 \mathrm{~s}$ ) in the acoustic beam. 
Table 13. Summary statistics for the travel speeds and duration that fish were observed by the DIDSON and ARIS acoustic cameras at the water temperature control (WTC) tower at Cougar Reservoir and Dam, Oregon, fall 2013.

[n, sample size; SD, standard deviation; IQR, interquartile range]

\begin{tabular}{|c|c|c|c|c|c|c|c|c|c|}
\hline Camera & $n$ & Mean & SD & IQR & Minimum & $\begin{array}{c}2.5 \\
\text { percent }\end{array}$ & $\begin{array}{c}50 \\
\text { percent }\end{array}$ & $\begin{array}{c}97.5 \\
\text { percent }\end{array}$ & Maximum \\
\hline \multicolumn{10}{|c|}{ Travel speed (meter per second) } \\
\hline DIDSON & 1,932 & 0.078 & 0.067 & 0.063 & 0.001 & 0.013 & 0.069 & 0.190 & 0.327 \\
\hline ARIS & 848 & 0.098 & 0.070 & 0.082 & 0.001 & 0.015 & 0.082 & 0.277 & 0.453 \\
\hline \multicolumn{10}{|c|}{ Time in acoustic beam (second) } \\
\hline DIDSON & 1,932 & 8.783 & 35.153 & 3.960 & 0.770 & 0.990 & 3.240 & 44.372 & 832.780 \\
\hline ARIS & 848 & 7.865 & 18.731 & 5.890 & 0.532 & 0.770 & 3.344 & 33.568 & 284.312 \\
\hline
\end{tabular}
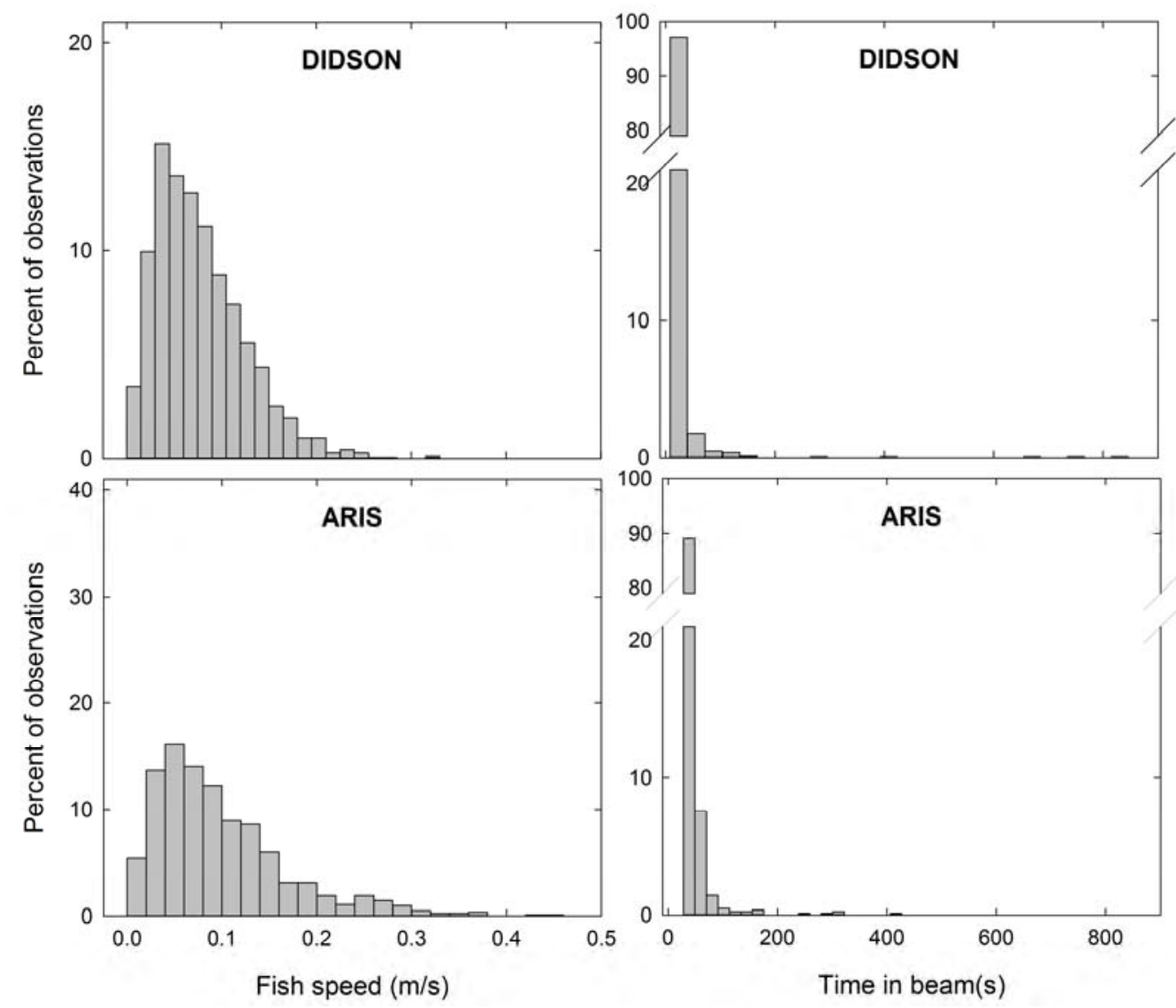

Figure 27. Graphs showing distributions of fish travel speeds (in meters per second $[\mathrm{m} / \mathrm{s}]$ ) and the amount of time fish spent within the acoustic beams of the DIDSON ${ }^{\circledR}$ and ARIS ${ }^{\circledR}$ acoustic cameras at Cougar Reservoir and Dam, fall 2013. 
Application of linear models to estimate the travel speeds of fish indicated a limited ability to predict the travel speeds of fish. All models had residuals that were evenly distributed over the predicted range, but they only explained less than 5 percent of the variation. Regardless of this poor model fit, however, modeling indicated camera- and location-specific differences in travel speeds near the WTC tower (table 14). In particular, modeling confirmed that travel speeds were faster in the area of the ARIS acoustic camera, and that the response to both temperature and discharge was more acute compared to travel speeds measured in the area of the DIDSON acoustic camera. This finding was especially apparent for the larger fish (table 14, fig. 28). Based on the AIC values for the single-predictor models, the order of importance for the predictors of travel speeds of fish in the area of the DIDSON acoustic camera in the fall was identical to the order of importance in the spring. These predictors, in descending order of importance, were (1) fish size (AIC = -4,148), (2) discharge (AIC = -4,120), (3) diel period $(\mathrm{AIC}=-4,110)$ and then $(4)$ temperature $(\mathrm{AIC}=-4,107)$. In the area of the ARIS acoustic camera, the order of single-predictor importance to fish travel speed was ranked slightly different with (1) diel period (AIC = -1,476), (2) discharge (AIC = -1,455), (3) fish size (AIC = -1,439) and (4) temperature $(\mathrm{AIC}=-1,406)$.

Table 14. Results for multiple regression models of mean travel speeds (square root of meter per second $[\sqrt{m / s}]$ ) of fish while in the acoustic beams of the DIDSON ${ }^{\circledR}$ and ARIS $^{\circledR}$ acoustic cameras upstream of the water temperature control (WTC) tower at Cougar Reservoir and Dam, Oregon, fall 2013.

[SE, standard error; AIC, Akaike Information Criterion; $R^{2}$, coefficient of determination; $n$, sample size; mm, millimeter; <, less than]

\begin{tabular}{lccccc}
\hline \multicolumn{1}{c}{ Model effect } & Estimate & SE & $t$-value & $p$-value & Single-predictor AIC \\
\hline \multicolumn{7}{c}{ DIDSON $\left(R^{2}=0.046, n=1,932\right.$, AIC=-4,187) } \\
\hline Intercept & 0.354 & 0.033 & 10.617 & $<0.0001$ & (intercept only) $-4,106$ \\
Diel period (day) & -0.012 & 0.004 & -3.073 & 0.0022 & $-4,110$ \\
Fish size (60-90 mm) & 0.033 & 0.014 & 2.303 & 0.0214 & $-4,148$ \\
Fish size (90-250 mm) & 0.065 & 0.013 & 5.244 & $<0.0001$ & $-4,148$ \\
Discharge & -0.012 & 0.002 & -5.867 & $<0.0001$ & $-4,120$ \\
Temperature & -0.017 & 0.004 & -4.672 & $<0.0001$ & $-4,107$ \\
\hline \multicolumn{7}{c}{ ARIS $\left(R^{2}=0.164, n=848\right.$, AIC=-1,547) } \\
\hline Intercept & 0.134 & 0.027 & 4.891 & $<0.0001$ & (intercept only) $-1,404$ \\
Diel period (day) & 0.051 & 0.007 & 7.507 & $<0.0001$ & $-1,476$ \\
Fish size (60-90 mm) & 0.013 & 0.013 & 0.998 & 0.319 & $-1,439$ \\
Fish size (90-250 mm) & 0.045 & 0.011 & 3.936 & $<0.0001$ & $-1,439$ \\
Discharge & 0.028 & 0.004 & 7.342 & $<0.0001$ & $-1,455$ \\
Temperature & 0.010 & 0.003 & 3.916 & $<0.0001$ & $-1,406$ \\
\hline
\end{tabular}



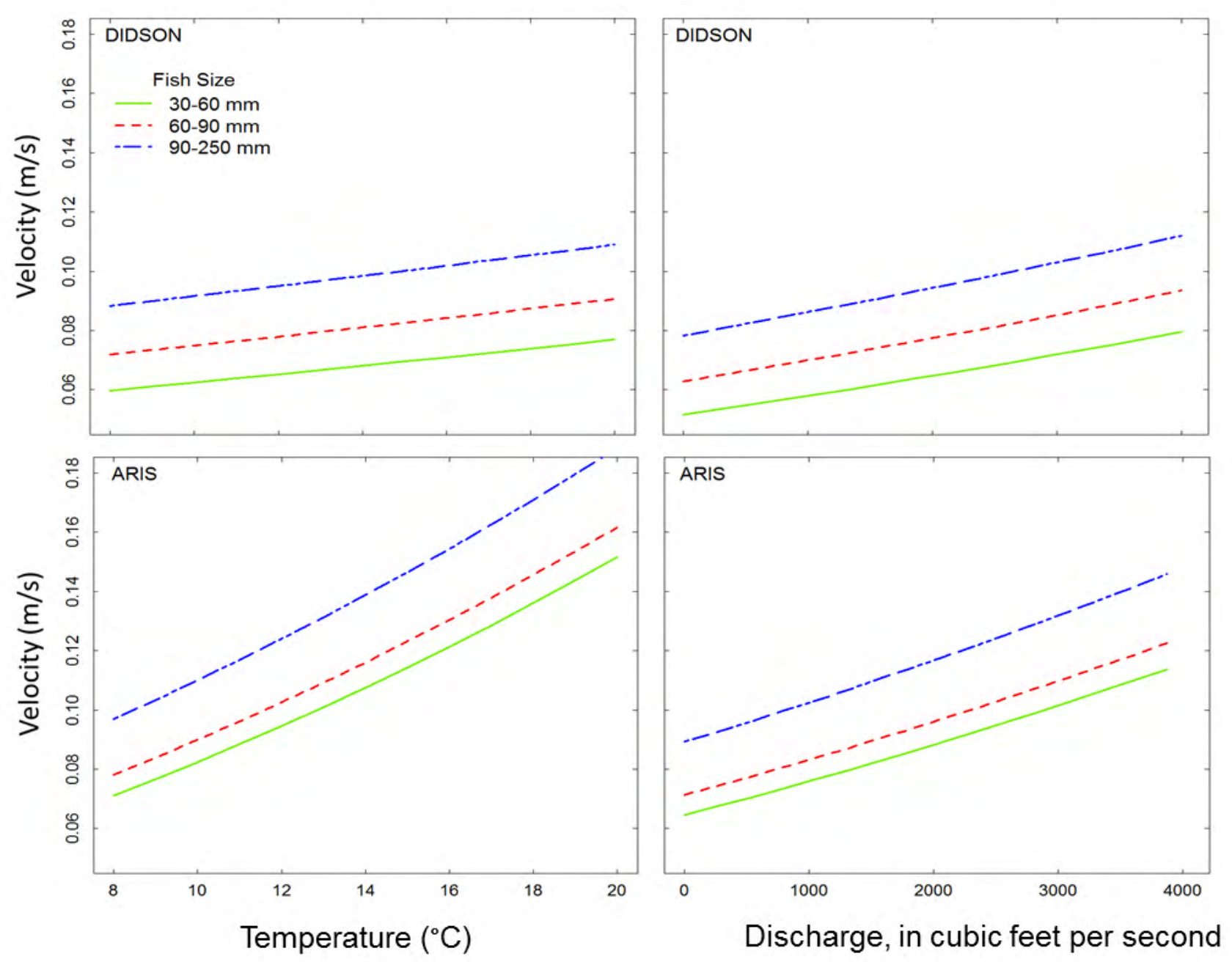

Figure 28. Plots for the multiple regression model estimates of mean travel speed of fish (in meters per second $[\mathrm{m} / \mathrm{s}]$ ), by size category (in millimeters [mm]), within the beams of the DIDSON ${ }^{\circledR}$ and ARIS $^{\circledR}$ acoustic cameras upstream of the water temperature control (WTC) tower at Cougar Reservoir and Dam, Oregon, fall 2013. 


\section{Quantifying Movement Toward Water Temperature Control Tower}

Fall results differed slightly from spring results when we used Poisson rate regressions to quantify the numbers of fish moving toward the WTC tower given the total number of fish in the acoustic beam (per 3-s interval). However, it should be cautioned that the global model had structural problems similar to those found in the analysis of the spring data. The Q-Q plots were jagged and suggested departure from the theoretical quantiles at the upper tail of the distribution. Additionally, calculation of Nagelkerke's (1991) coefficient of determination $\left(R^{2}\right)$ indicated that less than 5 percent of the deviance was explained (after accounting for the rate variable) regardless of the camera, indicating poor model predictive ability (table 15). The rate variables used in the models were the most significant determinant of the numbers of fish moving toward the tower, so we assume that this rate was equal to 1 and was offset from the model. No indication of overdispersion was discovered in the global models, irrespective of whether the data were obtained from the DIDSON $(\varphi=0.97)$ or the ARIS $(\varphi=1.03)$ acoustic cameras (fig. 29).

Table 15. Results for reduced Poisson rate regression models of fish traveling toward the water temperature control (WTC) tower while in the acoustic beams of the DIDSON ${ }^{\circledR}$ and ARIS ${ }^{\circledR}$ acoustic cameras at Cougar Reservoir and Dam, Oregon, fall 2013.

[The model effect in brackets is the factor level being measured against the reference category. SE, standard error; <, less than; $R^{2}$, coefficient of determination; $n$, sample size]

\begin{tabular}{|c|c|c|c|c|}
\hline Model effect & Estimate & SE & $z$-value & $p$-value \\
\hline \multicolumn{5}{|c|}{ DIDSON (Nagelkerke's $R^{2}=0.022, n=4,668$ ) } \\
\hline Intercept & -2.1700 & 0.4962 & -4.3730 & $<0.0001$ \\
\hline $\log \left(\mathrm{N}_{\text {beam } t}\right)$ & 1.3880 & 0.0551 & 25.2040 & $<0.0001$ \\
\hline Photoperiod[LIGHT] & -0.1117 & 0.0618 & -1.8060 & 0.0709 \\
\hline Predator count & 0.2124 & 0.1075 & 1.9760 & 0.0482 \\
\hline Discharge & 0.0002 & 0.0000 & 5.0680 & $<0.0001$ \\
\hline Temperature & -0.0550 & 0.0548 & -1.0020 & 0.3164 \\
\hline Photoperiod[LIGHT]:Predator count & 0.1288 & 0.0739 & 1.7430 & 0.0813 \\
\hline DISCHARGE: Predator count & -0.0002 & 0.0001 & -2.4820 & 0.0130 \\
\hline \multicolumn{5}{|c|}{ ARIS (Nagelkerke's $R^{2}=0.018, n=1,995$ ) } \\
\hline Intercept & -2.1610 & 0.4968 & -4.3500 & $<0.0001$ \\
\hline $\log \left(\mathrm{N}_{\text {beam } t}\right)$ & 1.2900 & 0.1149 & 11.2260 & $<0.0001$ \\
\hline Photoperiod[LIGHT] & -0.4274 & 0.1097 & -3.8950 & 0.0001 \\
\hline Predator count & 1.5660 & 0.8246 & 1.9000 & 0.0575 \\
\hline Discharge & 0.0000 & 0.0001 & 0.5020 & 0.6155 \\
\hline Temperature & -0.0327 & 0.0434 & -0.7520 & 0.4519 \\
\hline Photoperiod[LIGHT]:Predator count & 1.5920 & 0.6844 & 2.3260 & 0.0200 \\
\hline DISCHARGE: Predator count & -0.0017 & 0.0010 & -1.7300 & 0.0837 \\
\hline
\end{tabular}



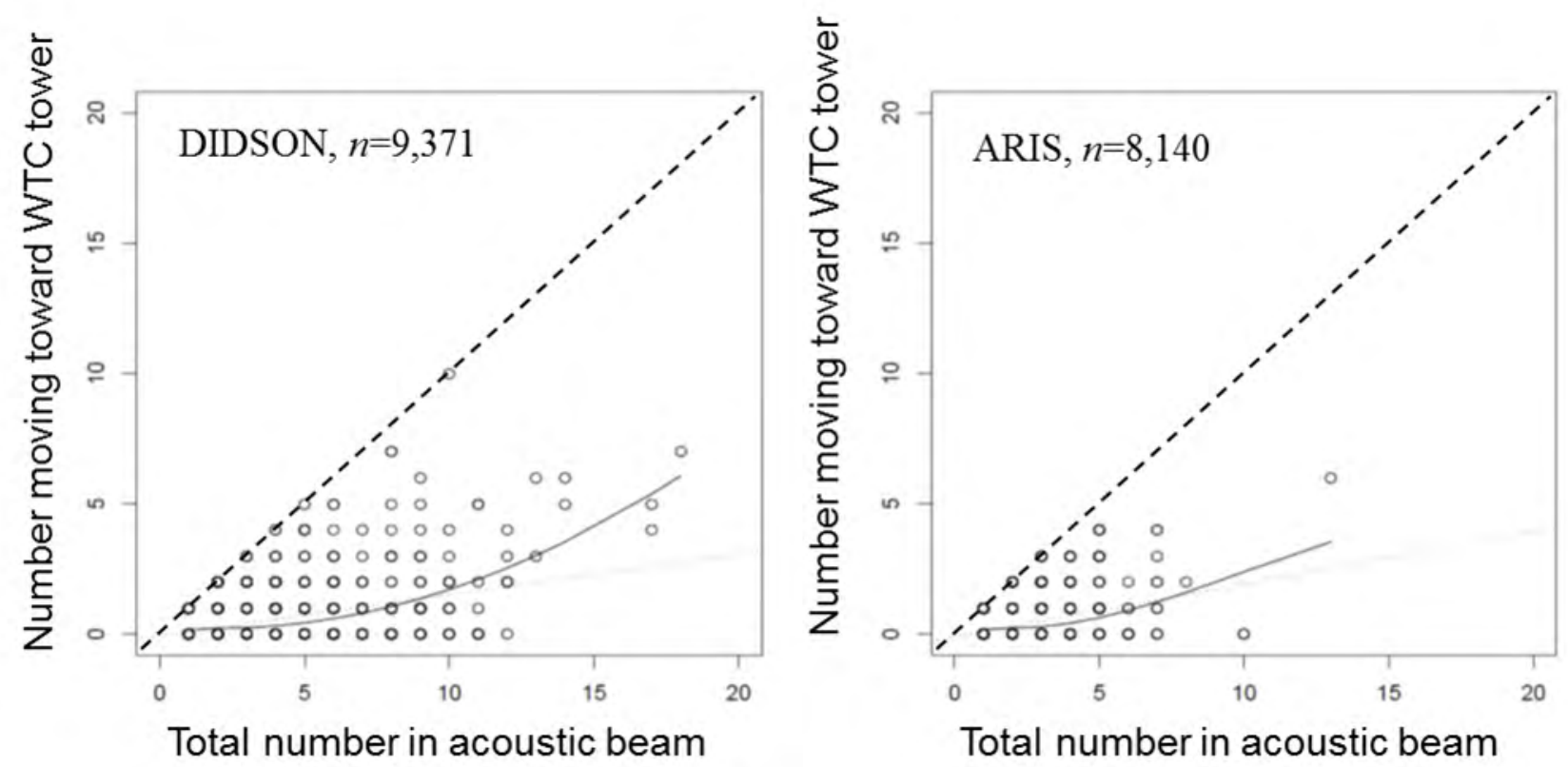

Figure 29. Scatter plots showing number $(n)$ of fish moving toward the water temperature control (WTC) tower (per 3-second interval) and total number of fish observed in the acoustic beam (per 3-second interval) of the DIDSON ${ }^{\circledR}$ and ARIS ${ }^{\circledR}$ acoustic cameras at Cougar Reservoir and Dam, Oregon, fall 2013. Solid lines represent the average trend using a loess smoothing function, dotted lines represent average trend using a linear model, and dashed lines represent 1:1 line of equality.

Perhaps, the most significant finding from this analysis was the effect of predators on fish moving toward the WTC tower at the different locations and cameras. For example, in the area covered by the DIDSON acoustic camera, the number of predators was important to the model, but in the area covered by the ARIS acoustic camera, the number of predators had little influence on the numbers of fish moving toward the WTC tower. In the area covered by the DIDSON acoustic camera, there also was evidence for an interaction between predators and discharge (fig. 30), supporting the conclusion that predation risk, time of day, discharge, and location upstream of the WTC tower can interact with and influence the number of fish moving toward the WTC tower. In the area covered by the ARIS acoustic camera, stepwise removal of the non-significant predictors supported the conclusion that photoperiod was the only significant contributor to the numbers of fish moving toward the WTC tower (table 16, fig. 31). 
Table 16. Results for reduced Poisson rate regression models with removal of nonsignificant predictors of fish traveling toward the water temperature control (WTC) tower while in the acoustic beams of the DIDSON ${ }^{\circledR}$ and ARIS acoustic cameras at Cougar Reservoir and Dam, Oregon, fall 2013.

[The model effect in brackets is the factor level being measured against the reference category. SE, standard error; $n$, sample size]

\begin{tabular}{lcrrr}
\hline \multicolumn{1}{c}{ Model effect } & Estimate & SE & z-value & $p$-value \\
\hline DIDSON $(n=4,668)$ & & & \\
\hline Intercept & -2.4190 & 0.0693 & -34.9080 & $<0.0001$ \\
Predator count & 0.3788 & 0.0886 & 4.2730 & $<0.0001$ \\
Discharge & 0.0003 & 0.0000 & 6.4110 & $<0.0001$ \\
DISCHARGE: Predator count & -0.0002 & 0.0001 & -2.5140 & 0.0120 \\
\hline \multicolumn{1}{c}{ ARIS $(n=1,995)$} & & & \\
\hline Intercept & -2.20649 & 0.07474 & -29.521 & $<0.0001$ \\
Photoperiod[LIGHT] & -0.38051 & 0.10726 & -3.548 & 0.0004 \\
\hline
\end{tabular}

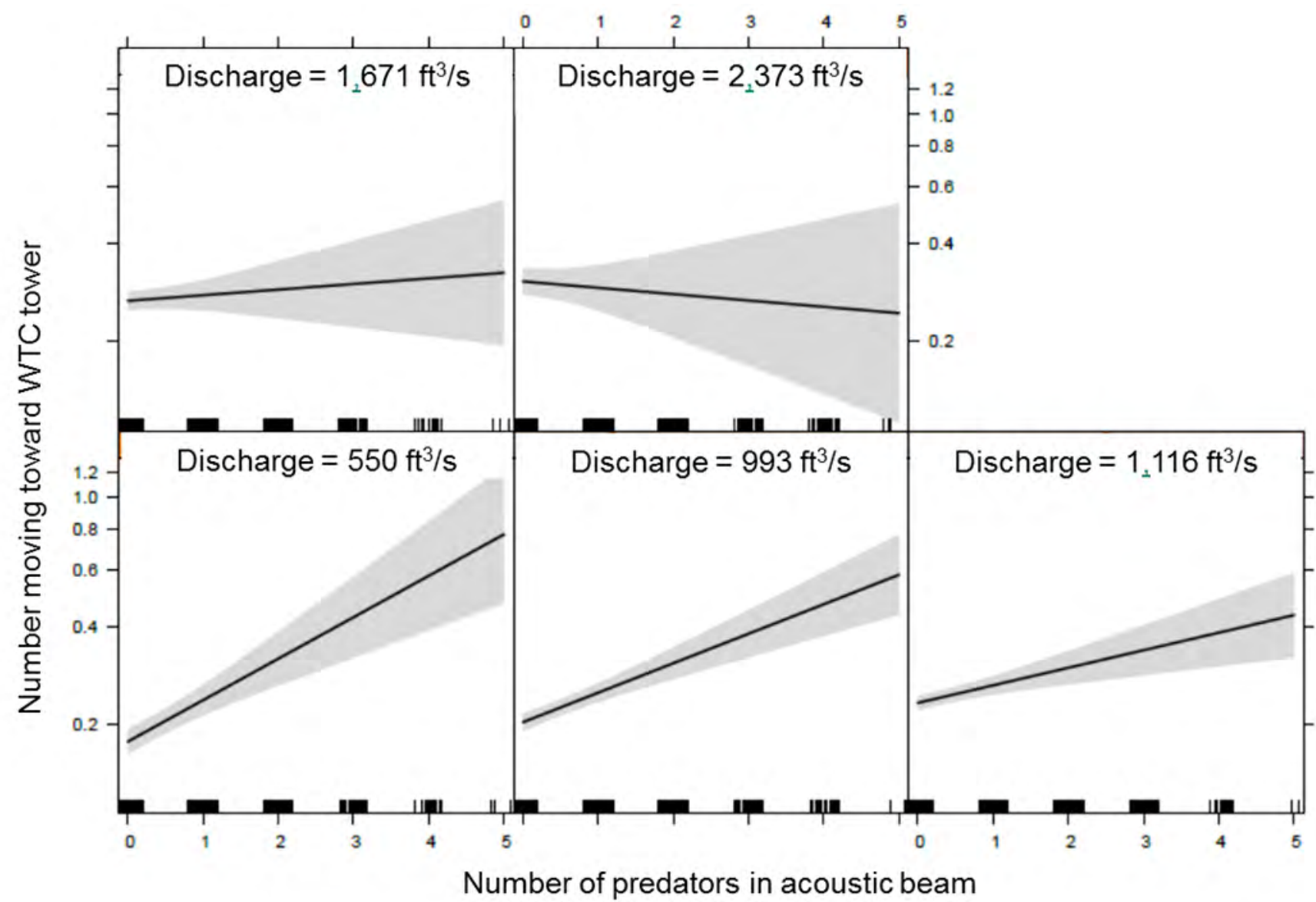

Figure 30. Effects plots for the reduced Poisson rate regression modeling the numbers of fish traveling toward the water temperature control (WTC) tower while in the beam of the DIDSON ${ }^{\circledR}$ acoustic camera at Cougar Reservoir and Dam, Oregon, fall 2013. 

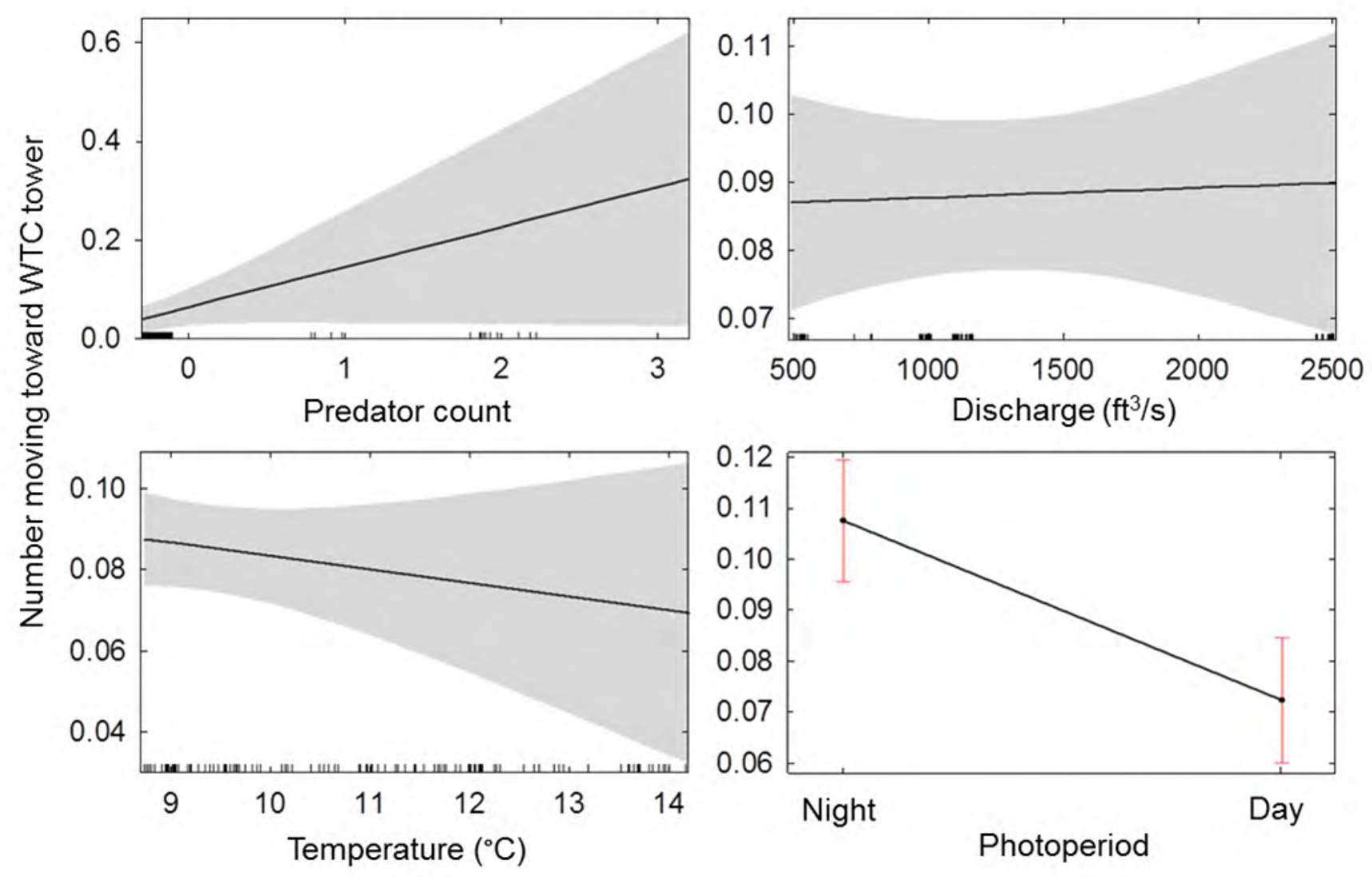

Figure 31. Effects plots for the reduced Poisson rate regression model of the numbers of fish traveling toward the water temperature control (WTC) tower while in the beam of the ARIS ${ }^{\circledR}$ acoustic camera at Cougar Reservoir and Dam, Oregon, fall 2013.

\section{Timing of Detection}

The timing of fish present in the acoustic beams varied among fish sizes and time of day (fig. 32). As observed during the spring, data from the fall also showed an increase in the detections of fish from all size groups during the crepuscular periods. Additionally, there was an increase in the number of all fish sizes near midday that was not observed during the spring. Compared to spring, the percentage of detections of predator-sized fish (>300 $\mathrm{mm}$ ) in fall more closely followed peak detections of the smaller fish, with peak observations occurring at about 8:00 a.m. and 3:00 p.m. Detections of fish that were traveling directly toward the WTC tower peaked between 10:00 a.m. and 3:00 p.m. (fig. 33). As was the case in the spring, detections of all fish-size classes in the fall generally were low during the night. 


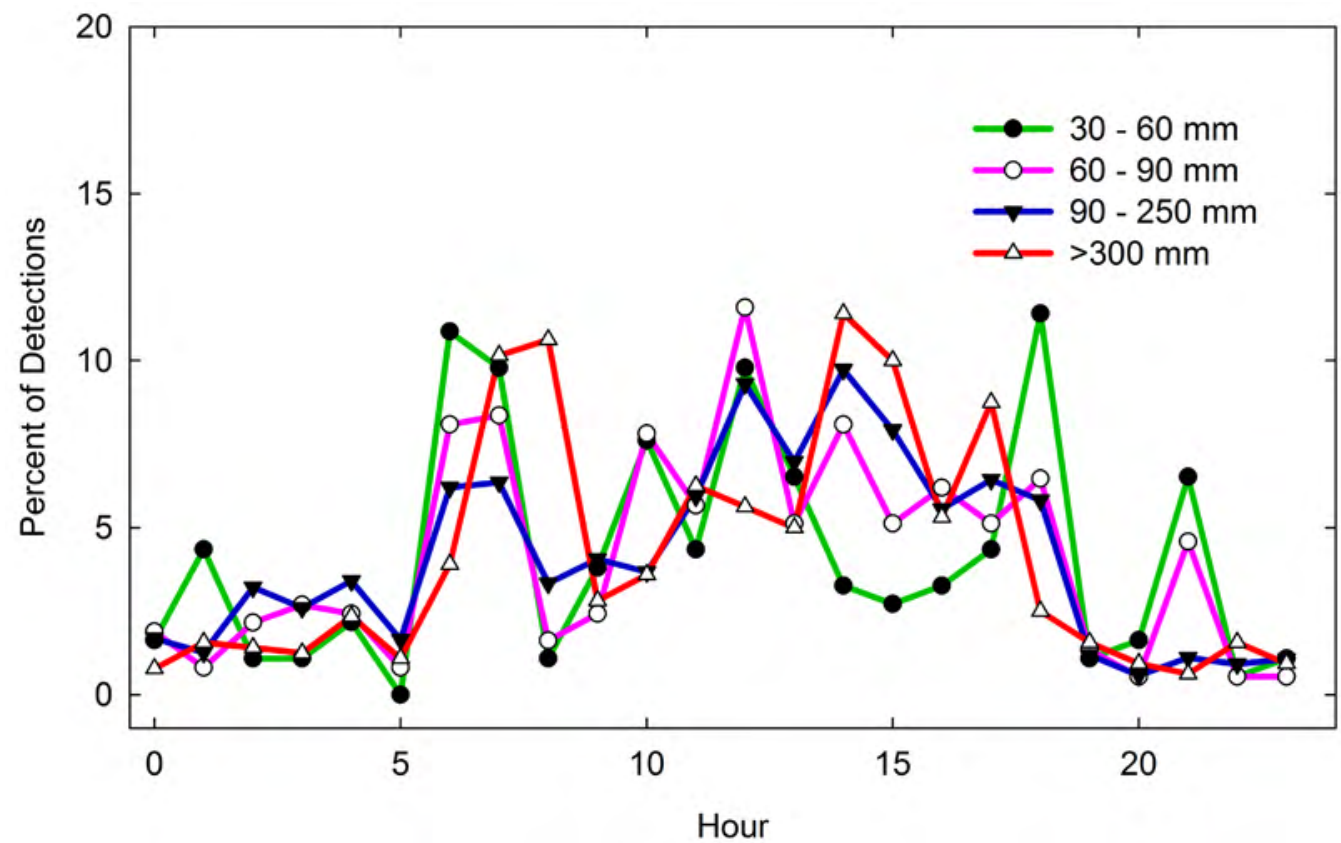

Figure 32. Graph showing hour of detection of fish, by size category (in millimeters [mm]), using the DIDSON® and ARIS $^{\circledR}$ acoustic cameras upstream of the water temperature control (WTC) tower at Cougar Reservoir and Dam, Oregon, fall 2013.

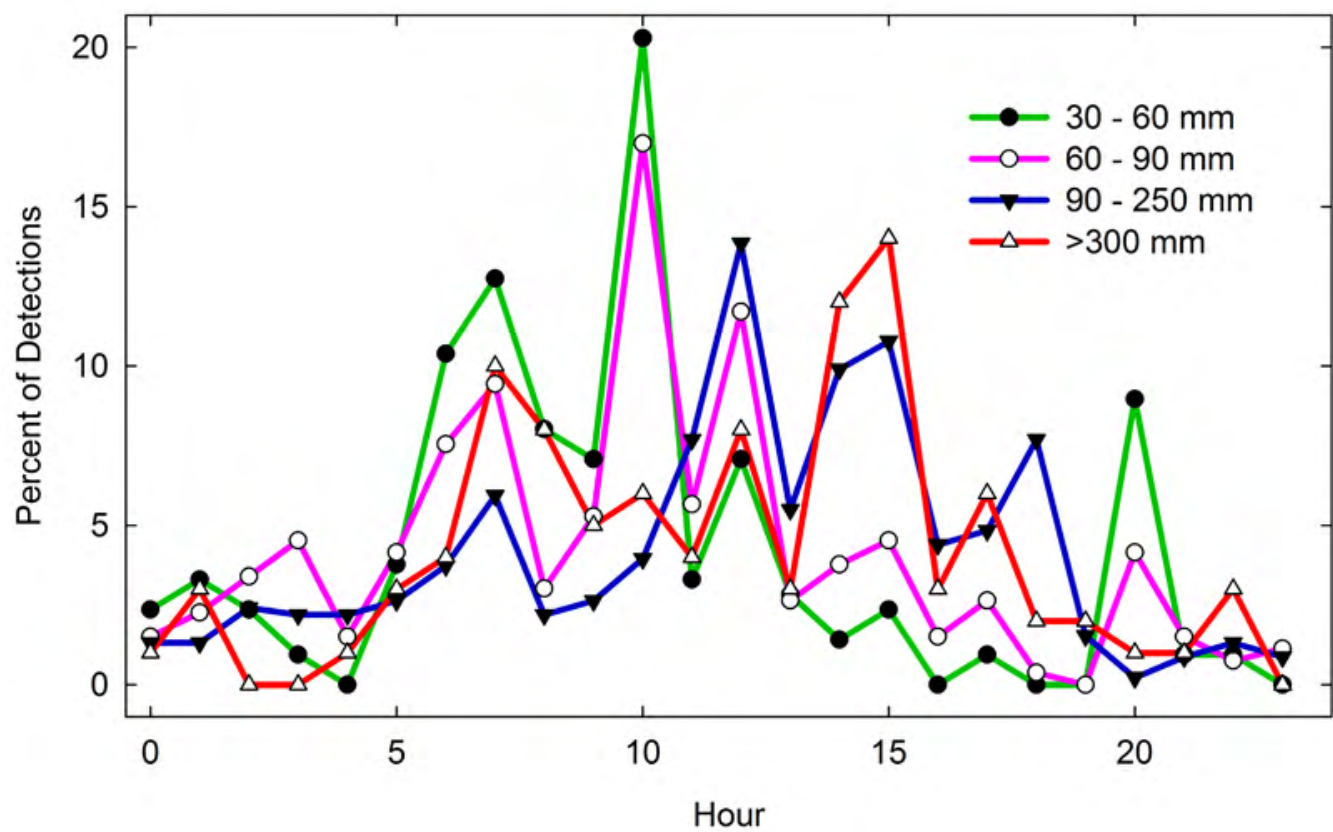

Figure 33. Graph showing hour of detection of fish, by size category (in millimeters [mm]), that were observed moving toward the water temperature control (WTC) tower using the DIDSON ${ }^{\circledR}$ and ARIS ${ }^{\circledR}$ acoustic cameras at Cougar Reservoir and Dam, Oregon, fall 2013. 


\section{Fish Track Density}

The spatial distribution of fish tracks near the WTC tower varied by fish size, but was similar between season and photoperiod (appendix C). The fish densities in the view of the DIDSON and ARIS acoustic cameras during the spring are represented by 9,026 individual tracks. The spatial densities of fish that were less than $90 \mathrm{~mm}$ in length were more concentrated upstream of the WTC tower during spring and fall. Alternatively, spatial densities of the $90-250 \mathrm{~mm}$ fish were more uniformly distributed across the face of the WTC tower. The spatial densities of predators $(>300 \mathrm{~mm})$ were more concentrated toward the center of the WTC tower compared to the other fish-size classes. During the fall, predator locations were more uniformly distributed across the view of both the DIDSON and ARIS acoustic cameras.

\section{Discussion}

Although there was a previous study (Kahn and others,. 2012) that used acoustic cameras to evaluate fish behavior at Cougar Dam, the study we conducted in 2013 was unique in numerous ways. Our study was one of the first to implement the latest technology in acoustic cameras (ARIS) to monitor the movement of relatively small fish (30-60 mm). This study also was the only one we are aware of that attempted to use existing software (Echoview) to automate processing and tracking of the data collected on fish smaller than $250 \mathrm{~mm}$ in fork length. Automation enables more of the data to be processed in a timely manner so a larger proportion of the data can be used in the analysis. Finally, acoustic camera data historically have provided mostly qualitative data that summarize trends in fish movement. In this study we implemented a number of analytical methods designed to provide a quantitative assessment of fish movement and how it is influenced by environmental factors such as photoperiod, discharge, water temperature, and proximity to predators. Although there were some challenges, our study was largely successful.

Not surprisingly, we determined that discharge at the dam had an important influence on the direction, travel speed, and numbers of fish moving toward the WTC tower. Discharge seemed to effect a complete reversal in the directional movement of juvenile salmon in the spring, such that at both high and low discharges fish were directed similarly, but at the more common mid-range discharges (400$1,000 \mathrm{ft}^{3} / \mathrm{s}$ ), the mean directions of the juvenile salmon were undergoing change. Interestingly, a similar linkage between fish direction and discharge was not observed during the fall study, suggesting that migratory disposition (that is, level of smoltification) of the fish may affect the influence of discharge on fish movement. We also noted an increase in mean travel speed as discharge at the dam increased. However, there also was an increase in travel speeds with an increase in temperature. Given that higher temperatures increase the rate of smoltification and migratory status (Marine and Cech, 2004), these findings support the hypothesis that higher water temperatures may lead to faster travel speeds upstream of the WTC tower. Of the responses evaluated in this report, the modeling results for travel speeds were the most consistent between the spring and fall studies. In contrast, our modeling of fish directions and the numbers of fish moving toward the WTC tower were much more varied in their conclusions. A lack of uniform direction upstream of the WTC tower is supported by the results from fish tagged with acoustic transmitters that also showed extensive milling behavior in this area (Beeman and others, 2014). 
Interactions between behavioral and physical processes can alter the diel activity patterns of fish, and, in turn, their movement toward the WTC tower. Others have evaluated the diel activities of juvenile Chinook salmon at dams. Beeman and Maule (2006) showed that juvenile Chinook salmon in the Columbia River occupied shallower water during the night when the risk of predation was presumably lower than during daytime. Predation likely is lower during the night because prey fish, such as juvenile salmon, are not readily noticed by aerial and piscivorous predators when near the surface (Olla and Davis, 1990; Sundström and others, 2003). Thus, factors such as predation risk can greatly alter the diel activity patterns of juvenile Chinook salmon, and we show that movement toward the WTC tower was influenced by time of day and the number of predators in the acoustic beam. By applying a Poisson rate regression to the counts of fish per unit time that moved toward the WTC tower, given the number of fish in the acoustic beam, we were able to verify that the numbers of fish moving toward the WTC tower were influenced by the number of predators, the time of day, and the discharge at the dam. Interestingly, the influence of the number of predators on the numbers of fish moving toward the WTC tower differed between spring and fall, suggesting that migratory status of the juvenile salmon and predation risk may interact to affect fish movement toward the WTC tower. It should be noted, however, that our Poisson rate regressions had some structural problems, which we think mostly were owing to an "unaccounted-for" or perhaps an "improperly specified" effect in the model. Nonetheless, the exploratory nature of the analysis during the first year of this study will help inform the analyses for the 2014 study at Cougar Dam when the USACE plans to test the passage effectiveness of a Portable Floating Fish Collector.

Acoustic camera data can yield previously unattainable information on fish behavior, but this technology is limited in the ability to definitively determine the species of fish that is in the acoustic beam. In the case of Cougar Reservoir, it is reasonable to assume that most fish that were less than 300 $\mathrm{mm}$ long were juvenile salmon, and that those fish greater than $300 \mathrm{~mm}$ long likely were either bull trout or rainbow trout (Oncorhynchus mykiss). However, dace (Rhinichthys sp.) were observed in the near-dam area, so it is possible that our smallest size class $(30-60 \mathrm{~mm})$ may not exclusively represent juvenile salmon. Given that this uncertainty may exist, fish size was considered an important factor in determining fish direction and travel speeds upstream of the WTC tower. On average, we noted that the larger the size of the fish, the faster the travel speed. Larger fish (in this case, what we believe were predators) not only tended to move faster, but generally were deeper in the water column and their direction of movement tended to be offset to the direction of the smaller fish.

Although there were many challenges when collecting, processing, and analyzing the relatively larger volume of data (20 terabytes) that can be obtained using acoustic-camera technology, that technology was an informative tool for evaluating fish movements. Nonetheless, there was a relatively large degree of unpredictability when modeling fish movements at such fine space and time scales. For example, differences in observations may be attributed to camera type and location, sampling angle, and range of the acoustic beam. The area ensonified by the beam was fairly limited relative to the overall size of the near-dam area, and varied among the different cameras with the ARIS acoustic camera being the most limited. For example, predators are believed to occupy the region near the center of the WTC tower, yet they might be underrepresented in the sample because of the limited range of the acoustic beam resulting in undersampling the area in the center of the tower, and especially so with the ARIS acoustic camera. Similarly, statements about changes in fish depth across changing environmental conditions were difficult to make because the camera angle was changed on a random basis to investigate potential differences in the size of fish that occurred at various depths in the water column. 
As a result of the changing angle and the relatively limited range of the acoustic beam, the area sampled at each depth was very limited, and making inferences about how environmental variables influence the presence or absence of fish at a particular depth was not feasible; therefore, we did not formally model fish depth as a response in this analysis. Despite such limitations, there was clear support for biological and environmental effects on fish directions and travel speeds within the acoustic beams upstream of the WTC tower. Two of the main objectives of the 2013 study were to determine if this technology could be used to aid in the evaluation of fish passage alternatives in the future and to establish the data processing and analytical procedures in advance to facilitate the timely analysis and reporting of the results. The results of the 2013 study meet these objectives and, as a result this technology, the 2013 study is well suited for evaluating the efficacy of fish passage alternatives such as the Portable Floating Fish Collector.

\section{References Cited}

Able, K.W., Grothues, T.M., Rackovan, J., and Buderman, F.E., 2014, Application of mobile dualfrequency identification sonar (DIDSON) to fish in estuarine habitats: Northeastern Naturalist, v. 21, no. 3, p. 192-209.

Agresti A., 1996, An introduction to categorical data analysis: Wiley, New York, 290 p.

Beeman, J.W., Evans, S.D., Haner, P.V., Hansel, H.C., Hansen, A.C., Smith, C.D., and Sprando, J.M., 2014, Passage and survival probabilities of juvenile Chinook salmon at Cougar Dam, Oregon, 2012: U.S. Geological Survey Open-File Report 2014-1038, 64 p. [Also available at http://pubs.usgs.gov/of/2014/1038/.]

Beeman, J.W., Hansen, A.C., Evans, S.D., Haner, P.V., Hansel, H.C., and Smith, C.D., 2012, Passage probabilities of juvenile Chinook salmon through the powerhouse and regulating outlet at Cougar Dam, Oregon, 2011: U.S. Geological Survey Open-File Report 2012-1250, 26 p. [Also available at http://pubs.usgs.gov/of/2012/1250/.]

Beeman, J.W., Hansel, H.C., Hansen, A.C., Haner, P.V., Sprando, J.M., Smith, C.D., Evans, S.D., and Hatton, T.W., 2013, Behavior and dam passage of juvenile Chinook salmon at Cougar Reservoir and Dam, Oregon, March 2011-February 2012: U.S. Geological Survey Open-File Report 2013-1079, 48 p. [Also available at http://pubs.usgs.gov/of/2013/1079/.]

Beeman, J.W., and Maule, A.G., 2006, Migration depths of juvenile Chinook salmon and steelhead relative to total dissolved gas supersaturation in a Columbia River Reservoir: Transactions of the American Fisheries Society, v. 135, no. 3, p. 584-594.

Boswell, K.M., Wilson, M.P., and Cowan, Jr., J.H., 2008, A semiautomated approach to estimating fish size, abundance, and behavior from dual-frequency identification sonar (DIDSON) data: North American Journal of Fisheries Management, v. 28, p. 799-807.

Burnham, K.P., and Anderson, D.R., 2002, Model selection and multimodel inference-A practical information-theoretic approach: New York, Springer-Verlag, 488 p.

Doehring, K., Young, R.G., Hay, J., and Quarterman, A.J., 2011, Suitability of dual-frequency identification sonar (DIDSON) to monitor juvenile fish movement at floodgates: New Zealand Journal of Marine and Freshwater Research, v. 45, no. 3, p. 413-422.

Dunbar, R.D., 2008, Sonar estimation of fall chum salmon abundance in the Sheenjek River, 2004: Alaska Department of Fish and Game, Fishery Data Series No. 08-34, Anchorage, 68 p.

Efron, B., and Tibshirani, R.J., 1993, An introduction to the bootstrap: Chapman and Hall, Inc., London, $456 \mathrm{p}$.

Faraway, J.J., 2006, Extending the linear model with R-Generalized linear, mixed effects and nonparametric regression models: Boca Raton, Florida, Chapman and Hall/CRC, 301 p. 
Kang, M., 2011, Semiautomated analysis of data from an imaging sonar for fish counting, sizing, and tracking in a post-processing application: Fisheries and Aquatic Sciences, v. 14, no. 3, p. 218-225.

Khan, F., Johnson, G.E., Royer, I.M., Phillips, N.R., Hughes, J.S., Fischer, E.S., Ham, K.D., and Ploskey, G.R., 2012, Acoustic imaging evaluation of juvenile salmonid behavior in the immediate forebay of the water temperature control tower at Cougar Dam, 2010: Pacific Northwest National Laboratory report PNNL-20625, 50 p.

Liedtke, T.L., Kock, T.J., and Rondorf, D.W., 2013, Evaluation of the behavior and movement patterns of adult coho salmon and steelhead in the North Fork Toutle River, Washington, 2005-2009: U.S. Geological Survey Open-File Report 2013-1290, 26 p. [Also available at http://dx.doi.org/10.3133/ofr20131290.]

Mardia, K.V., and Jupp, P.E., 2000, Directional statistics: Chichester, United Kingdom, John Wiley and Sons Ltd., 492 p.

Marine, K.R., and Cech, J.J., Jr., 2004, Effects of high water temperature on growth, smoltification, and predator avoidance in juvenile Sacramento River Chinook salmon: North American Journal of Fisheries Management, v. 24, p. 198-210.

Nagelkerke, N.J.D., 1991, A note on a general definition of the coefficient of determination:

Biometrika, v. 78, p. 691-692.

National Oceanic and Atmospheric Administration, 2008, Endangered Species Act section 7(a)(2) consultation biological opinion and Magnuson-Stevens Fishery Conservation and Management Act essential fish habitat consultation-Consultation on the "Willamette River Basin Flood Control Project": National Oceanic and Atmospheric Administration Fisheries Log Number: FINWRl2000/02117, June 11, 2008. [Also available at http://www.westcoast.fisheries.noaa.gov/fish_passage/willamette_opinion/index.html.]

Olla, B.L., and Davis, M.W., 1990, Effects of physical factors on the vertical distribution of larval walleye pollock Theragra chalcogramma under controlled laboratory conditions: Marine Ecology Progress Series, v. 63, p. 105-112.

Pavlov, D.S., Borisenko, E.S., and Pashin, V.M., 2009, Investigations of spawning migration and assessment of abundance of the Kamchatka steelhead (Parasalmo mykiss) from the Utkholok River by means of Didson dual-frequency identification sonar: Journal of Ichthyology, v. 49, no. 1, p. 1,0421,064 .

Pewsey, A., Neuhauser, M., and Ruxton, G.D., 2013, Circular statistics in R (1st ed.): Oxford, United Kingdom, Oxford University Press, 208 p.

R Core Team, 2014, R-A language and environment for statistical computing: Vienna, Austria, R Foundation for Statistical Computing Web site, accessed May 2015 , at URL http://www.Rproject.org/.

Simmonds, J. and MacLennan, D., 2005, Fisheries acoustics—Theory and practice (2d ed.): Oxford, United Kingdom, Blackwell Scientific Publications, 456 p.

Sundström, L.F., Devlin, R.H., Johnsson, J.I., and Biagi, C.A., 2003, Vertical position reflects increased feeding motivation in growth hormone transgenic coho salmon (Oncorhynchus kisutch): Ethology, v. 109, p. 701-712.

Tiffan, K.F., Rondorf, D.W., and Skalicky, J.J., 2005, Diel spawning behavior of chum salmon in the Columbia River: Transactions of the American Fisheries Society, v. 134, no. 4, p. 892-900. 


\section{Appendix A. Sample Dates Selected for Analysis of DIDSON and ARIS Acoustic Camera Data Collected at the Cougar Reservoir Water Temperature Control (WTC) Tower, Oregon, 2013}

[ $\mathrm{ft}^{3} / \mathrm{s}$, cubic foot per second; NGVD 29, National Geodetic Vertical Datum of 1929]

\begin{tabular}{|c|c|c|c|c|c|}
\hline Date & Season & Acoustic cameras & $\begin{array}{c}\text { Project } \\
\text { discharge } \\
\left(\mathrm{ft}^{3} / \mathrm{s}\right)\end{array}$ & $\begin{array}{c}\text { Forebay } \\
\text { elevation } \\
\text { (feet above } \\
\text { NGVD 29) }\end{array}$ & $\begin{array}{c}\text { Temperature } \\
\text { (degrees } \\
\text { Celsius) }\end{array}$ \\
\hline 05-03-2013 & Spring & DIDSON, ARIS & 952.9 & $1,662.7$ & 9.9 \\
\hline 05-05-2013 & Spring & DIDSON, ARIS & 957.1 & $1,662.7$ & 11.2 \\
\hline 05-07-2013 & Spring & DIDSON, ARIS & 955.8 & $1,662.9$ & 12.0 \\
\hline 05-09-2013 & Spring & DIDSON & 952.1 & $1,663.0$ & 12.9 \\
\hline 05-11-2013 & Spring & DIDSON, ARIS & 951.7 & $1,663.1$ & 12.9 \\
\hline 05-13-2013 & Spring & DIDSON, ARIS & $1,003.2$ & $1,662.9$ & 12.4 \\
\hline 05-15-2013 & Spring & DIDSON, ARIS & 979.6 & $1,662.1$ & 12.0 \\
\hline 05-17-2013 & Spring & DIDSON, ARIS & $1,047.5$ & $1,660.9$ & 12.5 \\
\hline 05-19-2013 & Spring & DIDSON, ARIS & 957.9 & $1,659.7$ & 11.9 \\
\hline 05-21-2013 & Spring & DIDSON, ARIS & 945.4 & $1,658.5$ & 12.4 \\
\hline 05-23-2013 & Spring & DIDSON, ARIS & 931.7 & $1,657.6$ & 11.5 \\
\hline 05-25-2013 & Spring & DIDSON, ARIS & 459.6 & $1,658.2$ & 11.9 \\
\hline 05-27-2013 & Spring & DIDSON, ARIS & 455.8 & $1,659.6$ & 11.7 \\
\hline 05-29-2013 & Spring & DIDSON, ARIS & 446.7 & $1,662.7$ & 12.1 \\
\hline 05-31-2013 & Spring & DIDSON, ARIS & 450.4 & $1,665.9$ & 11.3 \\
\hline 06-02-2013 & Spring & DIDSON, ARIS & 451.2 & $1,667.8$ & 11.1 \\
\hline 06-04-2013 & Spring & DIDSON, ARIS & 442.9 & $1,668.9$ & 12.1 \\
\hline 06-06-2013 & Spring & DIDSON, ARIS & 442.5 & $1,669.5$ & 13.8 \\
\hline 06-08-2013 & Spring & DIDSON, ARIS & 449.6 & $1,669.9$ & 14.4 \\
\hline 06-10-2013 & Spring & DIDSON, ARIS & 928.2 & $1,670.0$ & 14.5 \\
\hline 06-12-2013 & Spring & DIDSON, ARIS & 928.8 & $1,668.9$ & 12.4 \\
\hline 06-14-2013 & Spring & DIDSON, ARIS & 937.1 & $1,667.3$ & 12.2 \\
\hline 06-16-2013 & Spring & DIDSON, ARIS & 942.9 & $1,665.5$ & 12.6 \\
\hline 06-18-2013 & Spring & DIDSON, ARIS & 903.8 & $1,663.7$ & 14.1 \\
\hline 06-20-2013 & Spring & DIDSON, ARIS & 924.6 & $1,661.8$ & 12.6 \\
\hline 06-22-2013 & Spring & DIDSON, ARIS & 927.2 & $1,659.7$ & 12.9 \\
\hline 06-24-2013 & Spring & DIDSON, ARIS & 939.2 & $1,657.6$ & 13.2 \\
\hline 06-26-2013 & Spring & DIDSON, ARIS & 740.4 & $1,656.0$ & 11.7 \\
\hline 06-28-2013 & Spring & DIDSON, ARIS & 415.0 & $1,655.7$ & 12.7 \\
\hline 06-30-2013 & Spring & DIDSON & 414.8 & $1,655.4$ & 13.7 \\
\hline
\end{tabular}




\begin{tabular}{|c|c|c|c|c|c|}
\hline Date & Season & Acoustic cameras & $\begin{array}{c}\text { Project } \\
\text { discharge } \\
\left(\mathrm{ft}^{3} / \mathrm{s}\right)\end{array}$ & $\begin{array}{c}\text { Forebay } \\
\text { elevation } \\
\text { (feet above } \\
\text { NGVD 29) }\end{array}$ & $\begin{array}{c}\text { Temperature } \\
\text { (degrees } \\
\text { Celsius) }\end{array}$ \\
\hline 07-02-2013 & Spring & DIDSON, ARIS & 412.1 & $1,655.0$ & 14.1 \\
\hline 07-04-2013 & Spring & DIDSON, ARIS & 418.0 & $1,654.5$ & 14.7 \\
\hline 07-06-2013 & Spring & DIDSON & 419.6 & $1,653.9$ & 16.0 \\
\hline 07-08-2013 & Spring & DIDSON & 418.5 & $1,653.3$ & 16.5 \\
\hline 09-27-2013 & Fall & ARIS & 529.6 & $1,599.4$ & 14.1 \\
\hline 09-29-2013 & Fall & ARIS & 540.4 & $1,600.0$ & 13.5 \\
\hline 10-01-2013 & Fall & ARIS & 540.8 & $1,605.5$ & 12.7 \\
\hline 10-03-2013 & Fall & ARIS & 547.1 & $1,607.3$ & 12.0 \\
\hline $10-05-2013$ & Fall & ARIS & 544.6 & $1,607.5$ & 12.1 \\
\hline 10-07-2013 & Fall & ARIS & 545.4 & $1,607.1$ & 12.1 \\
\hline 10-09-2013 & Fall & ARIS & 810.8 & $1,606.6$ & 11.2 \\
\hline 10-11-2013 & Fall & ARIS & $1,094.2$ & $1,603.8$ & 11.4 \\
\hline 10-13-2013 & Fall & ARIS & $1,102.1$ & 1,600.6 & 8.1 \\
\hline 10-15-2013 & Fall & ARIS & $1,155.0$ & $1,597.0$ & 10.7 \\
\hline 10-23-2013 & Fall & ARIS & 980.0 & $1,581.2$ & 9.6 \\
\hline 10-24-2013 & Fall & DIDSON, ARIS & 990.0 & $1,579.4$ & 9.3 \\
\hline 10-25-2013 & Fall & DIDSON, ARIS & 722.5 & $1,577.8$ & 8.9 \\
\hline 10-27-2013 & Fall & ARIS & 457.1 & 1,576.6 & 9.1 \\
\hline 10-29-2013 & Fall & ARIS & 492.9 & $1,575.5$ & 8.2 \\
\hline 10-30-2013 & Fall & DIDSON, ARIS & 476.5 & $1,574.9$ & 8.4 \\
\hline 10-31-2013 & Fall & DIDSON, ARIS & 469.2 & $1,574.3$ & 8.4 \\
\hline 11-02-2013 & Fall & ARIS & 370.4 & 1,573.6 & 8.7 \\
\hline 11-03-2013 & Fall & DIDSON & 426.3 & $1,573.7$ & 8.7 \\
\hline 11-04-2013 & Fall & DIDSON & 416.3 & $1,573.5$ & 8.5 \\
\hline 11-07-2013 & Fall & DIDSON & $1,033.3$ & $1,574.6$ & 8.0 \\
\hline 11-08-2013 & Fall & DIDSON & $1,635.4$ & $1,574.8$ & 7.9 \\
\hline 11-09-2013 & Fall & ARIS & $2,496.3$ & $1,572.1$ & 8.3 \\
\hline 11-11-2013 & Fall & DIDSON, ARIS & $2,445.4$ & $1,562.9$ & 8.3 \\
\hline $11-12-2013$ & Fall & DIDSON & $2,478.8$ & $1,557.7$ & 8.3 \\
\hline
\end{tabular}


Appendix B. Rose Plots and Circular Histograms of Mean Travel Directions of Fish Collected by Acoustic Cameras by Depth and Photoperiod at Cougar Reservoir and Dam, Oregon

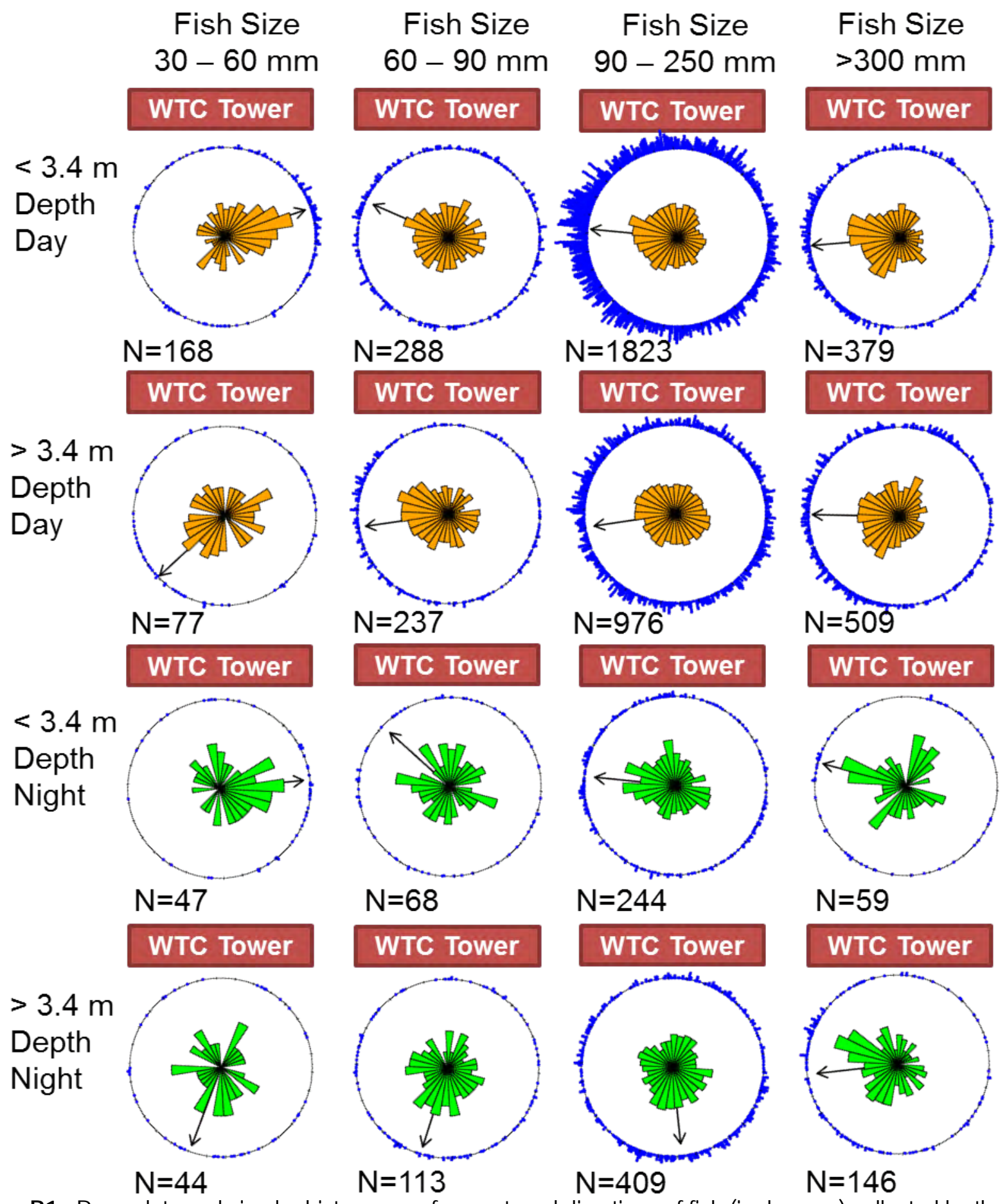

Figure B1. Rose plots and circular histograms of mean travel directions of fish (in degrees) collected by the DIDSON® acoustic camera by depth and photoperiod (day or night) at Cougar Reservoir and Dam, Oregon, spring 2013. 


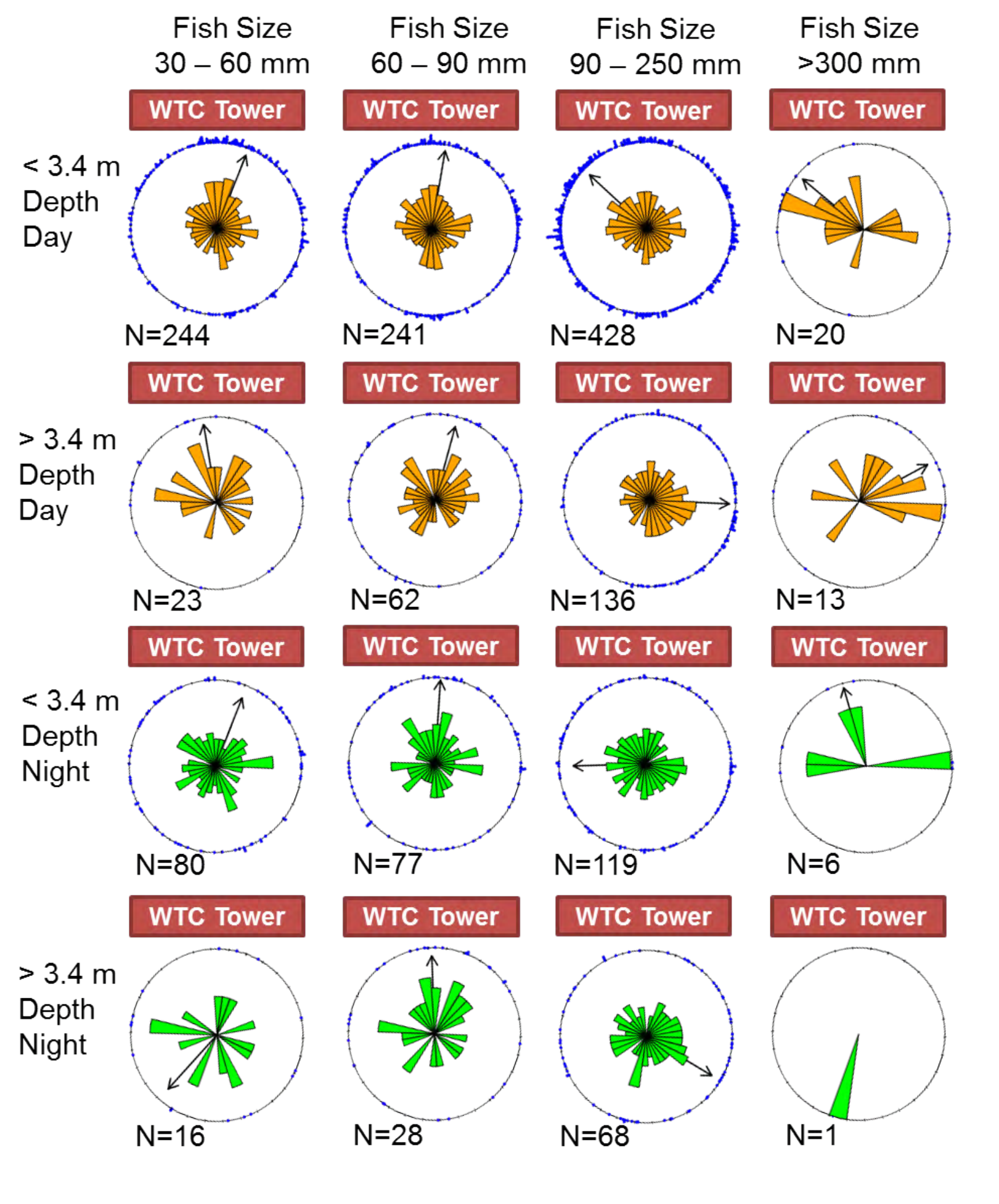

Figure B2. Rose plots and circular histograms of mean travel directions of fish (in degrees) collected by the ARIS ${ }^{\circledR}$ acoustic camera by depth and photoperiod (day or night) at Cougar Reservoir and Dam, Oregon, spring 2013. 


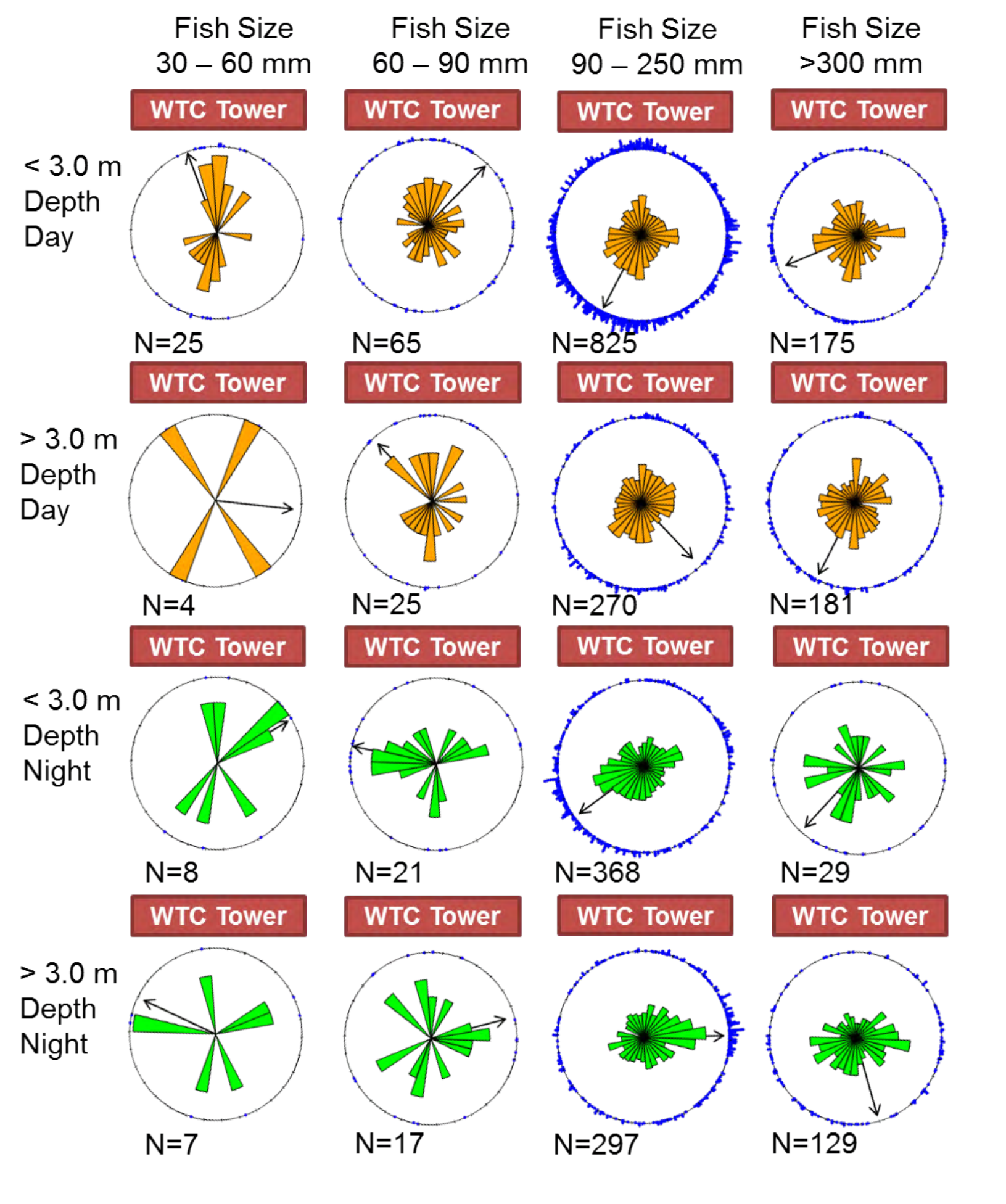

Figure B3. Rose plots and circular histograms of mean travel directions of fish (in degrees) collected by the DIDSON acoustic camera by depth and photoperiod (day or night) at Cougar Reservoir and Dam, Oregon, fall 2013. 


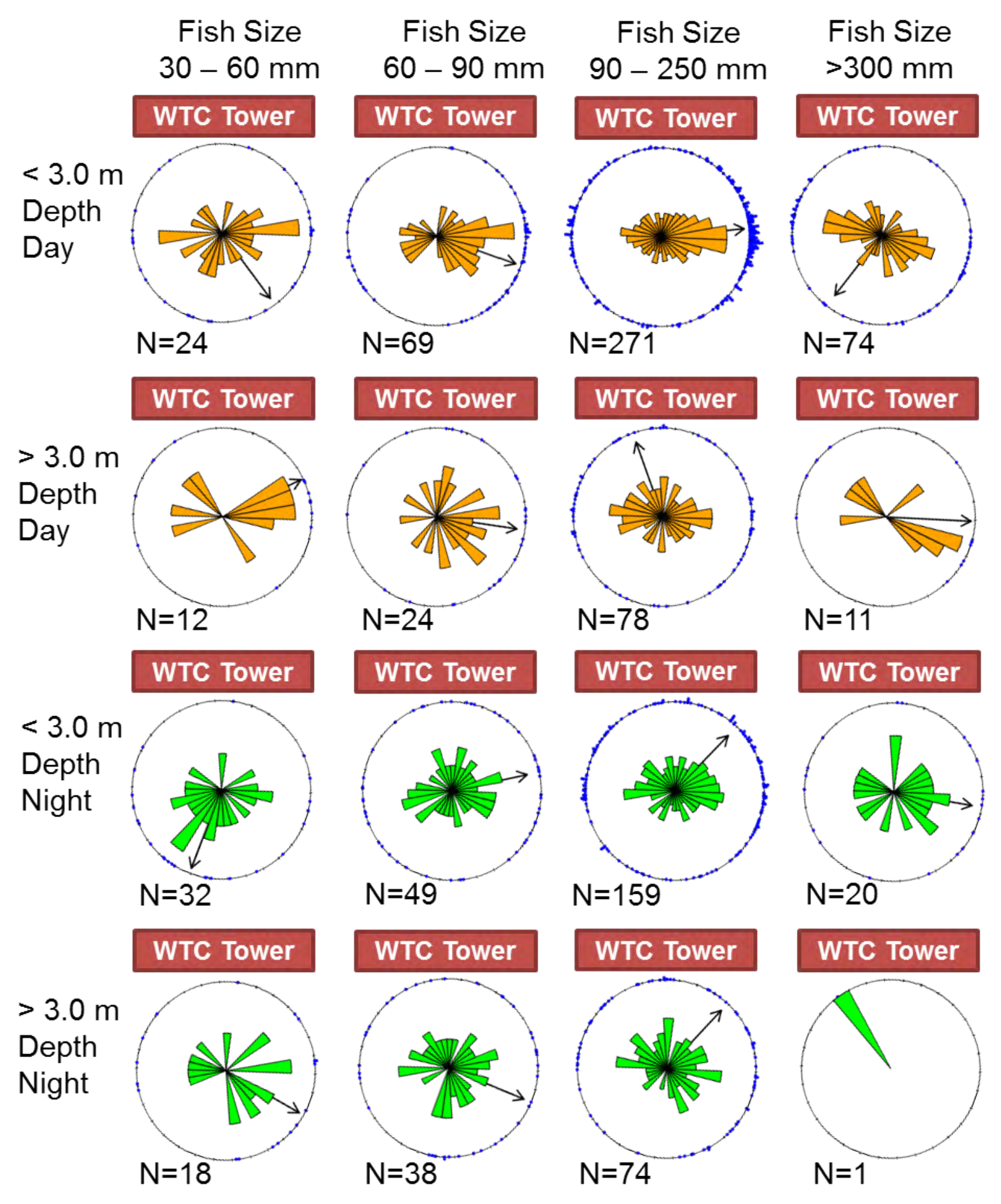

Figure B4. Rose plots and circular histograms of mean travel directions of fish (in degrees) collected by the ARIS ${ }^{\circledR}$ acoustic camera by depth and photoperiod (day or night) at Cougar Reservoir and Dam, Oregon, fall 2013. 
Appendix C. Density Plots of Fish Target Locations from DIDSON and ARIS Acoustic Camera Data Collected during the Fish Behavior Evaluations at Cougar Reservoir and Dam, Oregon, 2013

Fish Size $30-60 \mathrm{~mm}$
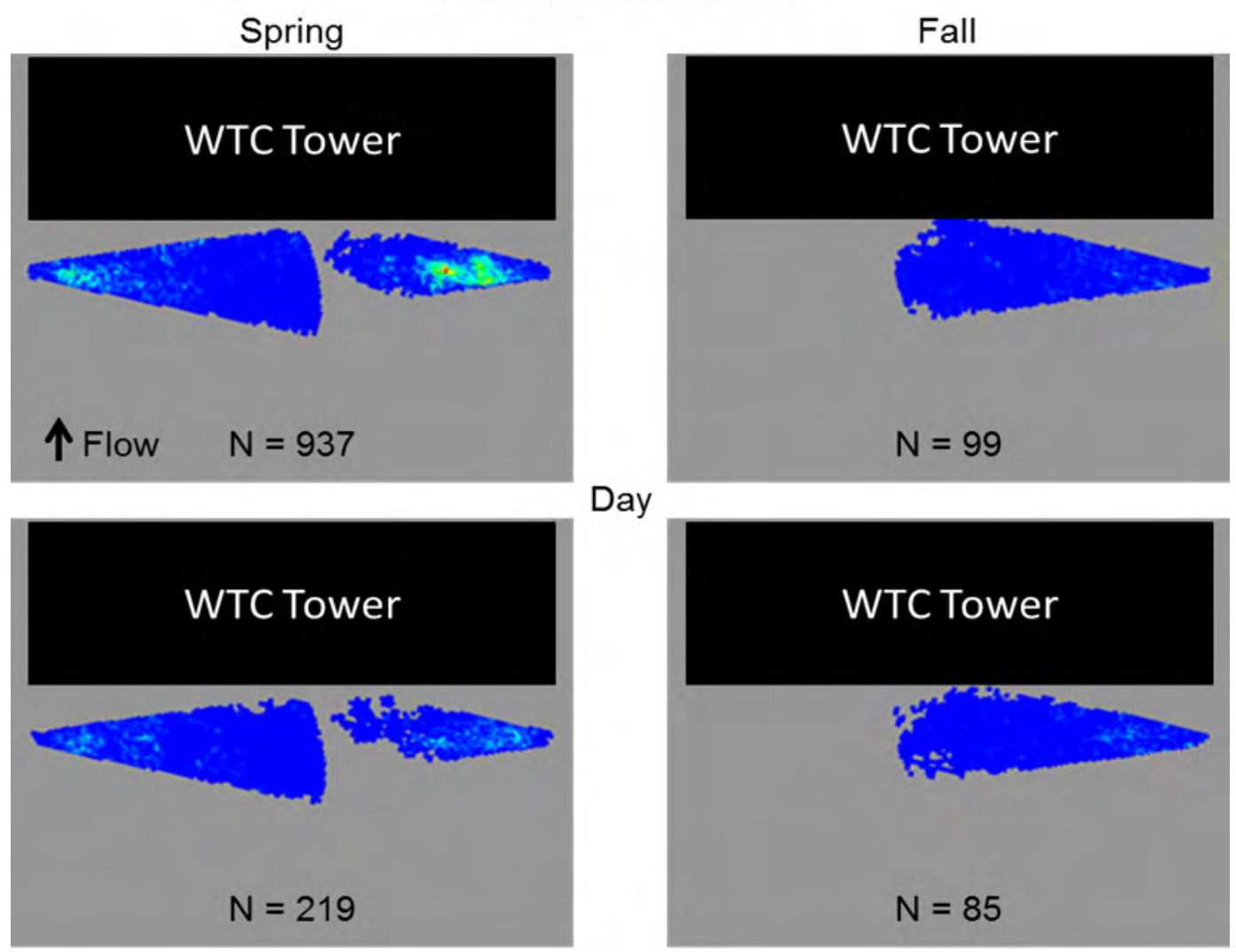

Day

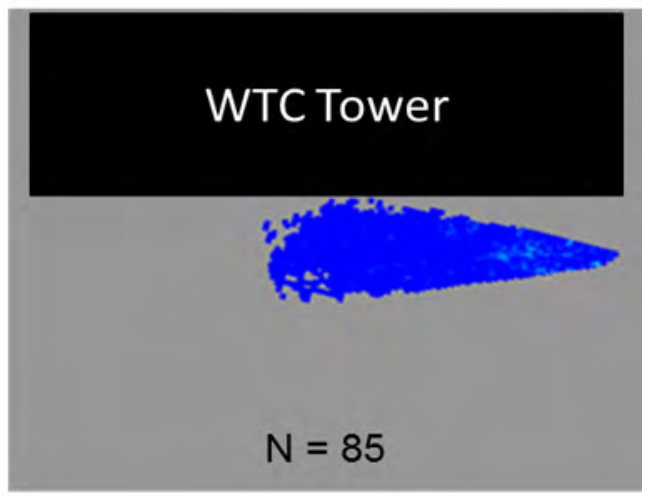

Night
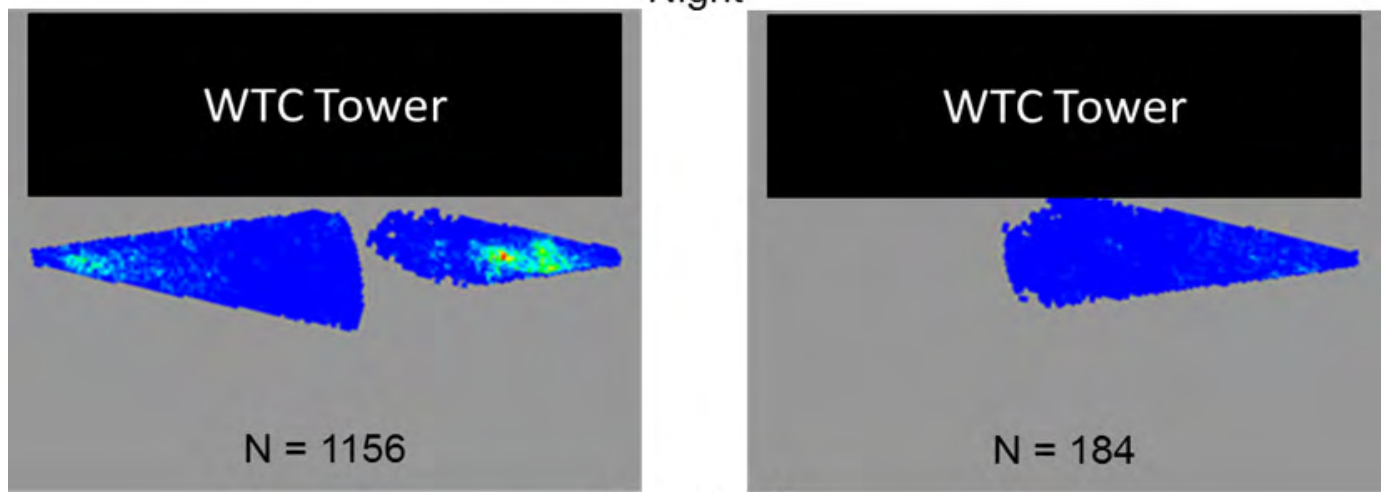

Combined

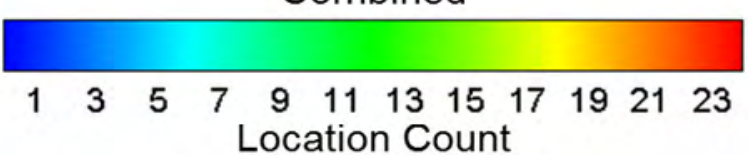

Figure C1. Top-down perspective density plots of fish target locations (fish size 30-60 millimeters [mm]) by photoperiod (day, night, or combined) from DIDSON ${ }^{\circledR}$ and ARIS ${ }^{\circledR}$ acoustic-camera data collected during the fish behavior evaluations at Cougar Reservoir and Dam, Oregon, 2013. 
Fish Size $60-90 \mathrm{~mm}$
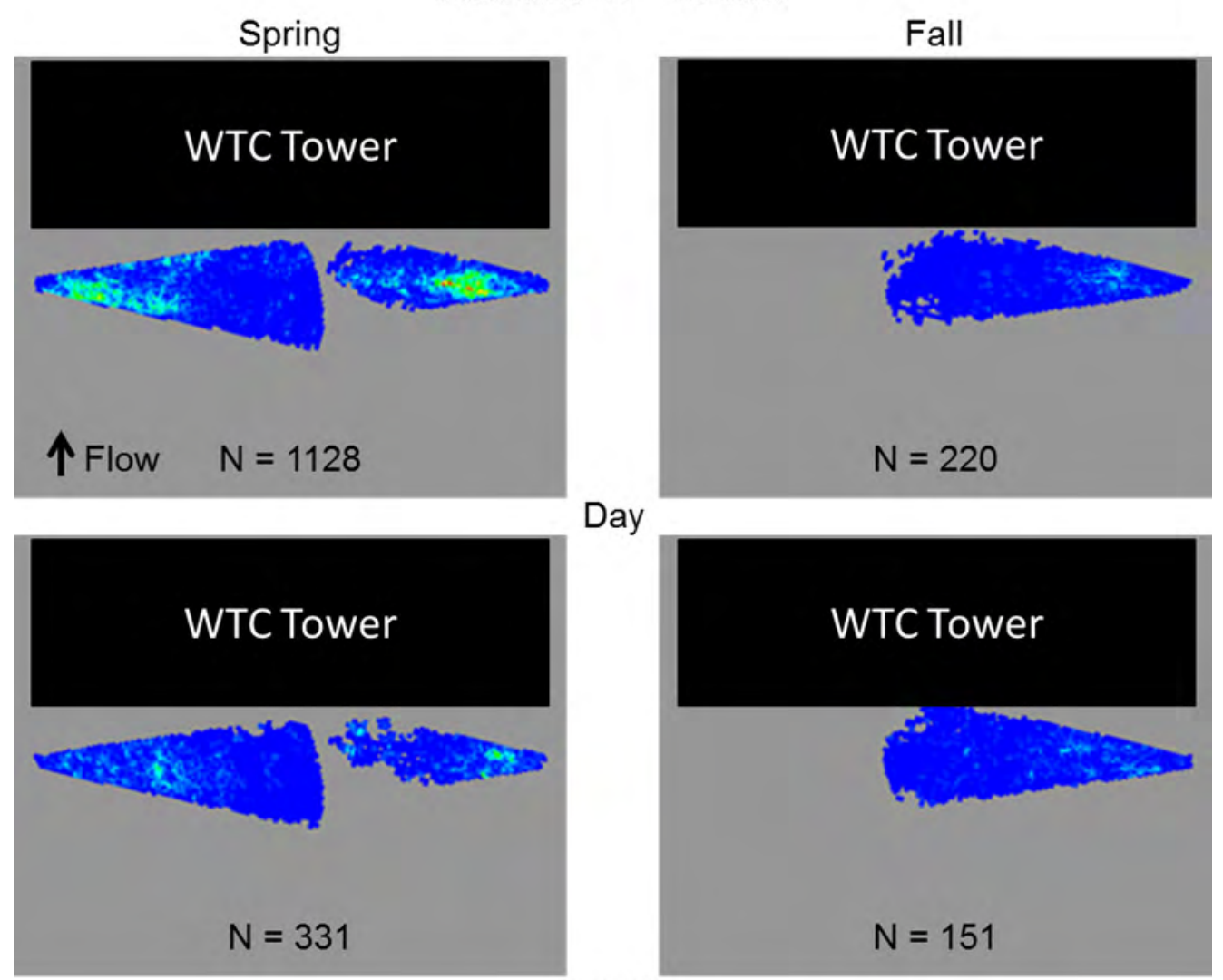

Day
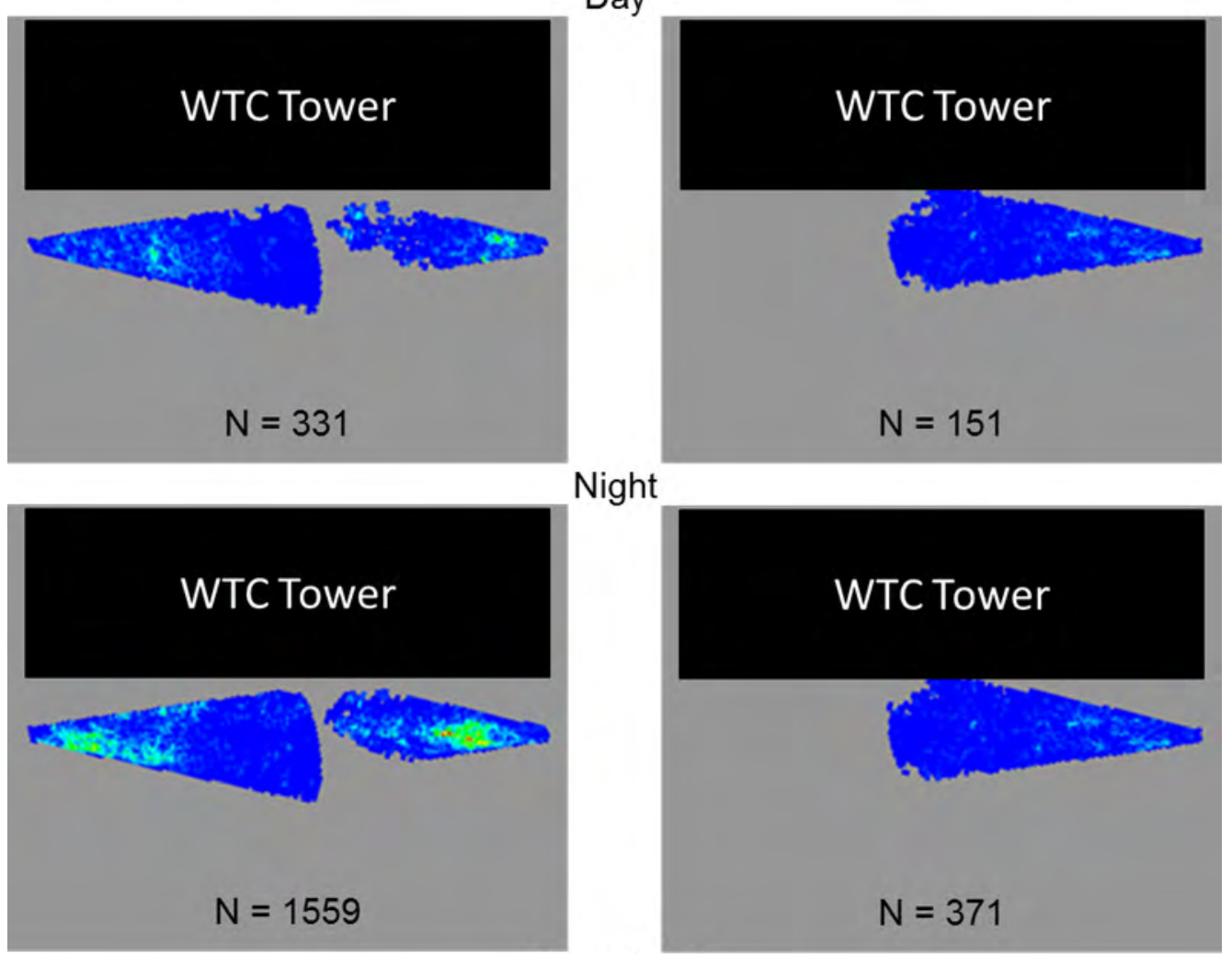

Night

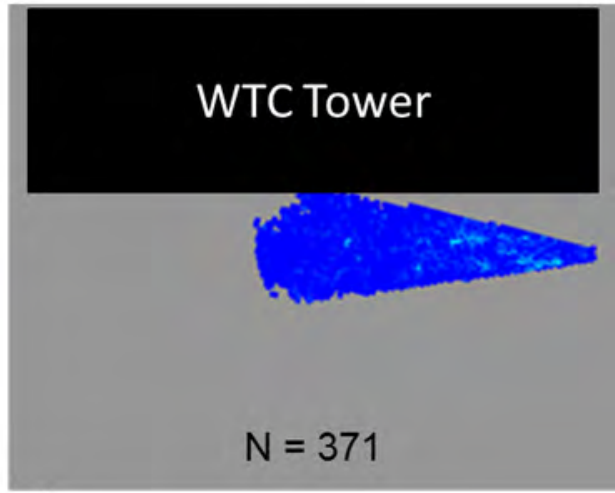

\section{Combined}

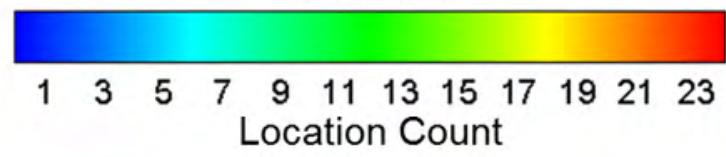

Figure C2. Top-down perspective density plots of fish target locations (fish size 60-90 millimeters [mm]) by photoperiod (day, night, or combined) from DIDSON ${ }^{\circledR}$ and ARIS ${ }^{\circledR}$ acoustic-camera data collected during the fish behavior evaluations at Cougar Reservoir and Dam, Oregon, 2013. 


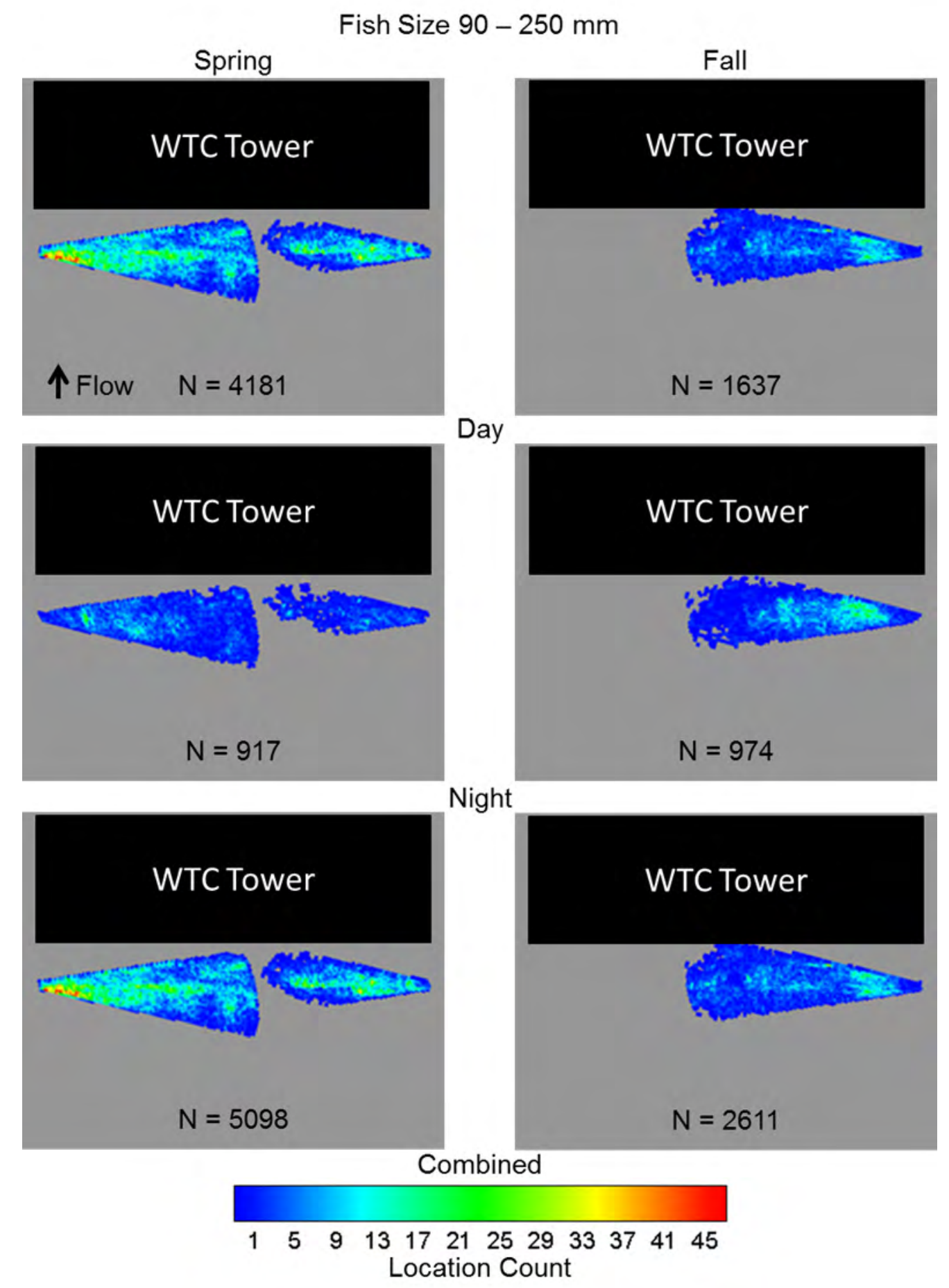

Figure C3. Top-down perspective density plots of fish target locations (fish size 90-250 millimeters [mm]) by photoperiod (day, night, or combined) from DIDSON ${ }^{\circledR}$ and ARIS ${ }^{\circledR}$ acoustic-camera data collected during the fish behavior evaluations at Cougar Reservoir and Dam, Oregon, 2013. 
Fish Size $>300 \mathrm{~mm}$
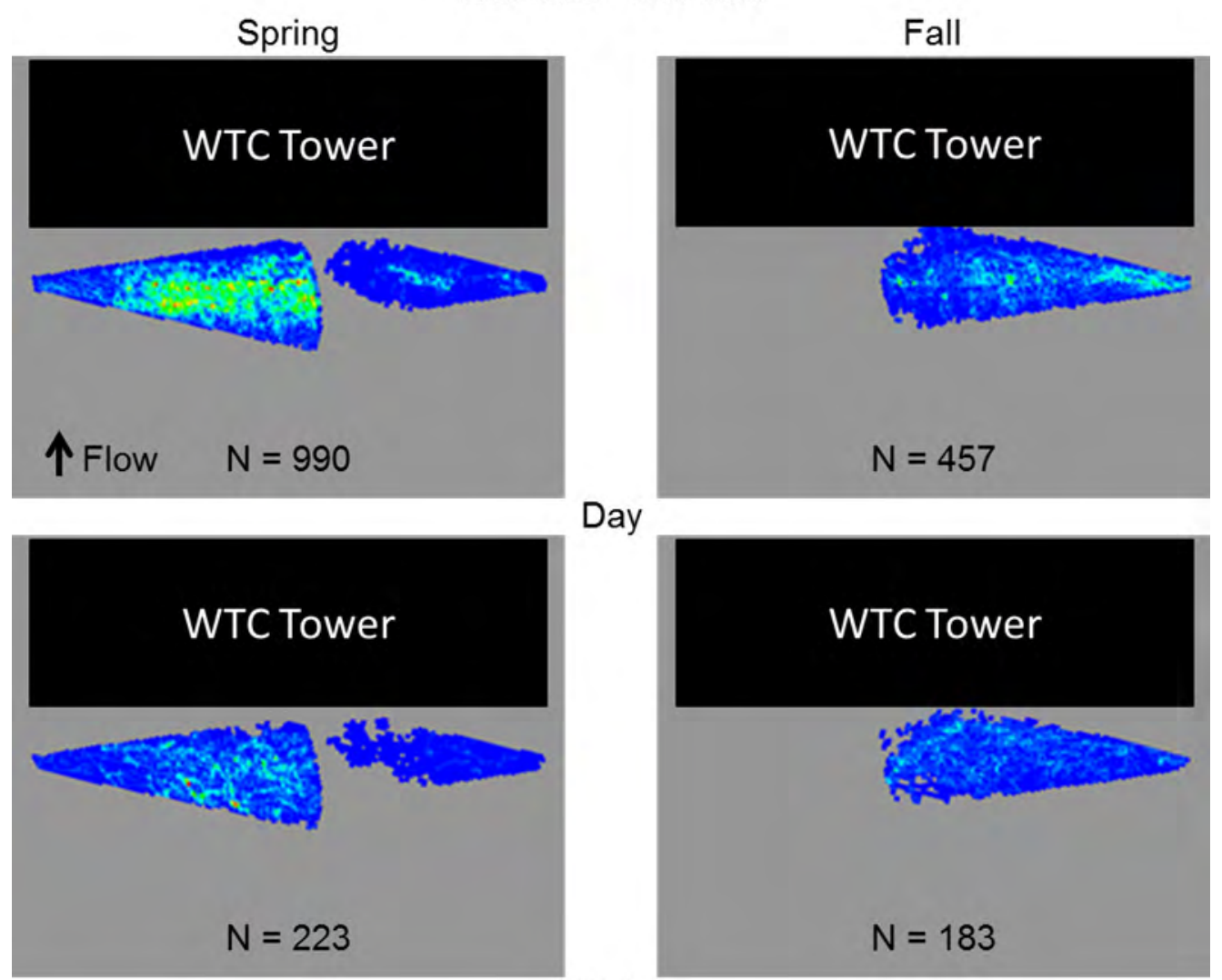

Day
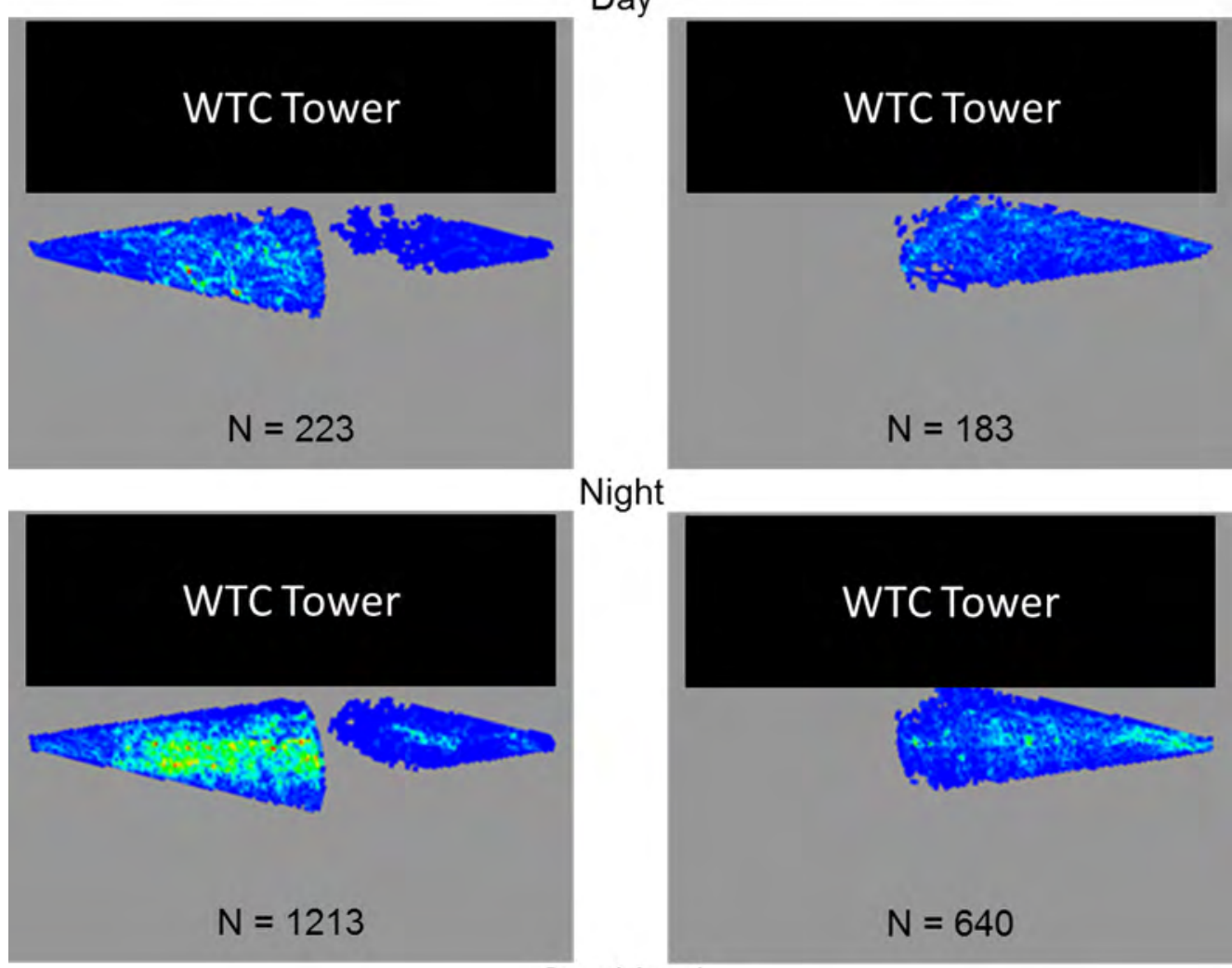

Night

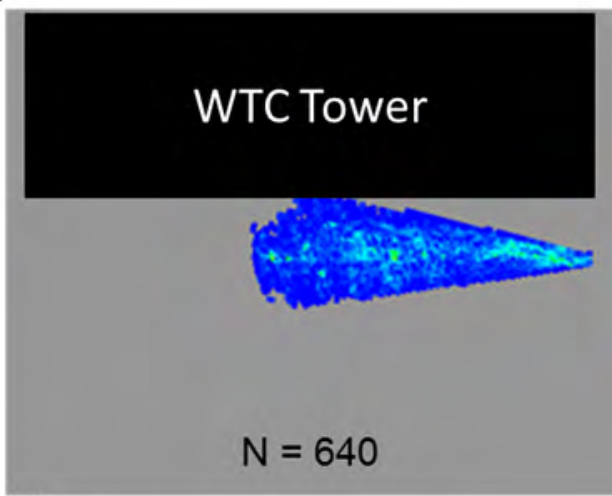

Combined

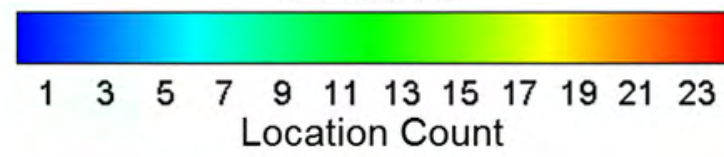

Figure C4. Top-down perspective density plots of fish target locations (fish size $>300$ millimeters [mm]) by photoperiod (day, night, or combined) from DIDSON ${ }^{\circledR}$ and ARIS ${ }^{\circledR}$ acoustic camera data collected during the fish behavior evaluations at Cougar Reservoir and Dam, Oregon, 2013. 
Publishing support provided by the U.S. Geological Survey

Science Publishing Network, Tacoma Publishing Service Center

For more information concerning the research in this report, contact the Director, Western Fisheries Research Center U.S. Geological Survey

6505 NE 65th Street

Seattle, Washington 98115

http://wfrc.usgs.gov/ 
